\title{
COMPARISON OF UNSTRUCTURED \& STRUCTURED MESHING FOR A CIRCULATION CONTROL WING \& ENGINE CONFIGURATION USING RANS CFD
}

\author{
A Thesis \\ presented to \\ the Faculty of California Polytechnic State University, \\ San Luis Obispo
}

\author{
In Partial Fulfillment \\ of the Requirements for the Degree \\ Master of Science in Aerospace Engineering
}

by

John Pham

Spring 2012 


\section{(c) 2012 \\ John Pham \\ ALL RIGHTS RESERVED}




\section{COMMITTEE MEMBERSHIP}

TITLE :

COMPARISON OF UNSTRUCTURED \& STRUCTURED

MESHING FOR A CIRCULATION CONTROL WING

\& ENGINE CONFIGURATION USING RANS CFD

AUTHOR: John Pham

DATE SUBMITED: $\quad$ Spring 2012

Dr. David D. Marshall

Advisor and Committee Chair

Aerospace Engineering

Dr. Kristina Jameson

Committee Member

Aerospace Engineering

Dr. Kim A. Shollenberger

Committee Member

Mechanical Engineering

Dr. Jin Tso

Committee Member

Aerospace Engineering 


\section{ABSTRACT \\ COMPARISON OF UNSTRUCTURED \& STRUCTURED MESHING FOR A CIRCULATION CONTROL WING \& ENGINE CONFIGURATION USING RANS CFD}

John Pham

This thesis was conducted as a contributing effort to an ongoing NASA Research Announcement (NRA,\#NNL07AA55C). The NRA investigates potential advanced commercial transport designs that could be utilized in the $\mathrm{N}+2$ time frame (about 2025). The basis of the advanced design revolves around a heavily researched technology called Circulation Control that will be investigated through computational and wind tunnel methods for its feasibility in commercial aviation. The work of this thesis evaluates two potential meshing topologies when conducting CFD; Unstructured and Structured Meshing.

Greatest challenges faced was handling the complexity of the computational model and capturing the correct physics that consisted of highly complex, 3-D, flow interactions. The complicated physics include mixing of subsonic/transonic fluid, engine jet entrainment, and extreme lift from the circulation control jet flow.

Results from this thesis showed that the Unstructured Meshing method applied introduced non-physical flow phenomenon not exhibited when applying Structured Meshing. The latter approach showed to be the superior method in its ability to capture the complicated physics of a circulation control aircraft.

As promising the results were, it still remains inconclusive at this time. Further investigation is still required to completely evaluate the accuracy of the two meshing methodologies employed. At the time of this thesis, wind tunnel data was not available, thus remains a variable when evaluating the two different meshing topologies. In addition, this thesis was constrained by limited computational resources and software tools. Thus, the tribulations faced with Unstructured Meshing could have potentially resulted from these two external factors. Further investigation into alternative software tools that allow more user control should be considered next, in addition to having access to more computational resources. Although Unstructured Meshing showed to be inferior in this thesis, these remaining factors need to be eliminated before concluding Unstructured Meshing as not feasible for studying circulation control applications. Numerous studies[1, 2, 3] for 2-D circulation control applications have shown that Unstructured Meshing can be accurate, but the verdict is still out for 3-D models. This thesis yielded encouraging results and helps to aid further research in addressing this critical component for accurate numerical simulation. 


\section{ACKNOWLEDGMENTS}

First and foremost I want to thank my advisor Dr. David Marshall for his assistance in funding and encouraging my work on this project. Without his guidance and funding this work would not have been possible. This work was funded as part of a NASA Research Announcement award under Contract \#NNL07AA55C with Craig Hange and Joe Posey as the technical monitors.

I wish to thank the excellent work of David Hall from DHC Engineering, Inc. in developing the design of the aircraft that was the basis of this work. A special thanks to Rory Golden and Nick Paciano for their help in generating the geometry for this work.

To my girlfriend, Lisa Aguirre, thank you for your extreme patience and understanding through this project. I know it was very tough on you when I'd go into isolation mode, throwing all of my energy into this project, leaving you with the short end of the stick. Words can't express how grateful I am for your support the last 3 years.

And last, I'd like to thank my parents for giving me the opportunity to succeed and lead by example for my brothers and sisters. Being the first to go to college, you always found a way to keep me motivated and hungry for success. 25 years, 2 college degrees, and gallons of beer later, I can proudly say to you: I made it and I couldn't have done it without your support. 


\section{Table of Contents}

List of Tables viii

List of Figures $\quad$ xi

Nomenclature $\quad$ xii

1 Introduction $\quad 1$

1.1 NRA Review ........................ . . . . . . . . . . . .

1.2 Circulation Control Review . . . . . . . . . . . . . . 3

1.3 Literature Review . . . . . . . . . . . . . . . . 6

2 Model Description $\quad 11$

2.1 AMELIA Geometry . . . . . . . . . . . . . . . . . . 11

2.2 Experimental Model . . . . . . . . . . . . . . . . . . . . . . . 12

2.3 Computational Model . . . . . . . . . . . . . . . . . . . . 14

3 Mesh Generation $\quad 17$

3.1 Unstructured Meshing . . . . . . . . . . . . . . . . . . . 21

3.1 .1 Surface Mesh . . . . . . . . . . . . . . . . . . . 22

3.1.2 Boundary Layer Mesh . . . . . . . . . . . . . . . . 23

3.1.3 Near-body Volume Mesh . . . . . . . . . . . . . . . . . 25

3.1.4 Far-body Volume Mesh . . . . . . . . . . . . . . . 26

3.2 Structured Meshing . . . . . . . . . . . . . . . . . . . . . . . 27

3.2 .1 Surface Mesh . . . . . . . . . . . . . . . . . . 28

3.2.2 Boundary Layer and Shear Layer Mesh . . . . . . . . . . . . . 31

3.2.3 Near-body Volume Mesh . . . . . . . . . . . . . . . . . . . . 33

3.2.4 Far-body Volume Mesh . . . . . . . . . . . . . . . 34

4 Simulation Setup $\quad 36$

4.1 Solver Settings . . . . . . . . . . . . . . . . . 36

4.1.1 Computational Resources . . . . . . . . . . . . . 37

4.2 Flow Conditions . . . . . . . . . . . . . . . . . 37 
4.2 .1 Boundary Conditions . . . . . . . . . . . . . . . . . 38

4.3 Modeling Turbulence . . . . . . . . . . . . . . . . . . . . . . 41

4.3 .1 Near Wall Treatment . . . . . . . . . . . . . . . . . . . . 41

4.3.2 Turbulence Model Selection . . . . . . . . . . . . . . . . . . 44

5 Results 46

5.1 2-D GACC Airfoil Validation . . . . . . . . . . . 46

5.2 3-D CCW and Engine Simulator Validation for GTRI . . . . . . . . 48

5.3 Aerodynamic Impacts from Fuselage Body . . . . . . . . . . . . 50

5.4 CC Slot Boundary Condition _. . . . . . . . . . . . . . 51

5.5 Convergence . . . . . . . . . . . . . . . . . . 53

5.6 Comparison of Unstructured and Structured Meshing . . . . . . . . 56

5.7 Mesh Independence . . . . . . . . . . . . . . . . . . . . . 64

6 Concluding Remarks and Recommendations $\quad 67$

6.1 Hybrid Meshing . . . . . . . . . . . . . . . . . . . . . . . . . . 69

6.2 Lessons Learned . . . . . . . . . . . . . . . . . . . . . . . . 71

$\begin{array}{ll}\text { Bibliography } & 74\end{array}$

$\begin{array}{ll}\text { Appendices } & 85\end{array}$

A Governing Equations $\quad 85$

A.1 Continuity Equation . . . . . . . . . . . . . . . . 85

A.2 Momentum Equation . . . . . . . . . . . . . . 86

A.3 Energy Equation . . . . . . . . . . . . . . . 86

B Turbulence Modeling $\quad 88$

B.1 Boussinesq Approximation . . . . . . . . . . . . . . . 88

B.2 Standard k- $\epsilon$ Model . . . . . . . . . . . . . . . . . . . . . . . . . . . . . 89

B.3 Realizable k- $\epsilon$ Model . . . . . . . . . . . . . . . . . . . . . . . . . . . . 91

B.4 Standard k- $\omega$ Model . . . . . . . . . . . . . . . . . . . . . . . . 93

B.5 Shear Stress Transport k- $\omega$ Model . . . . . . . . . . . . . . 95 


\section{List of Tables}

1.1 Review of CFD studies using unstructured meshing . . . . . . . . 9

1.2 Review of CFD studies using structured meshing . . . . . . . . . 10

2.1 List of complicated, 3-D physics expected for modeling AMELIA . . . 12

2.2 Removed parts from AMELIA . . . . . . . . . . . . . . . . . 14

4.1 General FLUENT solver settings _ . . . . . . . . . . . . . . 36

4.2 Model Conditions . . . . . . . . . . . . . . . . . . . . . . 37

4.3 Quantities set for boundary conditions . . . . . . . . . . . 41

B.1 Constants for the standard $\mathrm{k}-\epsilon$ model as described by White[4] . . . 91

B.2 Constants for the realizable $\mathrm{k}-\epsilon$ model as described by FLUENT[5] . . 93

B.3 Constants for the standard $k-\omega$ model as described by Wilcox $[6]$. . . 95

B.4 Constants for the shear stress transport $\mathrm{k}-\omega$ model as described by FLUENT[5] . . . . . . . . . . . . . . . . . . 96 


\section{List of Figures}

1.1 Optional caption for list of figures . . . . . . . . . . . . 3

1.2 Powered lift through circulation control flaps . . . . . . . . . . 4

1.3 Engine exhaust entrainment due to downward momentum strength of circulation control jet stream as studied by Blessing $[7] \ldots \ldots \ldots$. . . 5

1.4 CFD visualization of takeoff/landing vs cruise configuration $\ldots \ldots 6$

2.1 Cal Poly's CESTOL aircraft AMELIA _... . . . . . . . . . . 12

2.2 Schematic of AMELIA experimental model . . . . . . . . . . . . 13

2.31 1/10th Scale AMELIA . . . . . . . . . . . . . . . . . 13

2.4 Simplified and defeatured computational model of AMELIA utilizing symmetry plane to reduce total mesh size by $1 / 2 \ldots \ldots$

2.5 Areas of complex meshing: CC slots (LE and TE), Engine trailing edges, and Scissor junctions created by deflected flaps . . . . . . . 16

3.1 ICEM CFD[8] set and go user interface for automated unstructured meshing . . . . . . . . . . . . . . . . 20

3.2 Complicated mesh lines are created and mapped to the computational model to parameterize mesh settings at all locations of the computational domain . . . . . . . . . . . . . . . . . . . . 21

3.3 Unstructured surface mesh of wing, circulation control slots, \& engine 23

3.4 Prism boundary layer mesh utilizing $\mathrm{y}^{+} 1 \ldots \ldots \ldots 24$

3.5 Cutplane of near-body unstructured volume mesh . . . . . . . . 25

3.6 Multi-blocking in the far-body . . . . . . . . . . . . . . . 26

3.7 Structured blocks created for engine nacelle . . . . . . . . . . 27

3.8 Structured blocks created for wing . . . . . . . . . . . . . 28

3.9 Surface mesh comparison of engine nacelle and wing flaps . . . . . . 29

3.10 Comparison of small features are handled with unstructured and structured meshing . . . . . . . . . . . . . . . . . 30

3.11 Quantitative comparison of unstructured and structured surface meshing 31

3.12 Mesh slice through engine centerline . . . . . . . . . . . . . . 32

3.13 Comparison of how well shear layer is captured by unstructured and structured meshing . . . . . . . . . . . . . . . . . 33 
3.14 Mesh slice through engine centerline comparing how well near-body unsteady flow physics will be captured by the mesh . . . . . . . . . 34

3.15 Far-body mesh extending many chords upstream, downstream, and side 35

4.1 FLUENT Boundary conditions set for engine and circulation control slots . . . . . . . . . . . . . . . . . . 40

4.2 Velocity profile for turbulent flow . . . . . . . . . . . . 43

4.3 FLUENT boundary layer treatment methods . . . . . . . . . . . 44

5.1 GACC validation airfoil . . . . . . . . . . . . . 46

5.2 Blowing coefficient versus lift coefficient of a circulation control airfoil

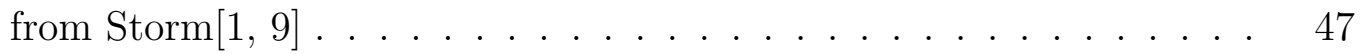

5.3 GTRI wind tunnel geometry for validation cases[10] . . . . . . . . 49

5.4 Blowing coefficient vs lift coefficient of GTRI model . . . . . . . . 50

5.5 Fuselage influence on overall lift coefficient . . . . . . . . . . . 51

5.6 Computational boundary comparison for slot geometry. Computational plane modeled at slot exit (left) and computational plane modeled in plenum (right). . . . . . . . . . . . . . . . . . . 52

5.7 Mach contours comparing the two slot modeling approaches . . . . 53

5.8 History of residual convergence by iteration steps . . . . . . . . 54

5.9 History of drag and lift convergence by iteration steps . . . . . . . 55

5.10 Fluid slice through engine centerline colored by Mach Number highlighting flow differences with engine jet exhaust for unstructured and structured meshing . . . . . . . . . . . . . 56

5.11 Fluid slice through engine centerline colored by Mach Number highlighting flow differences with shear layer coming off engine trailing edge 57

5.12 Fluid slice through engine centerline colored by Mach Number highlighting flow differences with CC jet flow over flaps . . . . . . . 58

5.13 Fluid slice through engine centerline colored by Mach Number highlighting flow differences with shear layer and CC jet exit slot . . . . 59

5.14 Static pressure contours showing separation upstream of slot exit as seen in Blessing $[11] \ldots \ldots \ldots \ldots$. . . . . . . . . . . 6 60

5.15 Streamlines showing flow path over the wing as seen in Blessing[11] . 61

5.16 Comparison of Coefficient of Pressure distribution for various stations a long wing highlighting significant differences near CC slots . . . . 62

5.17 Preliminary experimental data of Pressure Coefficient at B/L 500 station 63

5.18 Fluid slice through engine centerline colored by Mach Number highlighting flow differences with farfield wake . . . . . . . . . .

5.19 Grid independence study for 3 mesh sizes for unstructured and structured meshing to determine minimum amount of mesh elements required to reach within $5 \%$ accuracy $\ldots \ldots \ldots 66$ 
6.1 1st attempt at creating a hybrid mesh for engine jet exhaust. More resources needed to create a high quality structured mesh for CC jet . 6.2 Interface is key component for successful hybrid mesh. With limited resources, very difficult to create perfect elements for merging at the interface. Aspect ratio and skewness can be compromised but could introduce too much numerical error . . . . . . . . . . . . . . 


\section{Nomenclature}

$\begin{array}{ll}C E S T O L & \text { Cruise Efficient Takeoff and Landing } \\ C C & \text { Circulation Control } \\ C C W & \text { Circulation Control Wing } \\ S T O L & \text { Short Takeoff and Landing } \\ U S B & \text { Upper Surface Blowing } \\ C_{D} & \text { Drag Coefficient } \\ C_{L} & \text { Lift Coefficient } \\ C_{T} & \text { Thrust Coefficient } \\ C_{\mu} & \text { Blowing Coefficient } \\ G r e e k & \\ \alpha & \text { Angle of Attack, deg. } \\ \mu & \text { Dynamic Viscosity } \\ \nu & \text { Kinematic Viscosity } \\ \rho & \text { Mass Density }\end{array}$




\section{Chapter 1}

\section{Introduction}

The basis for computational analysis in this thesis revolves around the interaction of circulation control wings (CCW) and upper surface blowing (USB). This complex coupling has been studied for years as a way to improve the Short Take-Off and Landing (STOL) performance of an aircraft[12] . STOL configurations are one way researchers are trying to tackle the problem of global air traffic congestion. The problem doesn't appear to be slowing down either as the Bureau of Transportation Statistics recently reported that passenger traffic on U.S airlines increased $1.8 \%$ in August 2010 compared to the same time in 2009 . Air traffic congestion causes unnecessary and excess fuel usage in addition to the air and noise pollution associated with it near airports.

This thesis will be organized as follows. In the next section, a review of where this thesis fits in a joint effort between Cal Poly and NASA will be discussed followed by a brief overview of Circulation Control Technology. Chapter 2 will review the computational model used for numerical simulation. Chapter 3 will discuss and compare various methodologies for creating a mesh using ANSYS ICEMCFD[8]. Chapter 4 will go over boundary conditions, solver settings, and solver models set within AN- 
SYS FLUENT[5] for simulation. Chapter 5 will discuss and compare the CFD results of the various meshing methodologies discussed in Chapter 3.

\section{$1.1 \quad$ NRA Review}

The work of this thesis has been funded by a NASA Research Announcement (Contract NNL07AA55C) awarded to Cal Poly. The goal of the joint project is to design an $\mathrm{N}+2$ generation Commercial Aircraft similar to the current aging Boeing 737 and Airbus 320 fleet. Generally speaking, the N+2 distinction requires that the aircraft meet the following objectives: 1) Reduce Ground Noise 2) Reduce Emissions 3) Improve Fuel Efficiency. The technology that will be implemented in hopes of achieving these goals is called Circulation Control which will be explained further in the next section. The aircraft has been given the acronym, AMELIA, which stands for Advanced Model for Extreme Lift and Aeroacoustics. The NRA project is divided into two parts: 1) Develop CFD techniques and database 2) Conduct scaled model wind tunnel test for CFD validation. The role this thesis plays into the overall goal of the project is to investigate various meshing techniques for best accuracy in predicting RANS CFD analysis for this Circulation Control Aircraft. More details of this joint project with NASA can be seen in Marshall[13]. 


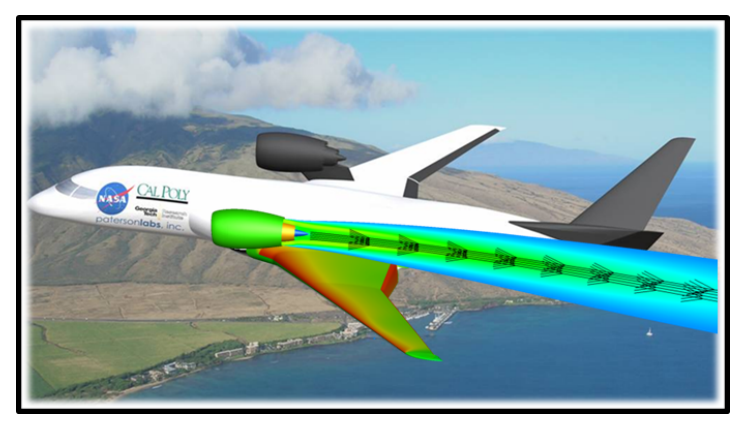

(a) Proposed circulation control aircraft

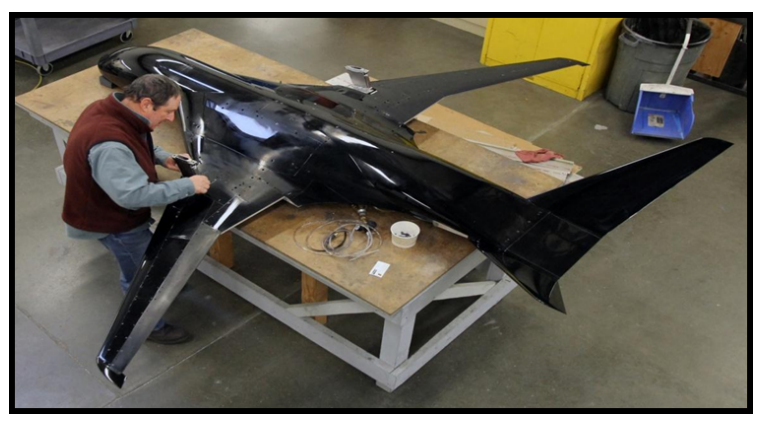

(b) $1 / 10$ th scaled model for testing

Figure 1.1: NRA two part effort. (a) CFD (b) Wind Tunnel Testing

\subsection{Circulation Control Review}

AMELIA utilizes circulation control to generate its STOL capabilities. Lift is traditionally generated for subsonic airfoils through increasing angle of attack and/or camber. However, the increase in lift eventually builds an adverse pressure gradient over the surface of a traditional wing causing the flow to separate and limit the wing's maximum lift coefficient. To overcome this, the use of complex devices such as flaps and slats are utilized at the expense of overall mechanical complexity, noise, and cost. However, this lift improvement is still not enough to achieve the goals for the $\mathrm{N}+2$ distinction.

To improve upon this concept, AMELIA utilizes a circulation control wing (CCW) which is an active flow control device as a simpler and more effective performance alternative to the usual high-lift devices seen on conventional aircrafts[14]. Figure 1.2(a) gives a general physics of the technology while Figure 1.2(b) shows the cross section of the CCW with the trailing edge flaps deflected at various angles. The flap system of AMELIA is specialized dual-radii design for the purpose of the NRA. The design was conducted by Golden et al.[2]. The mechanical simplification of 
circulation control devices over traditional flaps and slats help reduce noise and drag upon takeoff and landing. This is due to large complex wing components no longer obstructing the freestream flow. The largest effect of using CCW will be seen during takeoff and landing where high lift coefficients are needed at low airspeeds. This technology is made possible through the use of the Coanda effect along the adjacent curved surface of the wing, where the accelerated fluid is able to stay attached for an extended amount of time, thus delaying separation and increasing lift[15]. In other words, when the fluid is accelerated tangentially through a finite slot height at high enough speeds, the fluid will stay attached despite the surface turning away from the initial jet acceleration. Moreover, the camber of the airfoil and dual radius flap are manipulated such that the stagnation point on the leading edge and flow separation point on the trailing edge provides a positive circulation around the wing and consequently increases lift.

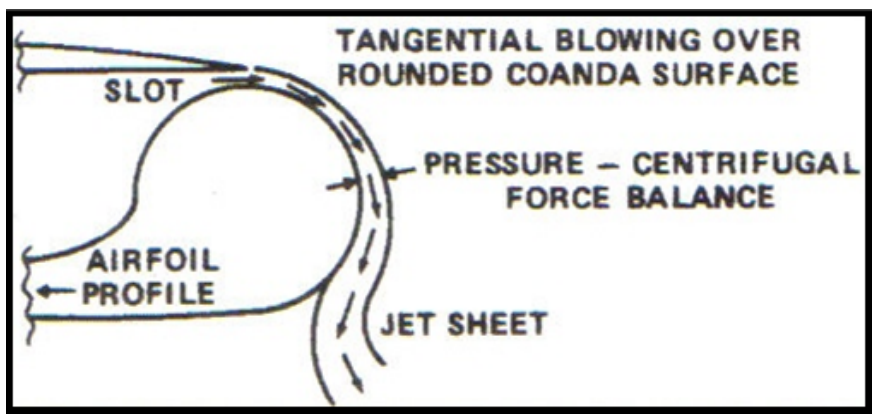

(a) Physics of circulation control

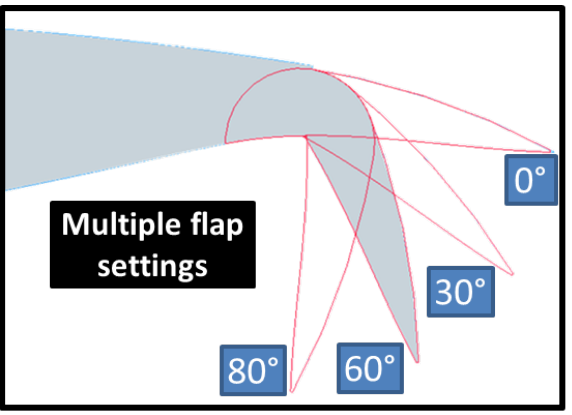

(b) AMELIA flap configurations

Figure 1.2: Powered lift through circulation control flaps

In addition, initial research into the flow physics of AMELIA reveals additional unexpected lift through the engine exhaust entrainment due to the downward momentum strength of the circulation control jet stream. This can be seen in Figure 1.3 and comes from the thesis work of Blessing[7] which is also funded by this NRA.

Overall, circulation control generates more lift through three sources. First, the 
accelerated fluid ejected from the slot significantly increases air velocity over the upper surface of the aft wing, more so than conventional flaps/slats. Secondly, the Coanda effect delays separation and allows the high speed jet to detach from the flap as late as possible to create a strong downward momentum jet away from the wing that increases wing circulation. And lastly, the coupling of the circulation control jet and engine exhaust causes downward entrainment similar to Upper Surface Blowing (USB). The increased lift production observed can improve the takeoff and landing performance of aircrafts immensely and can enable large aircrafts to operate out of smaller airports, thus alleviating the growing problem of air traffic congestion. In addition, AMELIA can help reduce noise through three sources. First the use of circulation control flaps as a means of improving lift performance is much simpler mechanically than conventional flaps/slats and has less freestream obstructing gaps. Next, mounting the engine over the wing helps shield the greatest source of noise from the engine exhaust. And lastly, with greater lift performance AMELIA will be able to takeoff at shorter distances through steeper climb-out angles, thus keeping most of the initial noise source within airport infrastructure and away from nearby communities. Figure 1.4 shows the general flow field for when AMELIA is in takeoff/landing and cruise configuration.

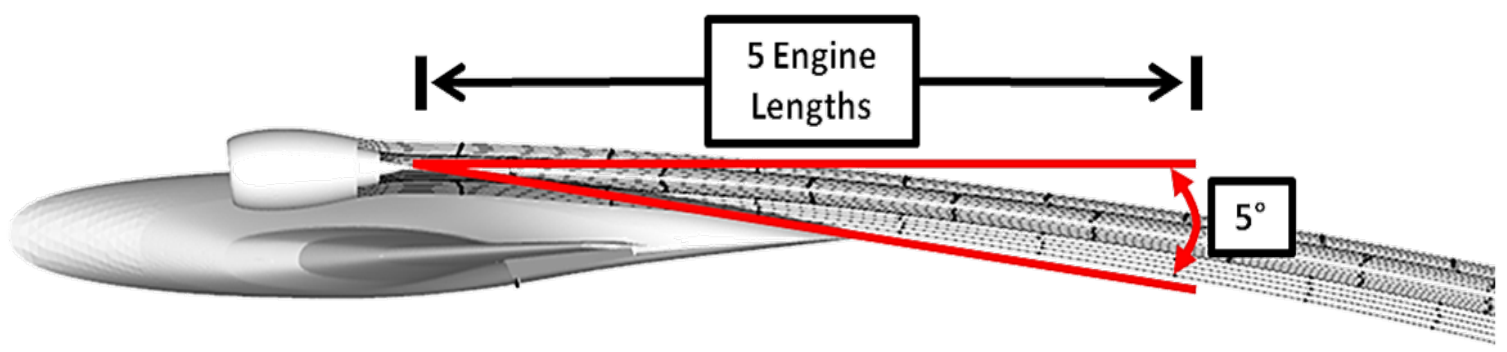

Figure 1.3: Engine exhaust entrainment due to downward momentum strength of circulation control jet stream as studied by Blessing $[7]$ 


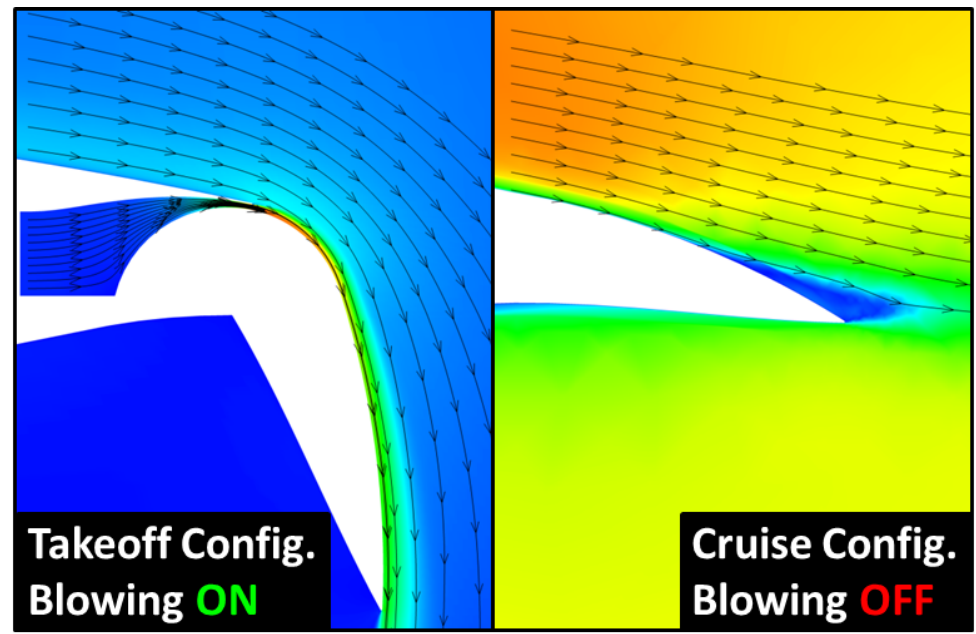

Figure 1.4: CFD visualization of takeoff/landing vs cruise configuration

\subsection{Literature Review}

Many studies have focused on assessing and validating the capabilities of computational fluid dynamics (CFD) to predict the performance of different flow control technologies including synthetic jets[16] and CC airfoils[17]. The CFD codes were validated through codetocode comparisons as well as through comparison with experimental data. Although the circular trailing edge CC airfoil has been the focus of the CC Workshop and other CFD studies,[18, 19, 20, 21] the dual radius CC airfoil developed by Englar[22] is also of interest for aeronautical applications because it has the potential to alleviate the high cruise drag associated with the circular trailing edge airfoil. The dual radius CC airfoil concept was tested by Englar[22] at Georgia Tech Research Institute (GTRI) and more recently by Jones at NASA LaRC as a modification to a General Aviation Circulation Control (GACC) airfoil[23].

Previous computational studies[17, 21] indicated that current CFD methods did not predict the circular Coanda flows robustly or accurately. The separation location 
on the Coanda surface was very sensitive to computational parameters including turbulence models and tended to over predict the performance (lift) of the airfoil in comparison with the experiment due to a delay in jet separation. In some cases, the CFD solutions predicted a physically unrealistic wrapping of the streamlines all the way around the airfoil. There were also questions regarding the precise conditions in the experiment including blowing rate and three-dimensional effects.

Paterson and Baker[19] used incompressible Reynolds-averaged Navier-Stokes and detached-eddy simulation methods to study the flow characteristics of 3D circulation control foil. They presented RANS simulations for two jet-momentum coefficients, and demonstrated that a linear Reynolds-stress closure and a blended $\mathrm{k}-\omega / \mathrm{k}-\epsilon$ turbulence model is able to successfully predict the pressure distribution trends. They stated that higher-order curvature-corrected models may only be required to resolve localized details such as the maximum suction peak on the Coanda surface.

Slomski et al.[18] studied the effect of different turbulence models on the numerical simulation of circulation control 2D airfoils. They solved RANS equations and compared their solutions to experimental data at five different blowing rates and zero degree angle of attack. They tested three different turbulence models including $\mathrm{k}-\epsilon$, realizable $\mathrm{k}-\epsilon$, and a full Reynolds stress model. They showed that the $\mathrm{k}-\epsilon$ and realizable $\mathrm{k}-\epsilon$ models can reasonably predict the lift generated by the circulation control for lower rates of blowing. However, at higher blowing rates, only the Reynolds stress turbulence model continues to capture the physics of the circulation control problem and hence reasonable lift prediction.

Slomski et al.[24] presented detailed study of unsteady, three-dimensional, turbulent flow over a cambered, 15-percent thick, circulation control airfoil at zero angle of attack. They used large-eddy simulation with a sub-grid scale turbulence model that 
combines a transport equation for the sub-grid scale turbulent kinetic energy and a turbulent length scale based on local grid dimensions. They obtained fairly well comparison of the resulting mean surface pressure distribution with experimental measurements. They indicated that "sufficient diffusion of momentum and turbulent kinetic energy from the Coanda jet across the shear layer is necessary for an accurate solution to the circulation control airfoil problem".

Chang et al.[20] applied incompressible Fluent(v6.1) RANS formulation to simulate two and three-dimensional circulation control airfoils. They tested two different trailing edge geometries and different jet exit slot hight and blowing rate. They obtained successful 2-D simulations using the full-Reynolds stress turbulence model (FRSM). However, the separation location of the jet was not accurately predicted for the 3-D simulations by applying k- $\omega$ SST turbulence model. They, also, indicated that the 3-D simulations using the the full- Reynolds stress model "could not be completed because of a stability problem that occurred in the coupling, in Fluent, of the mean flow and FRSM solution scheme".

Swanson et al.[21] investigated the use of different turbulence models on circulation control airfoil 2D flows. The tested turbulence models include the one-equation Spalart-Allmaras model (SA), the SA model with curvature correction (SARC), the two-equation shear-stress transport model (SST), and the two-equation model for the turbulent kinetic energy and enstrophy $\mathrm{k}-\zeta$. They used both structured and unstructured computational meshes to solve the compressible RANS equations. They demonstrated the importance of including curvature effects when computing circulation control airfoil flows. They indicated that "among the models tested, only the SARC model produces physically realistic solutions at highest blowing rate".

Table 1.1 and 1.2 list many more studies investigating circulation control applica- 
tions. Each table is organized by Unstructured and Structured Meshing, respectively.

Table 1.1: Review of CFD studies using unstructured meshing

\begin{tabular}{|c|c|c|c|c|c|}
\hline Authors & Geom & $\begin{array}{c}\text { Flow } \\
\text { Conditions }\end{array}$ & $\begin{array}{c}\text { Turb } \\
\text { Models }\end{array}$ & CFD Code & $\begin{array}{l}\text { Solver } \\
\text { Models }\end{array}$ \\
\hline $\begin{array}{l}\text { Baker et } \\
\text { al. }[25]\end{array}$ & CCW-LG & $\begin{array}{l}\mathrm{C} \mu=0.031-0.226 \\
\mathrm{M}_{\infty}=\mathrm{n} / \mathrm{a} \\
\operatorname{Re}_{c}=1 \times 10^{6}\end{array}$ & $\begin{array}{c}\mathrm{SA}, \mathrm{k} \epsilon, \\
\mathrm{k} \omega\end{array}$ & $\begin{array}{c}\text { CFDSHIP, } \\
\text { AcuSolve }\end{array}$ & $\begin{array}{c}\text { 2D, } \\
\text { RANS, } \\
\text { Incomp. }\end{array}$ \\
\hline $\begin{array}{c}\text { Chang et } \\
\text { al. }[20]\end{array}$ & $\begin{array}{c}\text { NCCR } \\
1510- \\
7067 \mathrm{~N}\end{array}$ & $\begin{array}{l}\mathrm{C} \mu=.048-.209 \\
\mathrm{M}_{\infty}=0.12 \\
\operatorname{Re}_{c}=5.45 \times 10^{5}\end{array}$ & $\begin{array}{l}\text { FRSM, } \\
\text { k } \omega\end{array}$ & FLUENT & $\begin{array}{l}\text { 2D, 3D, } \\
\text { RANS, } \\
\text { Incomp. }\end{array}$ \\
\hline $\begin{array}{l}\text { Friedman } \\
\text { et al. }[26]\end{array}$ & Elliptic & $\begin{array}{l}\mathrm{C} \mu=0.0-0.03 \\
\mathrm{M}_{\infty}=0.08-0.5 \\
\operatorname{Re}_{c}=7.5 \times 10^{5}\end{array}$ & $\mathrm{n} / \mathrm{a}$ & EZNSS & $\begin{array}{c}\text { 2D, RANS, } \\
\text { URANS, } \\
\text { Comp. }\end{array}$ \\
\hline $\begin{array}{l}\text { Jones et } \\
\text { al. }[27]\end{array}$ & GACC & $\begin{array}{l}\mathrm{C} \mu=0.0-0.162 \\
\mathrm{M}_{\infty}=0.10 \\
\operatorname{Re}_{c}=5.33 \times 10^{5}\end{array}$ & $\mathrm{SA}$ & FUN2D & $\begin{array}{c}2 \mathrm{D}, \\
\text { RANS, } \\
\text { Comp. }\end{array}$ \\
\hline $\begin{array}{c}\text { Lee- } \\
\text { Rausch } \\
\text { et al.[3] }\end{array}$ & GACC & $\begin{array}{l}\mathrm{C} \mu=0.0-0.09 \\
\mathrm{M}_{\infty}=0.08-0.1 \\
\operatorname{Re}_{c}=4.7 \times 10^{5}\end{array}$ & $\mathrm{SA}, \mathrm{k} \omega$ & $\begin{array}{c}\text { FUN2D, } \\
\text { TLNS3D, } \\
\text { CFL3D }\end{array}$ & $\begin{array}{c}\text { 2D, } \\
\text { RANS }\end{array}$ \\
\hline $\begin{array}{l}\text { McGowan } \\
\text { et al.[28] }\end{array}$ & GACC & $\begin{array}{l}\mathrm{C} \mu=0.0-0.078 \\
\mathrm{M}_{\infty}=0.10 \\
\operatorname{Re}_{c}=5.33 \times 10^{5}\end{array}$ & $\mathrm{SA}$ & FLUENT & $\begin{array}{c}\text { 2D, } \\
\text { RANS, } \\
\text { Comp. }\end{array}$ \\
\hline $\begin{array}{l}\text { Pfingsten } \\
\text { et al.[29] }\end{array}$ & $\mathrm{n} / \mathrm{a}$ & $\begin{array}{l}\mathrm{C} \mu=0.038-0.043 \\
\mathrm{M}_{\infty}=0.15 \\
\operatorname{Re}_{c}=1.0 \times 10^{6}\end{array}$ & $\mathrm{SA}$ & TAU & $\begin{array}{c}\text { 2D, } \\
\text { RANS, } \\
\text { Comp. }\end{array}$ \\
\hline $\begin{array}{l}\text { Slomski } \\
\text { et al.[18] }\end{array}$ & $\begin{array}{c}\text { NCCR } \\
1510- \\
7067 \mathrm{~N}\end{array}$ & $\begin{array}{l}\mathrm{C} \mu=0.01-0.208 \\
\mathrm{M}_{\infty}=0.12 \\
\operatorname{Re}_{c}=5.33 \times 10^{6}\end{array}$ & $\begin{array}{c}\mathrm{k} \epsilon \\
\text { FRSM }\end{array}$ & FLUENT & $\begin{array}{c}\text { 2D, } \\
\text { RANS, } \\
\text { Comp. }\end{array}$ \\
\hline $\begin{array}{l}\text { Swanson } \\
\text { et al.[21] }\end{array}$ & $\mathrm{LCC}$ & $\begin{array}{l}\mathrm{C} \mu=0.03-0.226 \\
\mathrm{M}_{\infty}=0.12 \\
\operatorname{Re}_{c}=9.86 \times 10^{5}\end{array}$ & $\mathrm{k} \omega, \mathrm{k} \zeta$ & $\begin{array}{l}\text { CFL3D, } \\
\text { FUN2D }\end{array}$ & $\begin{array}{l}\text { 2D, 3D, } \\
\text { RANS, } \\
\text { Comp. }\end{array}$ \\
\hline
\end{tabular}


Table 1.2: Review of CFD studies using structured meshing

\begin{tabular}{|c|c|c|c|c|c|}
\hline Authors & Geom & $\begin{array}{c}\text { Flow } \\
\text { Conditions }\end{array}$ & $\begin{array}{c}\text { Turb } \\
\text { Models }\end{array}$ & CFD Code & Models \\
\hline $\begin{array}{c}\text { Baker et } \\
\text { al. }[25]\end{array}$ & CCW-LG & $\begin{array}{l}\mathrm{C} \mu=0.031-0.226 \\
\mathrm{M}_{\infty}=\mathrm{n} / \mathrm{a} \\
\operatorname{Re}_{c}=1 \times 10^{6}\end{array}$ & $\begin{array}{c}\mathrm{SA}, \mathrm{k} \epsilon \\
\mathrm{k} \omega\end{array}$ & $\begin{array}{c}\text { CFDSHIP, } \\
\text { AcuSolve }\end{array}$ & $\begin{array}{c}\text { 2D, RANS, } \\
\text { FUN2D, } \\
\text { Incomp. }\end{array}$ \\
\hline $\begin{array}{c}\text { Chang et } \\
\text { al.[20] }\end{array}$ & $\begin{array}{c}\text { NCCR } \\
1510- \\
7067 \mathrm{~N} \\
\end{array}$ & $\begin{array}{l}\mathrm{C} \mu=0.048-0.209 \\
\mathrm{M}_{\infty}=0.12 \\
\operatorname{Re}_{c}=5.45 \times 10^{5}\end{array}$ & $\begin{array}{l}\text { FRSM, } \\
\text { k } \omega\end{array}$ & FLUENT & $\begin{array}{l}\text { 2D, 3D, } \\
\text { RANS, } \\
\text { Incomp. }\end{array}$ \\
\hline $\begin{array}{c}\text { Englar et } \\
\text { al.[30] }\end{array}$ & $\mathrm{CC} 020$ & $\begin{array}{l}\mathrm{C} \mu=0.046-0.123 \\
\mathrm{M}_{\infty}=0.10 \\
\operatorname{Re}_{c}=1.0-8.0 \times 10^{5}\end{array}$ & $\mathrm{k} \omega$ & $\begin{array}{l}\text { OVER- } \\
\text { FLOW }\end{array}$ & $\begin{array}{c}\text { 2D, } \\
\text { RANS, } \\
\text { Comp. }\end{array}$ \\
\hline $\begin{array}{l}\text { Friedman } \\
\text { et al.[31] }\end{array}$ & Elliptic & $\begin{array}{l}\mathrm{C} \mu=0.0-0.60 \\
\mathrm{M}_{\infty}=0.20 \\
\operatorname{Re}_{c}=7.5 \times 10^{5}\end{array}$ & $\mathrm{R}_{t}$ & EZNSS & $\begin{array}{c}\text { 2D, RANS, } \\
\text { URANS, } \\
\text { Comp. }\end{array}$ \\
\hline $\begin{array}{c}\text { Lee- } \\
\text { Rausch et } \\
\text { al. [3] }\end{array}$ & GACC & $\begin{array}{l}\mathrm{C} \mu=0.0-0.09 \\
\mathrm{M}_{\infty}=0.08-0.1 \\
\operatorname{Re}_{c}=4.7 \times 10^{5}\end{array}$ & $\mathrm{SA}, \mathrm{k} \omega$ & $\begin{array}{c}\text { FUN2D, } \\
\text { TLNS3D, } \\
\text { CFL3D }\end{array}$ & $\begin{array}{c}2 \mathrm{D}, \\
\text { RANS }\end{array}$ \\
\hline $\begin{array}{l}\text { Paterson } \\
\text { et al.[19] }\end{array}$ & $\begin{array}{c}\text { NCCR } \\
1510- \\
7067 \mathrm{~N} \\
\end{array}$ & $\begin{array}{l}\mathrm{C} \mu=0.184-0.209 \\
\mathrm{M}_{\infty}=0.12 \\
\operatorname{Re}_{c}=5.45 \times 10^{5}\end{array}$ & $\mathrm{k} \epsilon, \mathrm{k} \omega$ & CFDSHIP & $\begin{array}{l}\text { 2D, DES, } \\
\text { URANS, } \\
\text { Incomp. }\end{array}$ \\
\hline $\begin{array}{l}\text { Salem- } \\
\text { Said et } \\
\text { al.[32] }\end{array}$ & $\mathrm{n} / \mathrm{a}$ & $\begin{array}{l}\mathrm{C} \mu=0.10 \\
\mathrm{M}_{\infty}=0.15 \\
\operatorname{Re}_{c}=2.1 \times 10^{5}\end{array}$ & FRSM & FLUENT & $\begin{array}{c}3 \mathrm{D}, \\
\text { RANS }\end{array}$ \\
\hline $\begin{array}{c}\text { Slomski et } \\
\text { al. }[24]\end{array}$ & $\begin{array}{c}\text { NCCR } \\
1510- \\
7067 \mathrm{~N}\end{array}$ & $\begin{array}{l}\mathrm{C} \mu=0.09 \\
\mathrm{M}_{\infty}=0.12 \\
\operatorname{Re}_{c}=5.45 \times 10^{5}\end{array}$ & LES & CRAFT & $\begin{array}{c}\text { 3D, } \\
\text { URANS, } \\
\text { Comp. }\end{array}$ \\
\hline $\begin{array}{l}\text { Swanson } \\
\text { et al.[33] }\end{array}$ & LCC & $\begin{array}{l}\mathrm{C} \mu=0.10 \\
\mathrm{M}_{\infty}=0.12 \\
\operatorname{Re}_{c}=9.86 \times 10^{5}\end{array}$ & $\begin{array}{c}\mathrm{SA}, \mathrm{k} \omega \\
\mathrm{k} \psi\end{array}$ & CFL3D & $\begin{array}{c}\text { 2D, RANS, } \\
\text { URANS, } \\
\text { Comp. }\end{array}$ \\
\hline $\begin{array}{l}\text { Swanson } \\
\text { et al.[33] }\end{array}$ & GACC & $\begin{array}{l}\mathrm{C} \mu=0.013-0.20 \\
\mathrm{M}_{\infty}=0.10 \\
\operatorname{Re}_{c}=5.33 \times 10^{5}\end{array}$ & $\begin{array}{l}\mathrm{SA}, \mathrm{k} \omega \\
\mathrm{k} \psi\end{array}$ & CFL3D & $\begin{array}{c}\text { 2D, RANS, } \\
\text { URANS, } \\
\text { Comp. }\end{array}$ \\
\hline $\begin{array}{l}\text { Swanson } \\
\text { et al.[21] }\end{array}$ & $\mathrm{LCC}$ & $\begin{array}{l}\mathrm{C} \mu=0.03-0.226 \\
\mathrm{M}_{\infty}=0.12 \\
\operatorname{Re}_{c}=9.86 \times 10^{5}\end{array}$ & $\mathrm{k} \omega, \mathrm{k} \zeta$ & $\begin{array}{l}\text { CFL3D, } \\
\text { FUN2D }\end{array}$ & $\begin{array}{l}\text { 2D, 3D, } \\
\text { RANS, } \\
\text { Comp. }\end{array}$ \\
\hline $\begin{array}{l}\text { Swanson } \\
\text { et al.[34] }\end{array}$ & $\begin{array}{c}\text { NCCR } \\
1510- \\
7067 \mathrm{~N}\end{array}$ & $\begin{array}{l}\mathrm{C} \mu=0.184-0.342 \\
\mathrm{M}_{\infty}=0.12-0.60 \\
\operatorname{Re}_{c}=0.545-5.2 \times 10^{6}\end{array}$ & $\begin{array}{c}\text { SA, k } \omega \\
\text { FRSM }\end{array}$ & CFL3D & $\begin{array}{l}\text { RANS, } \\
\text { Comp. }\end{array}$ \\
\hline $\begin{array}{l}\text { Yi et } \\
\text { al. [35] }\end{array}$ & GTRI-DR & $\begin{array}{l}\mathrm{C} \mu=0.0-0.35 \\
\mathrm{M}_{\infty}=0.08 \\
\operatorname{Re}_{c}=3.95 \times 10^{5}\end{array}$ & $\mathrm{BL}, \mathrm{SA}$ & $\mathrm{n} / \mathrm{a}$ & $\begin{array}{c}\text { 3D, } \\
\text { URANS, } \\
\text { Comp. }\end{array}$ \\
\hline
\end{tabular}




\section{Chapter 2}

\section{Model Description}

\subsection{AMELIA Geometry}

The Advanced Model for Extreme Lift and Improved Aeroacoustics (AMELIA) as seen in Fig. 2.1 is the focus of research at Cal Poly funded under NASA's Subsonic Fixed Wing Program. The collaborative effort culminates into The Integrated Modeling and Verification of Hybrid Wing-Body Low Noise ESTOL Aircraft. Aerodynamic and aeroacoustic analysis will be carried out in an effort to develop and validate predictive modeling capabilities for AMELIA. In addition, a large scale wind tunnel test will be conducted in the 40 foot $\mathrm{x} 80$ foot wind tunnel at the National Full-Scale Aerodynamic Complex (NFAC) at Moffett Field, CA in the fall of 2011. Much of the research thus far for AMELIA revolves around aerodynamics, turbulence modeling, and developing CFD techniques required to reasonably predict accurate CFD solutions. Marshall[36] gives a complete description of current and future goals of the AMELIA project. Obtaining a numerical solution can be simply broken into two

parts: 1) Meshing 2) Simulation. From experience, the majority of the difficulty 
arise from building high quality meshes for complicated 3-D models. Table 2.1 lists many complicated, 3-D physics that AMELIA generates that need to be carefully considered when building an adequate mesh for numerical simulation.

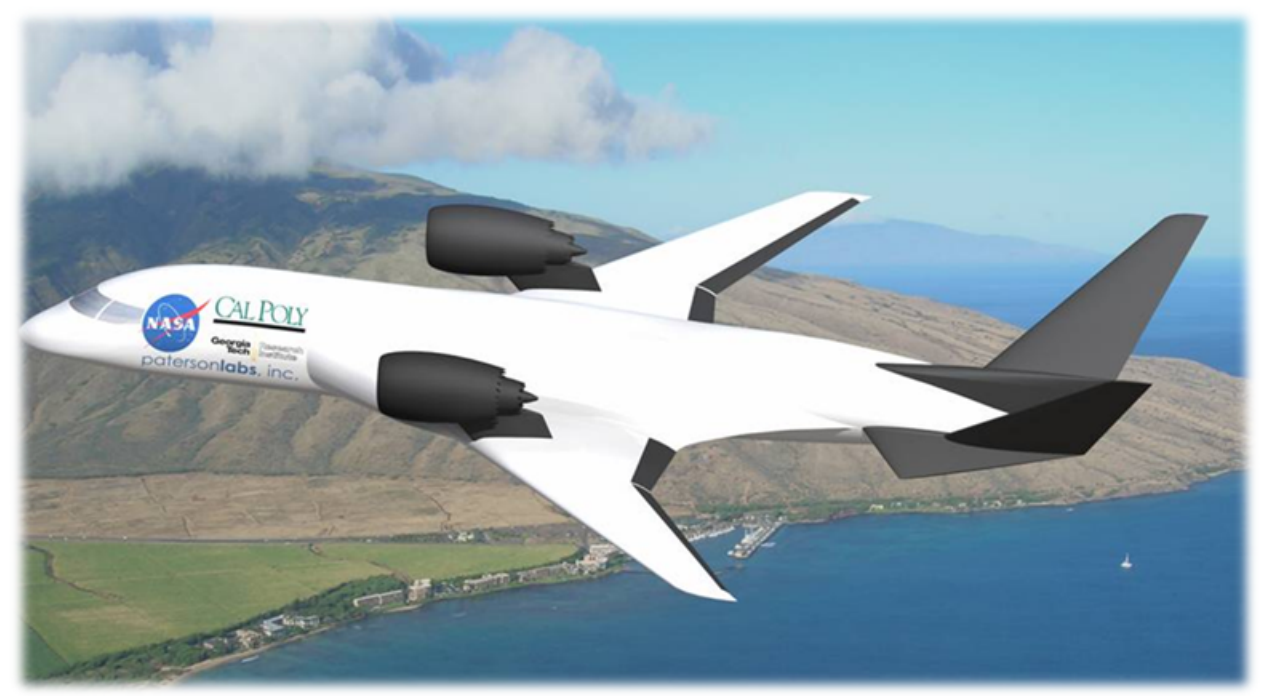

Figure 2.1: Cal Poly's CESTOL aircraft AMELIA

Table 2.1: List of complicated, 3-D physics expected for modeling AMELIA

1. Mixing of subsonic freestream flow and local transonic flow from CC slots

2. Engine-jet entrainment from Over-the-Wing (OTW) engine

3. High lift flap configuration resulting in extreme lift coefficients

4. Trailing Edge Circulation Control Slots

5. Non-uniform flow due to swept and tapered wing

6. Engine-jet interaction with $\mathrm{V}$-tail

7. Flow interaction with wind tunnel sting balance

\section{$2.2 \quad$ Experimental Model}

The experimental aspect of this contract will culminate in a full scale wind tunnel test of the AMELIA model. An in depth description of the experimental model as well as overall project details is provided by Marshall et al.[36]. Figure 2.2 shows a 
cut away view of the wind tunnel model, highlighting the leading and trailing edge circulation control slots as well as the TPS unit. Figure 2.3 shows the $1 / 10$ th scale model after being built.

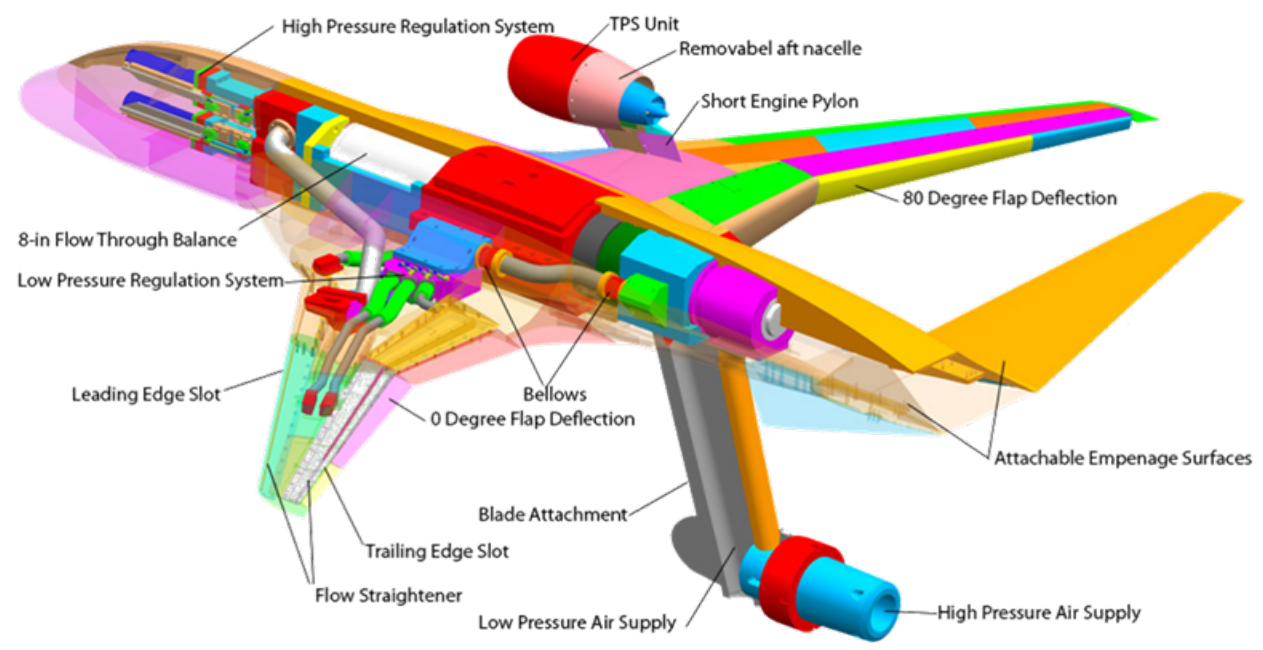

Figure 2.2: Schematic of AMELIA experimental model

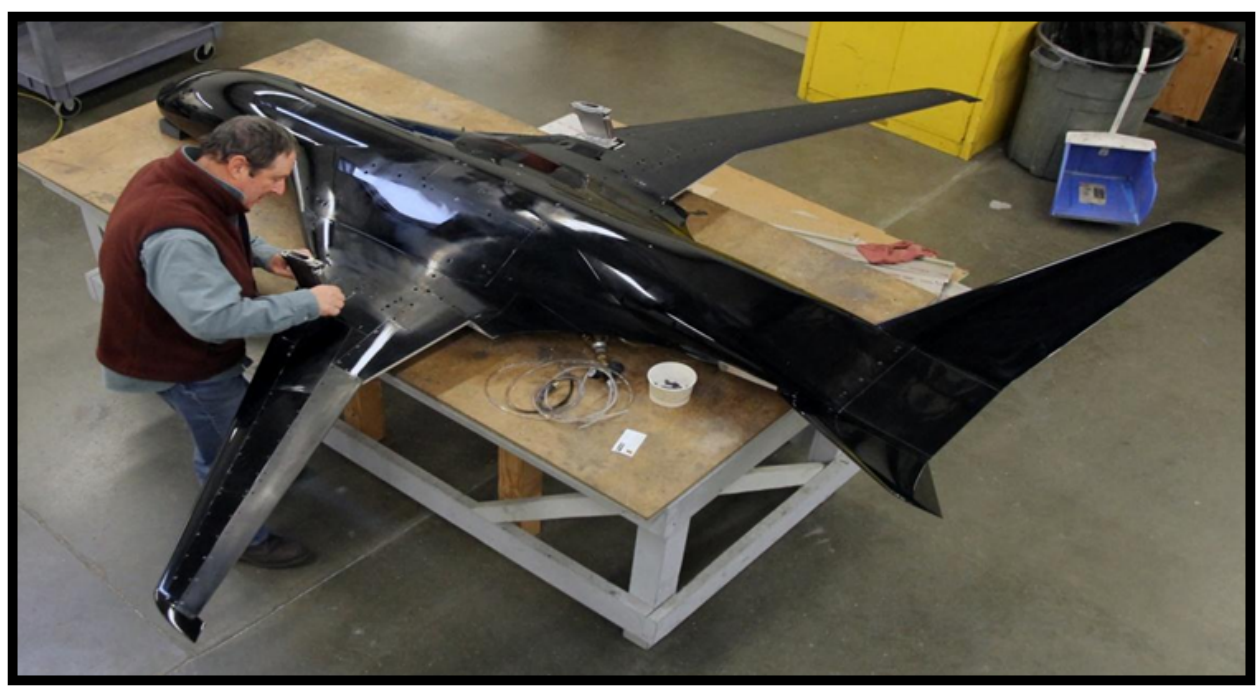

Figure 2.3: 1/10th Scale AMELIA 


\subsection{Computational Model}

Due to limited computational resources and the complexity of attempting to model AMELIA in its complete form, AMELIA had to be defeatured in order to accomplish the goals of this thesis. The focus is to compare Unstructured and Structured meshing techniques in evaluating AMELIA's most dominant physics. Table 2.2 lists features that were considered to add no value to the main goal and also helps simplify the geometry as much as possible. Keep in mind that these removed features will significantly impact aerodynamic performance, thus when validating against future wind tunnel data, these features need to be included in the computational model. Figure 2.4 shows the simplified computational model of AMELIA. The positioning of the engine nacelle was based on the work of Blessing[11]. Blessing investigated the effect on engine jet exhaust due to the circulation control slots. Geometry 5[11] yielded the most impact, thus was chosen for this thesis to study the worst case scenario. In addition, Blessing also investigated how to model the circulation control plenum. The choices were to model it completely as built in the wind tunnel model or simplify the plenum by applying a boundary condition only at the jet exit slot. It was concluded that modeling the plenum was critical to achieving accurate results. This study is further discussed in Section 5.4

Table 2.2: Removed parts from AMELIA

1. Wind tunnel sting balance
2. Wind tunnel testing domain
3. Engine pylon
4. V-tail
5. Fuselage body
6. $1 / 2$ of model (using symmetry plane)

An explanation for removing the fuselage body can be seen in Chapter 5.3. The 
computational model seen from here on is made of smooth surfaces everywhere after removing all tooling features (nuts, bolts, brackets, etc). There are still a couple areas of the model that need to be left in because of the role it plays in the physics but causes great difficulty in preparing a high quality mesh. The first is the "scissor-like junction" seen in Fig. 2.5 (bottom-right) that the flaps make with the wing when deflected for takeoff and landing configurations.

Generating an error-free high quality boundary layer mesh near these two junctions has become very difficult. The most complex feature of AMELIA is the circulation control slots located on the leading edge and trailing edge of the wing seen in Fig. 2.5 (top-left, top-right). The slot varies in height from inboard to outboard of the wing, where the smallest is 0.137 inches. The mean aerodynamic chord (MAC) of AMELIA is 18.6 inches, which makes the smallest gap in the slot $0.74 \%$ of the MAC. The drastic change in size from the slots to the remaining wing makes it very challenging to generate a good mesh that is within the limitations of existing computational resources. The last troubling issue about AMELIA is the large change in flow speed relative to freestream in the wake of the trailing edge circulation control slots and the engine. The ratio of flow speed of the slot wake to freestream flow is about 6 , while the engine wake's ratio to freestream flow is about 4 . These large flow speed ratios generate a strong shear layer that's been measured from the preliminary CFD solutions to travel at least 20 chord lengths downstream. The challenge this poses is that the mesh in the region of the shear layer and wake must be fine enough to capture the details of the flow feature, but existing computational resources limit the number of mesh elements that can exist in the computational model. 


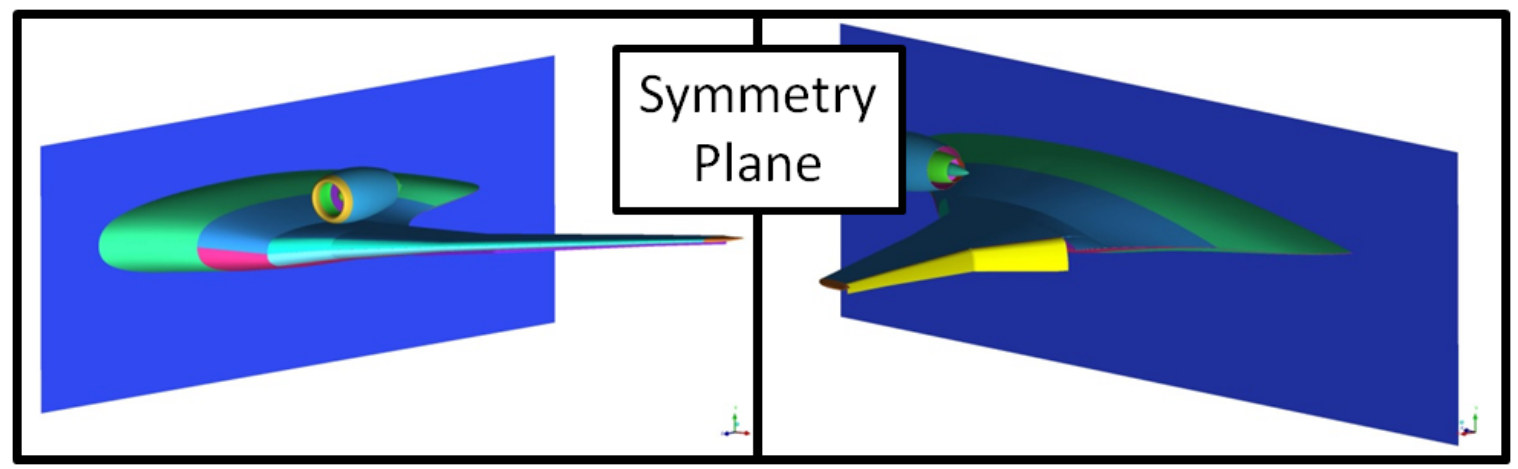

Figure 2.4: Simplified and defeatured computational model of AMELIA utilizing symmetry plane to reduce total mesh size by $1 / 2$

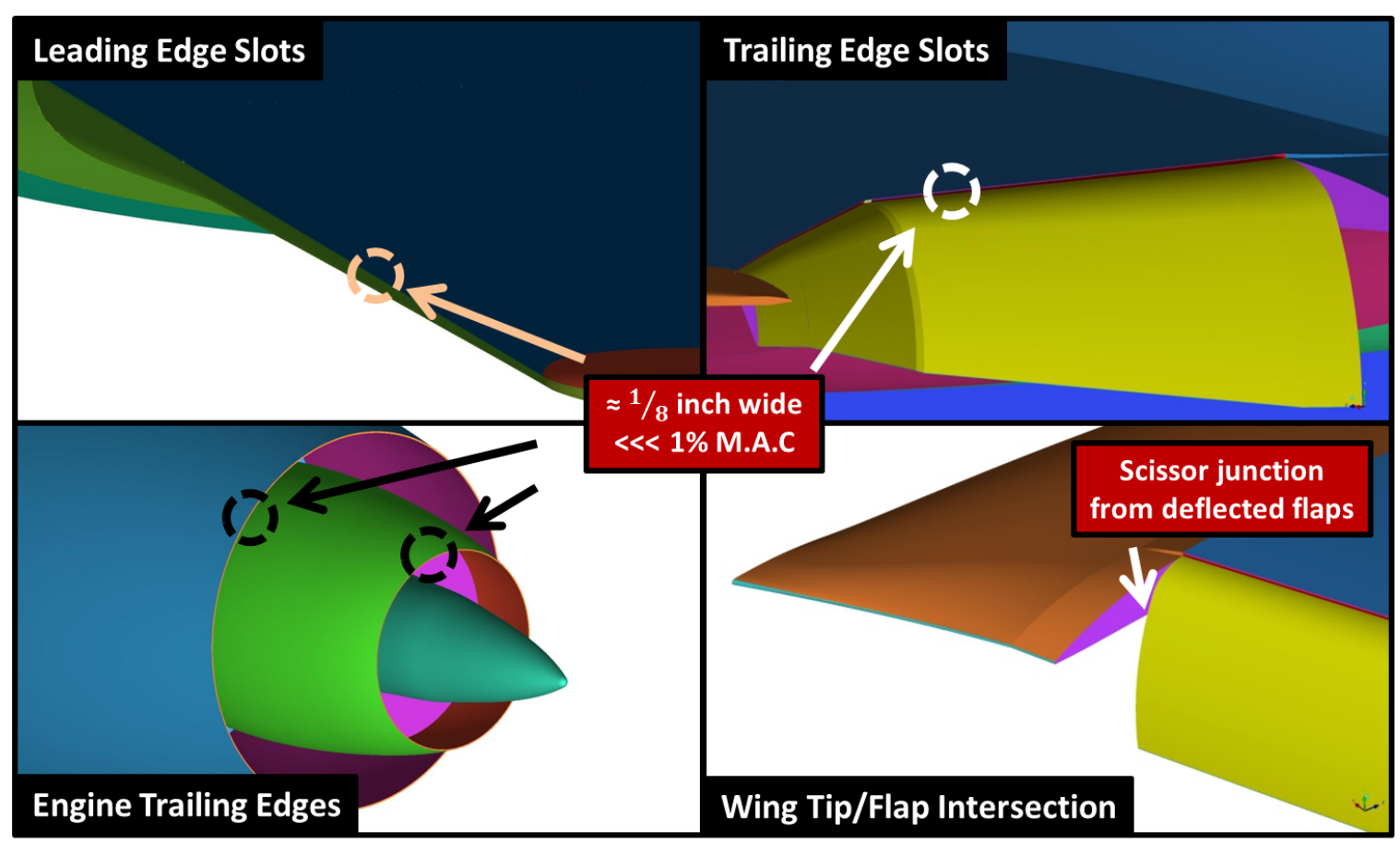

Figure 2.5: Areas of complex meshing: CC slots (LE and TE), Engine trailing edges, and Scissor junctions created by deflected flaps 


\section{Chapter 3}

\section{Mesh Generation}

In order to solve the Navier-Stokes equations accurately, all fluid variables at all locations in time and space must be computed. Depending on the size of the model, this can become extremely taxing on computational resources. As a compromise, the Navier-Stokes equations are discretized into a simpler, more manageable form where properties of the fluid at discrete spatial and temporal locations are computed numerically. This discrete set of locations is called the computational mesh. One of the requirements to achieve accurate solutions is to use an adequately resolved mesh. This means that there must be enough mesh points throughout a simulation volume to capture all of the relevant physics. This discretization step potentially introduces a lot errors depending on its quality into the solution of the desired continuous equations which, when coupled with an inadequately resolved grid, can potentially lead to divergent or unstable solutions, especially when complex models of unresolved physics, such as turbulence, are introduced. This is because the non-linear nature of these equations makes mathematical analysis of the discretization step difficult, and sometimes even impossible. There are also serious issues associated with the realization of physical boundary conditions. Lastly, in order to reduce the computational 
cost of these solutions, a steady-state solver is often employed as was done for this thesis.

The mesh generation software chosen for this NRA is ICEM CFD[8]. Careful mesh generation must be taken to ensure that the final mesh exhibits good quality elements. The quality of the mesh has significant implications on the convergence, stability, and accuracy of the numerical simulation. The mesh type and strategy can potentially play a big role in the success or failure of attaining a computational solution. The mesh must be sufficiently fine to provide an adequate resolution of the important flow features and geometry topology. Recirculation vortices and steep flow gradients within the viscous boundary layer have been observed in preliminary CFD solutions, thus requiring proper mesh resolution where these flow features are expected. The final mesh used for numerical simulation consists of four key components. The first is a high-quality surface mesh that maps itself to the computational model followed by a boundary layer and shear layer mesh that can capture complex viscous effects that occur in the surrounding fluid that bounds the model. Then there needs to be a refined near-body volume mesh that can capture the unsteadiness of the flow passing over the computational model. Lastly, there needs to be a far-body volume mesh resolved enough to capture flow features expected to extend many chord lengths downstream of the computational model. In the case of AMELIA, wingtip vortices, circulation control jet flow, and engine exhaust jet are all expected to mix together as it travels downstream. In addition, the far-body volume mesh must be large enough to allow these secondary flow features to dissipate into the freestream flow.

Since the beginning of the NRA project, the meshing approach has revolved around Unstructured Meshing. This approach has been utilized for its robustness of modeling complex geometries like AMELIA and has yielded encouraging results of 
the general nature of the circulation control wing interacting with the engine. ICEMCFD utilizes the Octree TETRA Algorithm to automatically generate the a complete mesh based on user input settings for the model as seen in Figure 3.1. However, this method limits the amount of control the user has if there is a specific area in the model the user wants to control how the mesh will be created. The resulting mesh is an irregular distribution of mesh points all throughout the computational domain filled with triangles, prisms, pyramids, and tetrahedral elements. Although easy to generate, this approach has done a poor job capturing important flow features near the computational model that are essential to producing the most accurate validation data for the future wind tunnel test expected to occur during Winter 2012 at Nasa AMES. The mesh regions that need to be improved first are in areas of large flow gradients such as the engine exhaust jet and high speed air accelerated through the circulation control slots. Work under this NRA project that uses the Unstructured Meshing approach can be seen in Blessing et al.[37, 7], Marcos et al.[10, 38] and Lichtwardt et al.[39].

In terms of time required to prepare a mesh, the preferred method is Unstructured Meshing due to its easy "set and go" type of user interface. However, because of the issues seen so far in the numerical solution, it must be quantified against a higher quality method stemming from Structured Meshing in order to understand the significance of compromising the mesh quality for quicker preparation time. Structured Meshing within ICEMCFD utilizes Multi-blocking HEXA Algorithm which results in a uniform mesh filled with quadrilateral and hexahedral elements. The user has complete control of all mesh points throughout the computational domain, thus, in areas of highly complicated flow physics, mesh points can be manipulated however the way the user wants in obtaining the most accurate solution. The process the user takes to 
create a structured mesh is highly complex and requires an extreme amount of manual labor. The result of this labor as can be seen in Figure 3.2 where webs of mesh lines are created all throughout the domain to parameterize mesh points. Although extremely time consuming, the end result is a very high quality mesh necessary to capture all pertinent flow features. For this NRA, there has been 2-dimensional work that has utilized fully structured meshes and can be seen in Lane et al.[40], Golden et al.[2] and Storm et al.[1]. The work from this paper has built and improved upon the methods learned thus far in simulating circulation control flow fields into the 3-D domain. The goal of this thesis is to compare the results of using Unstructured and Structured meshing, and then make a conclusion as to which method should be used going forward with the NRA.

\begin{tabular}{|c|c|c|c|c|c|c|c|c|c|}
\hline$\sqsupset$ & & \multicolumn{8}{|c|}{ 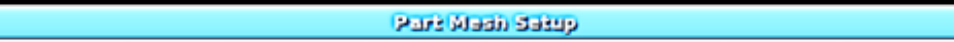 } \\
\hline part & prism & hexa-core & $\max$ size & height & | height ratio | & num layers & | tetra size ratio | & tetra width & min size limit \\
\hline AIR & $\Gamma$ & $\Gamma$ & 0 & & & & & & \\
\hline CURVES & $\Gamma$ & & 0 & 0 & 0 & & & & 0 \\
\hline CUTPLANE & $\Gamma$ & & 0.065 & 0 & 0 & 0 & 0 & 0 & 0.03 \\
\hline DOMAIN/BOTTOM & $\Gamma$ & $\Gamma$ & & & & & & & \\
\hline DOMAIN/CUTPLANE & $\Gamma$ & $\Gamma$ & & & & & & & \\
\hline DOMAINVINLET & $\Gamma$ & $\Gamma$ & & & & & & & \\
\hline DOMAIN/OUTLET & $\Gamma$ & $\Gamma$ & & & & & & & \\
\hline DOMAIN/SIDE & $\Gamma$ & $\Gamma$ & & & & & & & \\
\hline DOMAIN/TOP & $\Gamma$ & $\Gamma$ & & & & & & & \\
\hline ENGINE/CURVES & $\Gamma$ & & 0 & 0 & 0 & & & & 0 \\
\hline ENGINE/FAN/FAN_CONE & $\nabla$ & & 0.0063 & $7.98235 e-06$ & 1.65 & 12 & 1.46 & 0 & 0 \\
\hline ENGINE/FAN/FAN_INLET & $\nabla$ & & 0.0063 & $9.05882 e-06$ & 1.65 & 14 & 1.45 & 0 & 0 \\
\hline ENGINE/FAN/FAN_OUTLET & $\nabla$ & & 0.0063 & $5.88236 \mathrm{e}-06$ & 1.65 & 14 & 1.45 & 0 & 0 \\
\hline ENGINE $\Omega$ IP & $\nabla$ & & 0.0003 & $4.57059 \mathrm{e}-06$ & 1.65 & 9 & 1.4 & 0 & $\mathbf{0}$ \\
\hline ENGINE/NACELLE/NNNER & $\nabla$ & & 0.0075 & $9.05882 e-06$ & 1.65 & 14 & 1.45 & 0 & $\mathbf{0}$ \\
\hline ENGINE/NACELLE/NACELLE & $\nabla$ & & 0.0095 & $1.00412 \mathrm{e}-05$ & 1.7 & 14 & 1.5 & 0 & 0 \\
\hline ENGINE/NACELLE/NACELLE_INLET & $\nabla$ & & 0.0063 & $8.17059 e-06$ & 1.65 & 13 & 1.45 & 0 & $\mathbf{0}$ \\
\hline ENGINE/NACELLE/NACELLE_INNER & $\nabla$ & & 0.0075 & $9.05882 \mathrm{e}-06$ & 1.65 & 14 & 1.45 & 0 & $\mathbf{0}$ \\
\hline ENGINE/NOZZLE/CONE & $\nabla$ & & 0.00254 & $1.29411 e-06$ & 1.8 & 16 & 1.6 & 0 & 0 \\
\hline ENGINE/NOZZLE/NOZZLE_INNER & $\nabla$ & & 0.0034 & $1.264710-06$ & 1.5 & 16 & 0 & 0 & 0 \\
\hline ENGINE/NOZZLE/NOZZLE_OUTER & $\bar{\nabla}$ & & 0.0046 & $5.29412 e-06$ & 1.6 & 14 & 1.4 & 0 & 0 \\
\hline ENGINE/NOZZLE/NOZZLE_OUTLET & $\bar{\nabla}$ & & 0.0034 & $1.294110-06$ & 1.8 & 16 & 1.6 & 0 & 0 \\
\hline FREESTREAM & $\Gamma$ & $\Gamma$ & 0 & & & & & & \\
\hline FUSELAGE/BODY & $\nabla$ & & 0.03 & $1.21823 e-05$ & 1.6 & 17 & 1.4 & 0 & 0 \\
\hline \multicolumn{10}{|l|}{ GEOM } \\
\hline INTERFACE & $\Gamma$ & & 0.065 & 0 & 0 & 0 & 0 & 0 & 0 \\
\hline PLENUMM/BACK/NBOARDINLET & $\nabla$ & & 0.001 & $3.84706 e-06$ & 1.8 & 8 & 0 & 0 & 0.0005 \\
\hline PLENUM/BACKINBOARD/PLENUM & $\nabla$ & & 0.001 & $3.84706 e-06$ & 1.8 & 8 & 0 & 0 & 0.0005 \\
\hline PLENUM/BACKINBOARD/THROAT & $\nabla$ & & 0.0005 & $3.84706 \mathrm{e}-06$ & 1.4 & 6 & 0 & 0 & 0.00025 \\
\hline PLENUM/BACK/OUTBOARD/NLET & $\nabla$ & & 0.001 & $3.84706 \mathrm{e}-06$ & 1.8 & 8 & 0 & 0 & 0.0005 \\
\hline
\end{tabular}

Figure 3.1: ICEM CFD[8] set and go user interface for automated unstructured meshing 


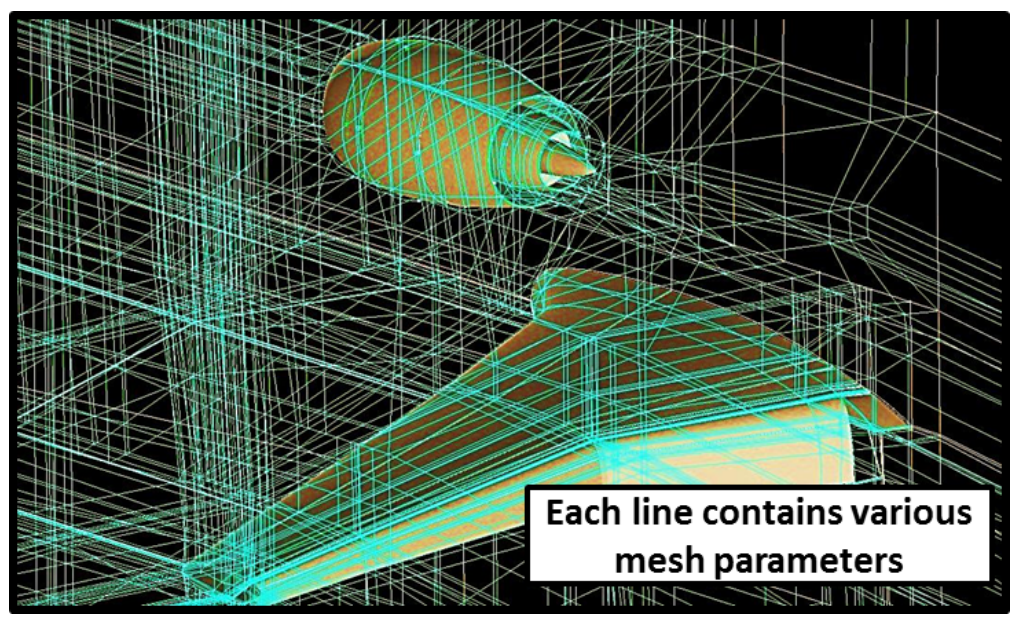

Figure 3.2: Complicated mesh lines are created and mapped to the computational model to parameterize mesh settings at all locations of the computational domain

The following sections will discuss the mesh generation procedure highlighting the four key components mentioned previously (surface, boundary/shear layer, near-body, far-body). Section 3.1 will discuss the four components of Unstructured Meshing, while Section 3.2 will discuss Structured Meshing

\subsection{Unstructured Meshing}

The Unstructured Meshing approach uses the Octree Algorithm within ICEM CFD to generate the surface and near-body volume mesh. This approach begins with a tetrahedron that encloses the entire computational model and is subdivided until all mesh size requirements set on the surface and volume of the model have been met. This top-down approach allow for faster mesh generation because it only refines the mesh where necessary, while maintaining larger elements everywhere else. The Octree method is great for computing a preliminary CFD solution for understanding the general flow features of the computational model. However, when generating validation data for a wind tunnel test, all complex flow features of the model must 
be captured and that's where the Octree method does a poor job. This has been improved upon and will be discussed in a later section of this paper.

\subsubsection{Surface Mesh}

There are various ways to generating a surface mesh. One can use all structured elements, all unstructured elements, or a combination of both. Unstructured surface meshing was chosen as it is the easiest and fastest. There are two methods in ICEMCFD for creating this surface mesh: 1) patch-dependent 2) patch-independent. The patch-dependent method requires a high-quality CAD model and tedious mesh size curve setting in order to generate a proper mesh. With more time, this method would be used because it yields a higher-quality surface mesh and allow the user more control over mesh parameters. The patch-independent method is best for low quality CAD models with poor connectivity. The surface mesh is created using the top-down Octree method which requires minimal input from the user and thus can be created very quickly. To start the Octree method, mesh sizes must be set for each part in the computational model. Parts that do not present severe curvature, such as the fuselage, flat surfaces of the wing and the tail, were set with coarse sizes. Surfaces that do present a lot of curvature, such as the leading edge and trailing edge of lifting surfaces are meshed with finer sizes so that the topology of the geometry can be captured.

The circulation control slots exhibited by the leading and trailing edge of the wing are the most novel features of this model. The air accelerated from these slots produce a strong viscous dominated region downstream. It is essential that these slots are adequately resolved in order to capture a high resolution flow field. Figure 3.3 shows the surface meshes of the forward and aft end of the wing using the Octree 
method.

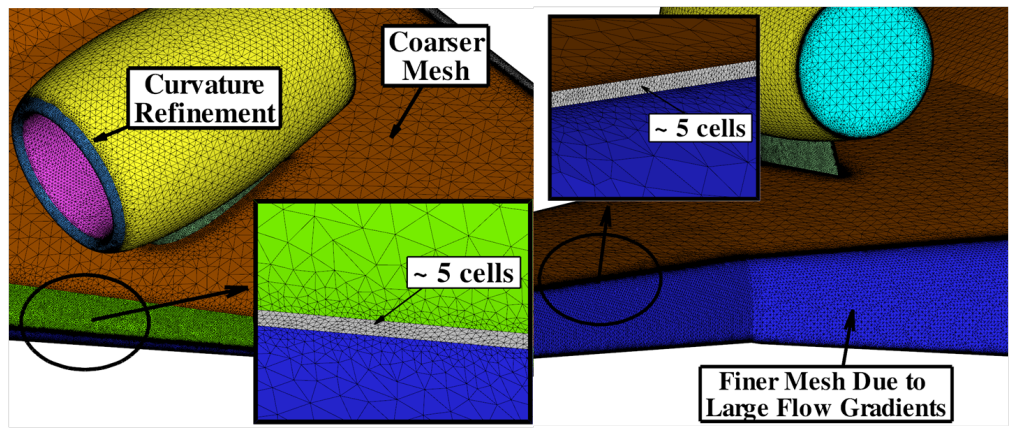

Figure 3.3: Unstructured surface mesh of wing, circulation control slots, \& engine

\subsubsection{Boundary Layer Mesh}

To create the near-wall mesh, prisms are generated off the surface triangles. This layer bridges the surface triangles to volumetric tetrahedrals. Prisms are used instead of tetrahedrals because they can be easily adjusted in accordance with the near-wall turbulence model requirements which will become an important issue in accurately capturing viscous effects. For most applications, it is acceptable to model the boundary to have at least one element within the fully turbulent log-law layer and allow the solver to use wall functions[4] to bridge the gap between the surface of the model and the fully turbulent log-law layer. Wall functions will be discussed further in Section $\mathrm{V}$. This method will be taken in order to obtain solutions more rapidly. As the mesh and solver settings become more evolved, modeling the mesh near the wall will migrate from the wall functions approach to a much more refined mesh near the wall so that the viscous dominated region can be fully resolved.

The high quality mesh that is desired will require careful consideration to cell shape in terms of aspect ratio, skewness, and warp angle. If care is not taken in the mesh setup, prism elements will exhibit very poor quality in these categories. Elements with large aspect ratios should always be avoided in critical regions of the 
flow field. These types of elements can degrade the solution accuracy and may result in instability of the simulation. As for skewed elements, this will be inevitable. It is up to the user to maintain as little as possible the number of elements below a certain skewness quality. For complicated geometries like AMELIA that contain very small features, this has been very difficult. Most mesh-generating packages have built-in smoothing algorithms that can help remedy the complications expected to be seen in building prism elements on the model.

There will be prisms, tetrahedral, and hexahedral elements used to model the volume of the computational domain. To ensure a good mesh, the user needs to consider volume transition ratio. For a good volume transition from the surface triangles to the volume elements, each prism element follows a $40 \%$ volume growth ratio. As for the interface between the prisms and tetrahedrals, the user should aim to have the last prism element be roughly 1:1 in volume ratio to the adjacent tetrahedral element. Figure 3.4 shows an example of how prism elements are to be mapped for each surface of the aircraft model.

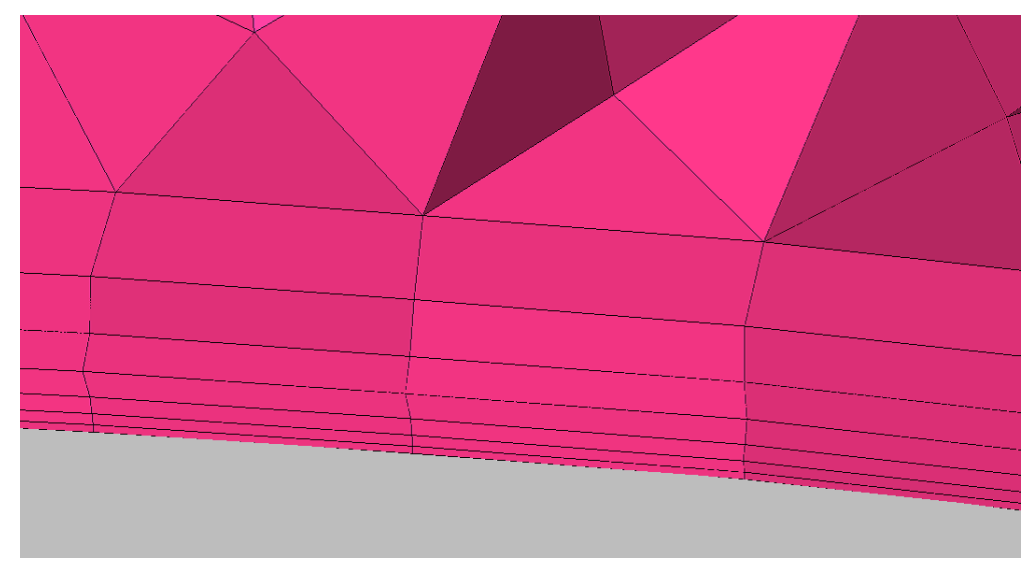

Figure 3.4: Prism boundary layer mesh utilizing $y^{+} \quad 1$ 


\subsubsection{Near-body Volume Mesh}

Constructing a good mesh in the region near the computational model will be important as it presents a lot of the unsteadiness that is expected to occur in the numerical simulation. Thus, the user must be extra careful choosing the proper techniques to model this region. Typically, there are three methods: (1) fully unstructured (2) fully structured (3) hybrid. This section outlines the use of fully unstructured meshing.

Tetrahedral elements are well suited for handling arbitrary shape geometries. This proves to be a major plus as the AMELIA configuration contains complex features. Employing unstructured tetrahedral meshing to the domain will inherently increase the total cell count because it has be to adequately fine enough to resolve the important flow features in that region. As mentioned previously, the near-body volume mesh is created using the top-down Octree Algorithm. Figure 3.5 shows a full mesh slice view of the near-body volume mesh. These elements extend up to 2 chordlengths in all directions away from the nearest point on the computational model to anticipate the highly unsteady flow regime that surrounds the model.

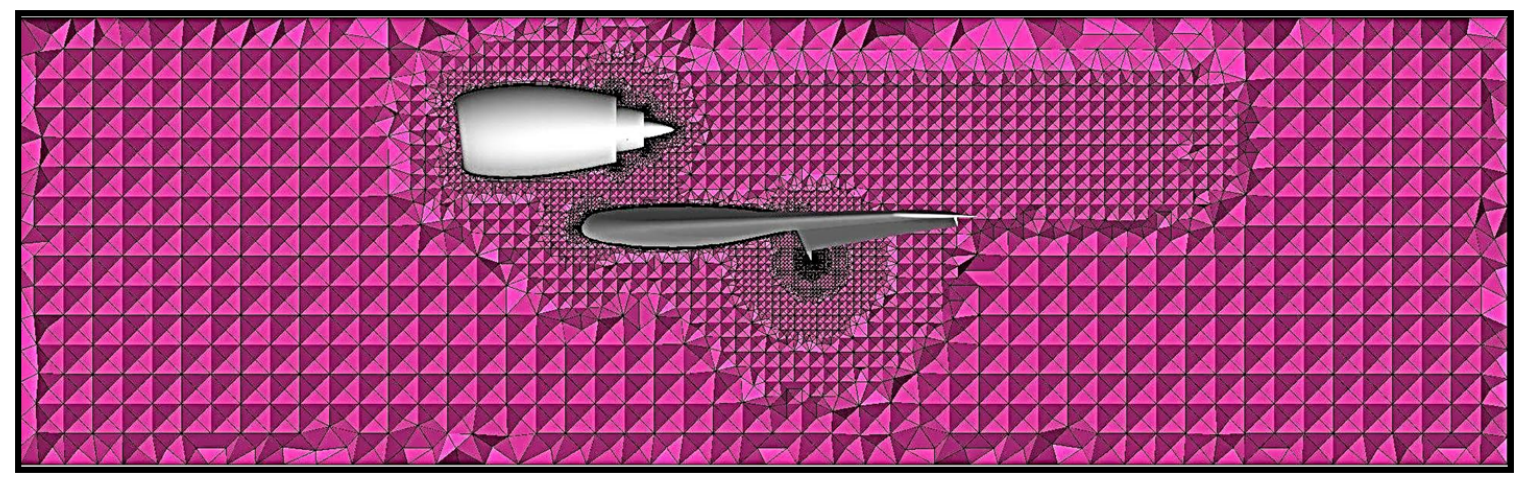

Figure 3.5: Cutplane of near-body unstructured volume mesh 


\subsubsection{Far-body Volume Mesh}

To handle the far-body mesh away from the body, a multi-blocking strategy was utilized to create structured elements to take advantage of the user control in laying out the mesh points in a particular manner. Figure 3.6 shows the blocking strategy. This was considered a trivial task because the multi-blocking did not have to adhere to the complete computational model. The multi-blocking mainly consists of orthogonal lines or blocks to parameterize the far-body mesh domain. Since the near-body mesh consist of unstructured elements (i.e: triangles, pyramids, tetrahedrals), the types of meshes must be merged together at the interface in order for fluid information to successfully pass from one element to the next during simulation. To merge the two mesh types together successfully, careful consideration must be taken when creating the elements at the interface. Ideally, the elements should be adequately large enough to allow the software to optimize the merging process. The edges of Figure 3.5 is the interface location of the unstructured and structured elements.

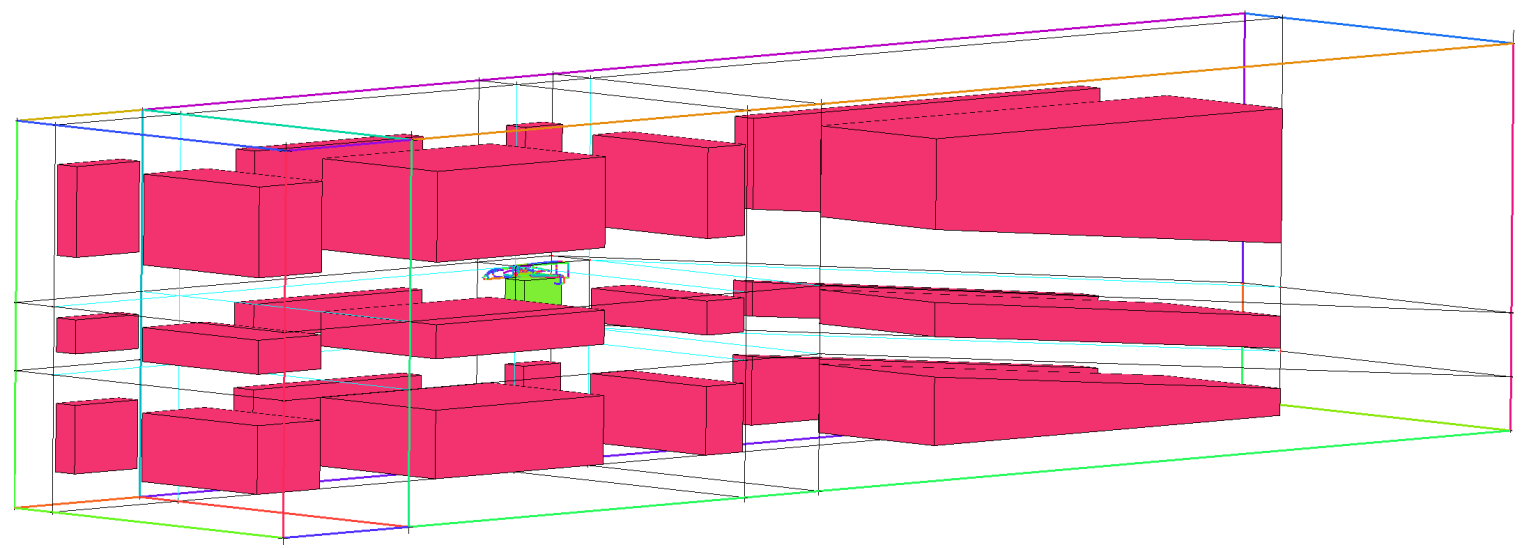

Figure 3.6: Multi-blocking in the far-body 


\subsection{Structured Meshing}

As previously mentioned, the process undertaken with Structured Meshing is creating blocks of mesh lines to parameterize the computational domain everywhere. Examples can be seen in Figures 3.7 and 3.8 highlighting this complex blocking strategy for the engine nacelle and wing. Users can control many things such as quantity, growth rate, cluster algorithm, aspect ratio, etc. However, with maximum control comes with more responsibility in ensuring mesh lines do not intersect one another which is a very difficult task when dealing with numerous small, curved features in the model. But once everything works as planned, the result is more uniform mesh everywhere, ideal for a stable numerical simulation. The following sections will quantitatively and qualitatively compare Unstructured and Structured Meshing of key features on AMELIA.

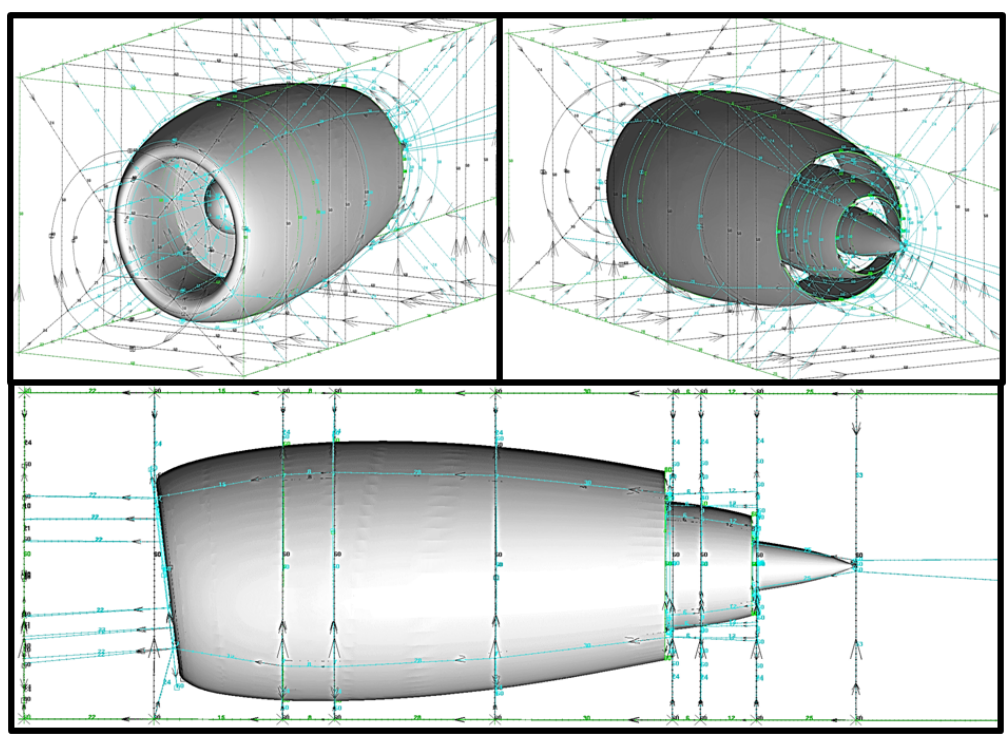

Figure 3.7: Structured blocks created for engine nacelle 


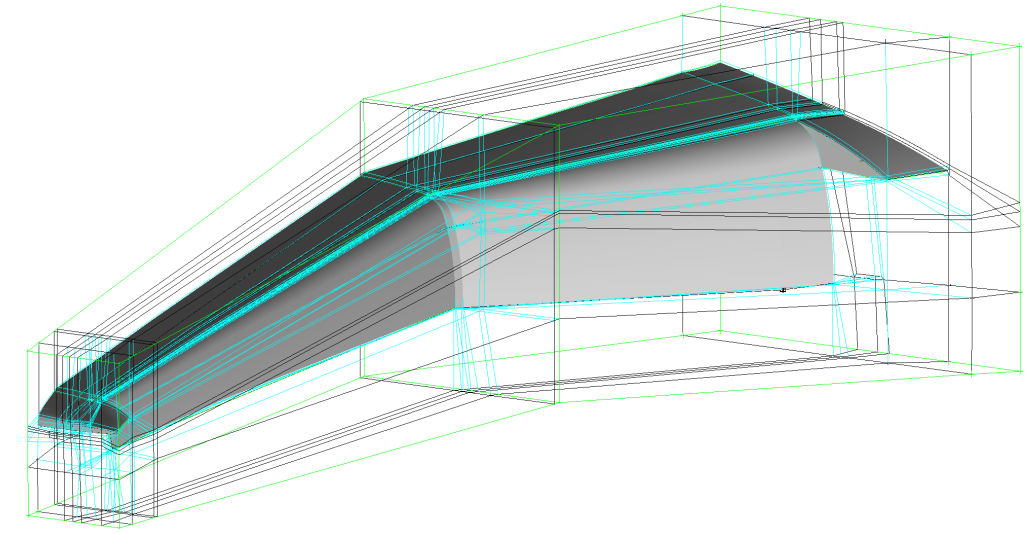

Figure 3.8: Structured blocks created for wing

\subsubsection{Surface Mesh}

Unlike the top-down approach for Unstructured Meshing, Structured Meshing implements bottom-up approach where you build the surface mesh first, then create the volume mesh. Figure 3.9 compares the unstructured and structured surface meshing on two critical AMELIA components; 1) engine nacelle 2) wing flaps. Generally speaking, the simulation software prefers uniform meshes created from the structured approach. With less irregularity in the mesh topology, the simulation minimizes numerical error, thus exhibits a more stable simulation. The biggest difference seen between the two approaches is the numbers cells needed to map the model topology. This is primarily due to the limitations of the tool in not allowing the user more control. Since ICEM CFD builds the mesh automatically, it tends over-refine small features such as those pointed out in Figure 2.5. Figure 3.10 show a closer look at the small features. With Unstructured Meshing, it takes more cells to resolve a finite space when compared to structured meshing. The advantage of using structured meshing is due to the user control of creating larger aspect ratio elements to map the 
same space.

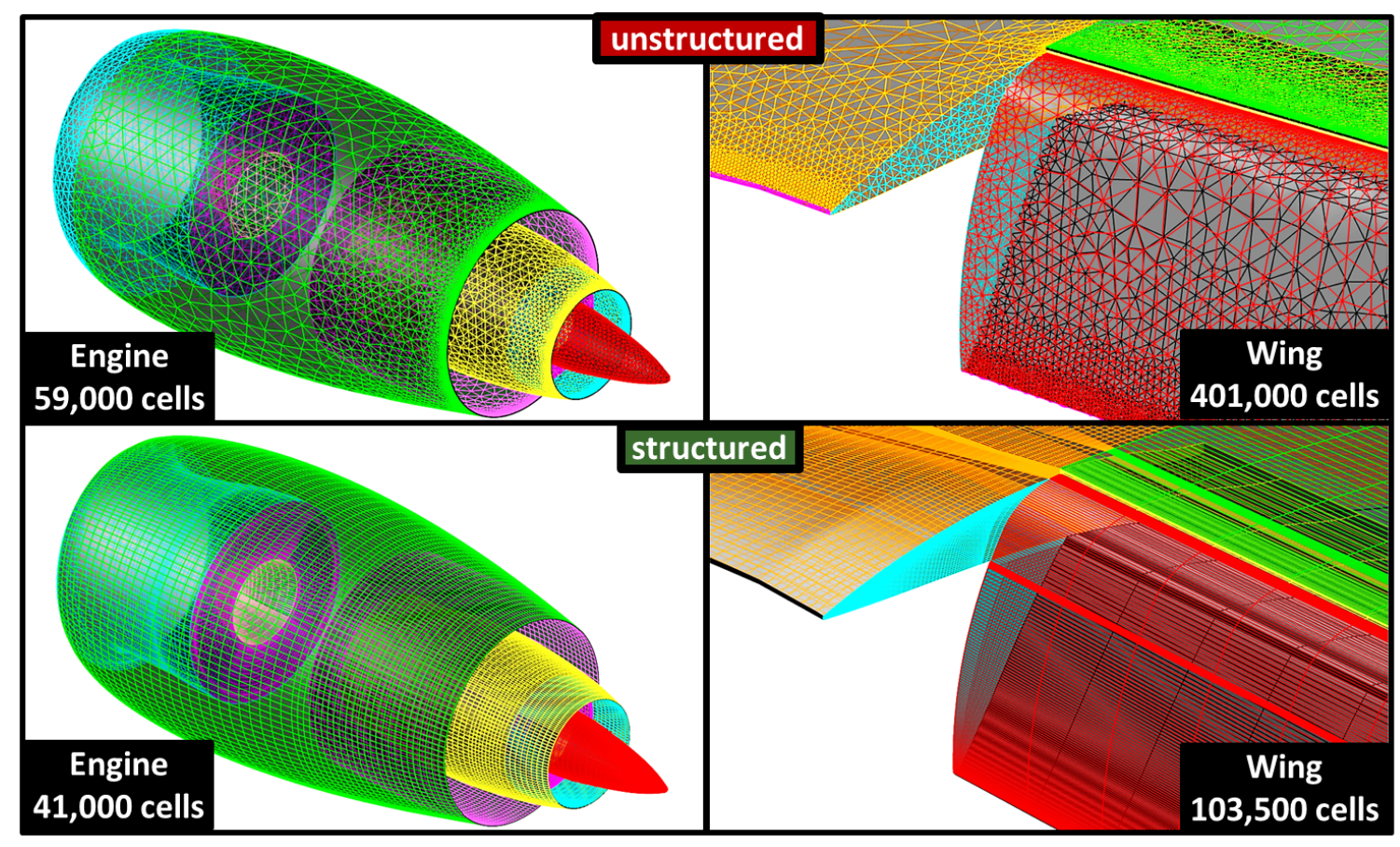

Figure 3.9: Surface mesh comparison of engine nacelle and wing flaps 


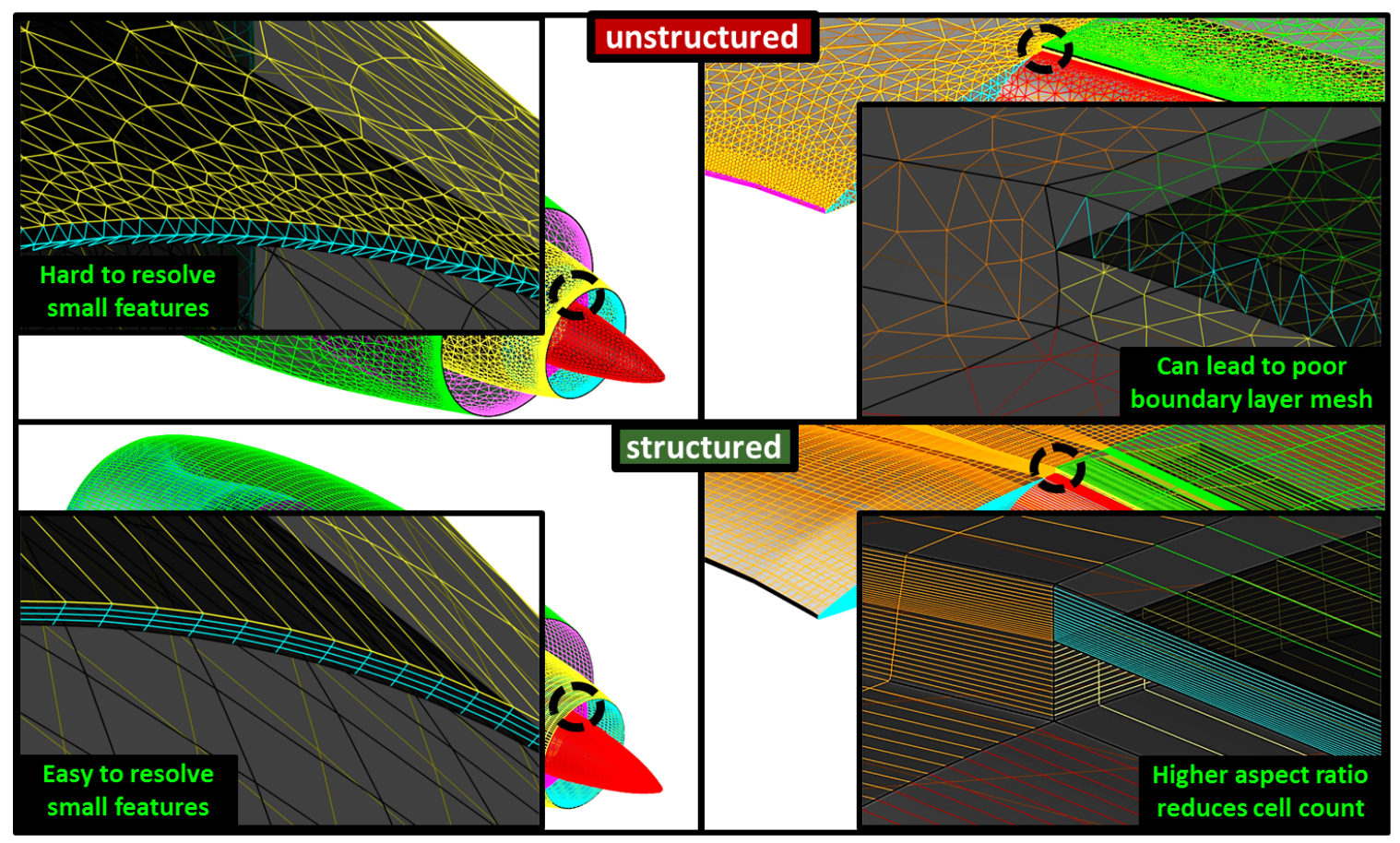

Figure 3.10: Comparison of small features are handled with unstructured and structured meshing

However, this approach is not ideal as aspect ratio of 1 is always preferred. But with limited computational resources, this approach was a compromise to achieve a mesh that fits current constraints. Without knowing ahead of time how using larger aspect ratio cells affect the simulation, this issue needs to re-evaluated when more computer resources are available. To summarize the surface meshing impact, Figure 3.11 shows the savings for critical components on AMELIA. The savings will play a significant role in generating a higher quality volume mesh that will be described later. 


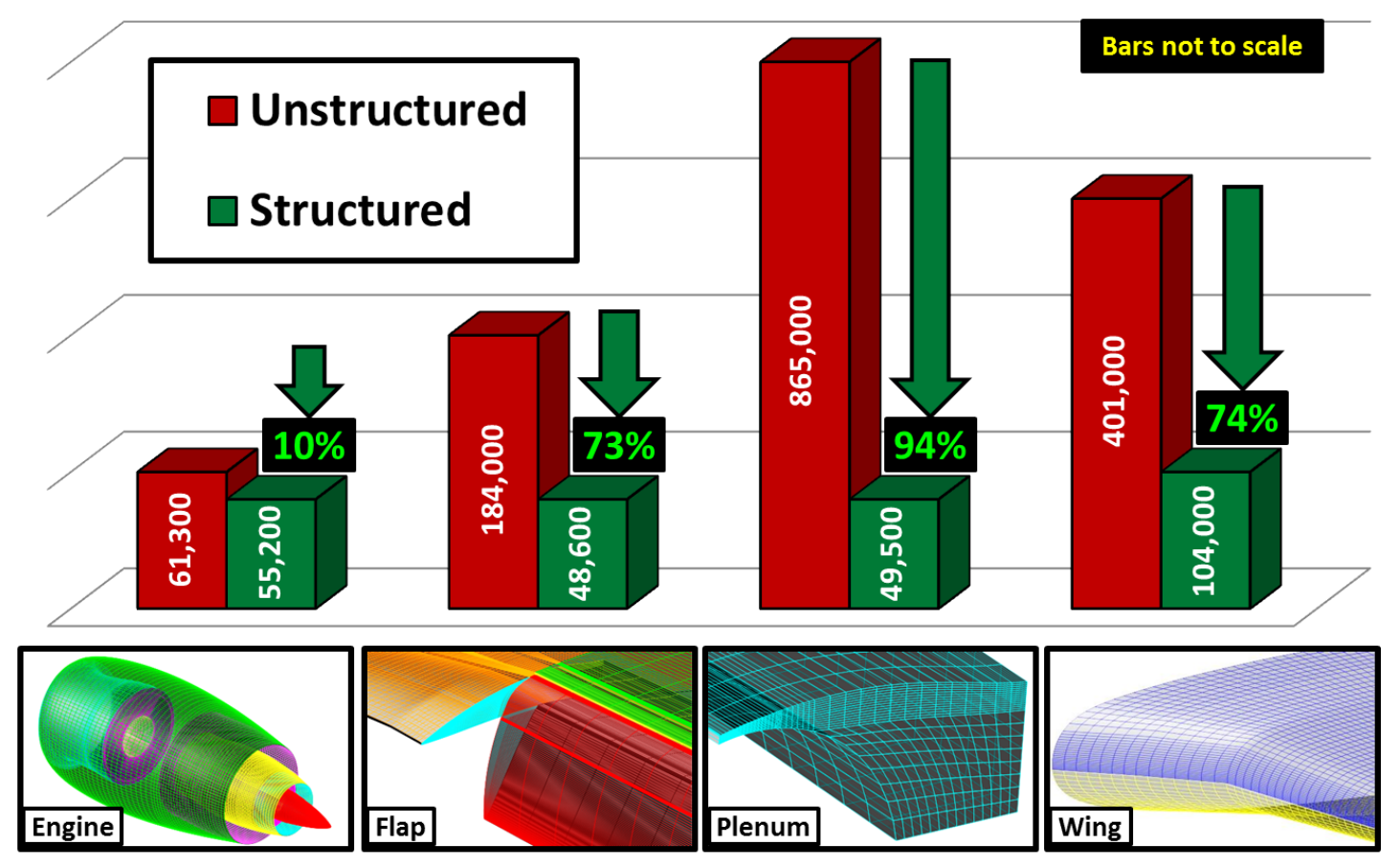

Figure 3.11: Quantitative comparison of unstructured and structured surface meshing

\subsubsection{Boundary Layer and Shear Layer Mesh}

The amount saved on the surface mesh is significant because of computational constraints. What was saved on the surface can be used in the volume to better capture pertinent flow features around critical components of the computational model. Figure 3.12 shows a slice of the mesh at the centerline of the engine nacelle showing the near-body mesh of the nacelle and wing flap. As mentioned previously, ICEM CFD does a very poor job minimizing the total cells near small features. This is evident in the figure by the dark rings in the surrounding areas of the engine trailing edge and CC slot edge. 


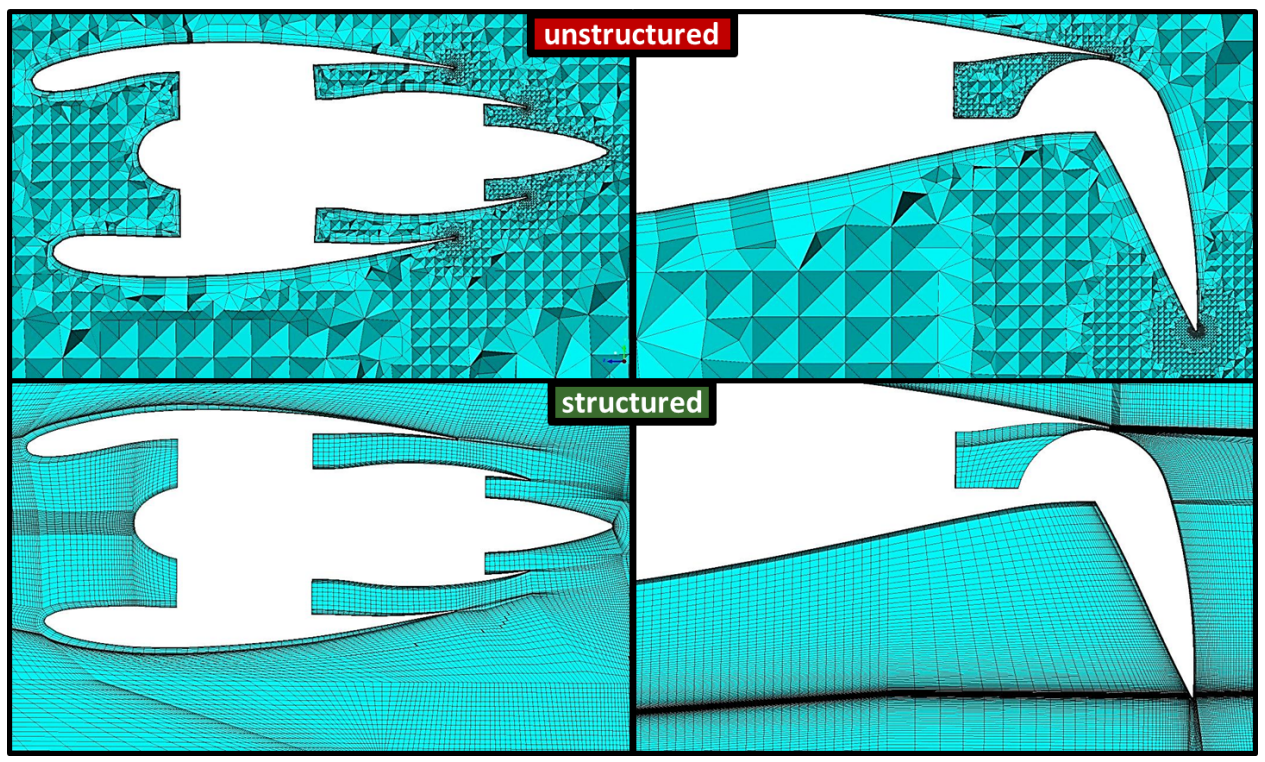

Figure 3.12: Mesh slice through engine centerline

A closer look at the shear layer can be seen in Figure 3.13. The comparison shows unstructured meshing not having nearly enough cells in the desired locations as seen in structured meshing. The shear layer between the low speed freestream flow and high speed jets from the engine and CC slots creates a very strong, directional gradient that requires the right amount of cells in order to capture correctly. Due to limitations of Unstructured Meshing with ICEM CFD is that the user cannot control the mesh points in the shear layer the way structured meshing allows. Even though unstructured meshing produced more cells in these areas, it did it inefficiently such that it did not place the cells in the areas of anticipated large flow gradients. The importance will be evident when evaluating the simulation results. 


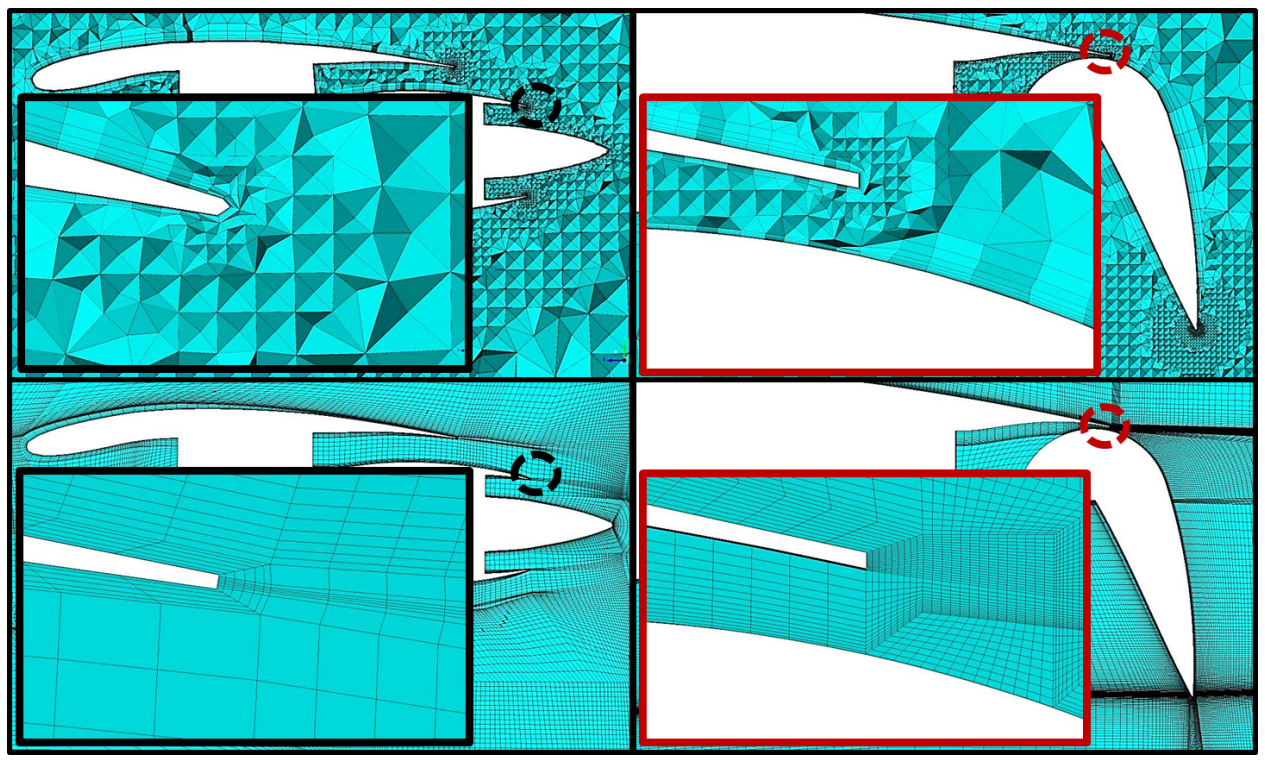

Figure 3.13: Comparison of how well shear layer is captured by unstructured and structured meshing

\subsubsection{Near-body Volume Mesh}

Beyond the boundary and shear layer, flow expands into the near-body region. This area exhibits complicated physics of unsteady flow that is also strongly dependent on the mesh quality. Figure 3.14 shows a slice through the mesh of the engine centerline. At first glance, one would think that the structured mesh most likely has a lot more cells compared to the unstructured mesh, but the total numbers say otherwise. This is attributed to the efficiencies of structured meshing in be able to control the mesh points at all locations of the computational domain. As mentioned in the previous sections, the over-refinement caused by ICEM CFD near thin geometry features propagates into the volume mesh and limits the user from placing cells in necessary regions of the flow field. Another advantage of having complete user control with structured meshing is to be able to manipulate the mesh angles. This is evident in the wake of the engine and wing. This was done in anticipation of the extreme downward momentum exerted by the $\mathrm{CC}$ slots entraining the engine jet exhaust to 
angle downward. Aligning the mesh cells to be as orthogonal as possible to flow will ensure proper resolution.

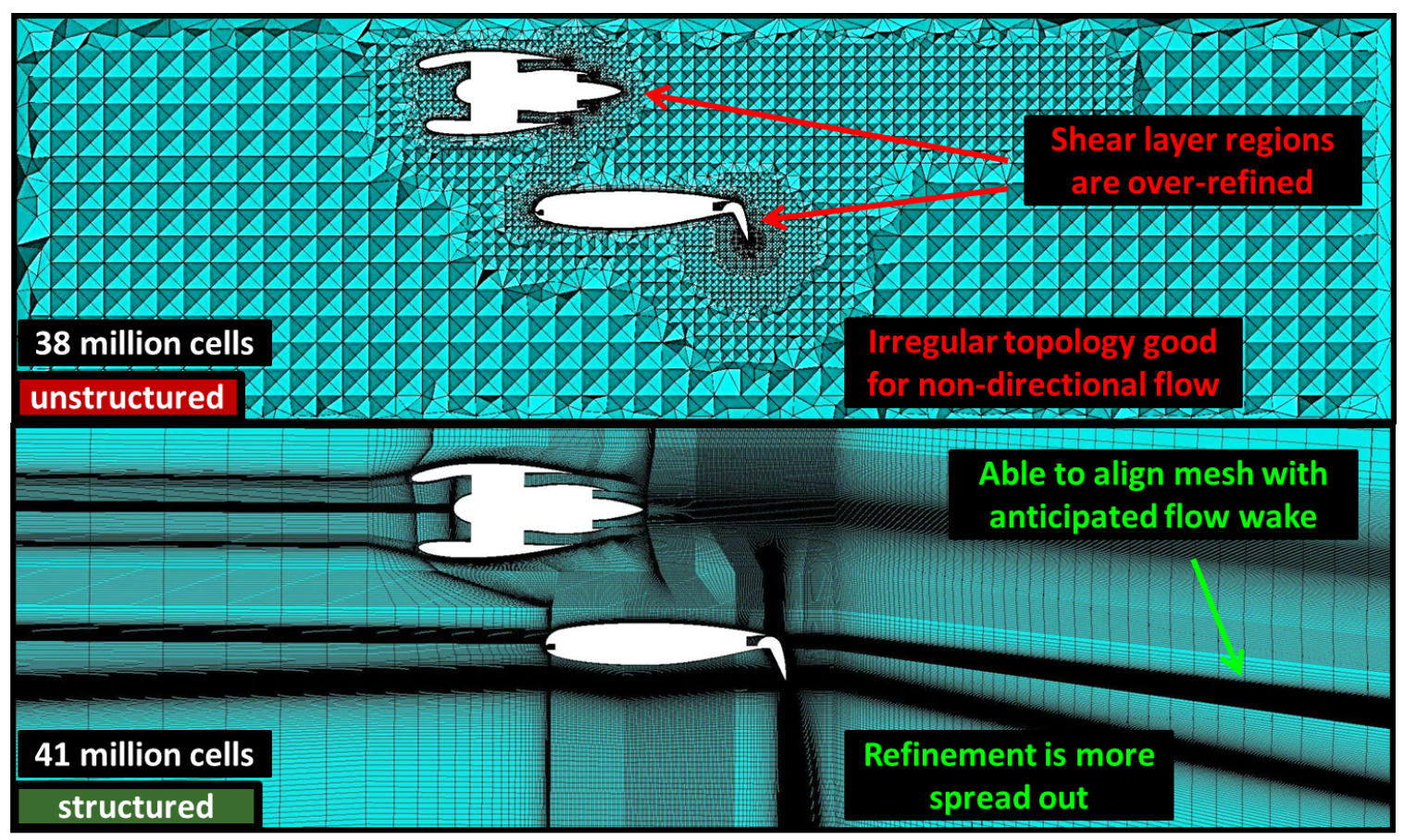

Figure 3.14: Mesh slice through engine centerline comparing how well near-body unsteady flow physics will be captured by the mesh

\subsubsection{Far-body Volume Mesh}

The far-body volume mesh that extends many chords upstream and downstream is created similarly to the mesh created for the unstructured mesh as seen in Figure 3.15. The majority of the computational domain is constrained to resemble the $40 \mathrm{ft}$ x 80ft NASA Ames Wind Tunnel where testing is expected to be conducted. The $1 / 10$ th scale model will be placed in the center of the test section, which is roughly 18 M.A.Cs downstream from a data probe set near the inlet of the tunnel. The ceiling, floor, and side walls are approximately 13 M.A.Cs away from the computational model. The only dimension that is not constrained by the wind tunnel is how far 
downstream to place the computational outlet. Theoretically, it should be placed at the minimum location required to allow all fluid properties near the outlet to return to freestream conditions. This distance varies with every computational model given a set of flow settings, so this distance must be determined methodically. For this thesis, the downstream distance $X$ was set equal to 4 times the distance of $L$. Through preliminary simulations, this distance showed to be adequate for dissipating dominant flow structures in addition to not adding more strain to the limited computational resources. However, a more in-depth investigation should be conducted for future studies in order to fully optimize the computational mesh.

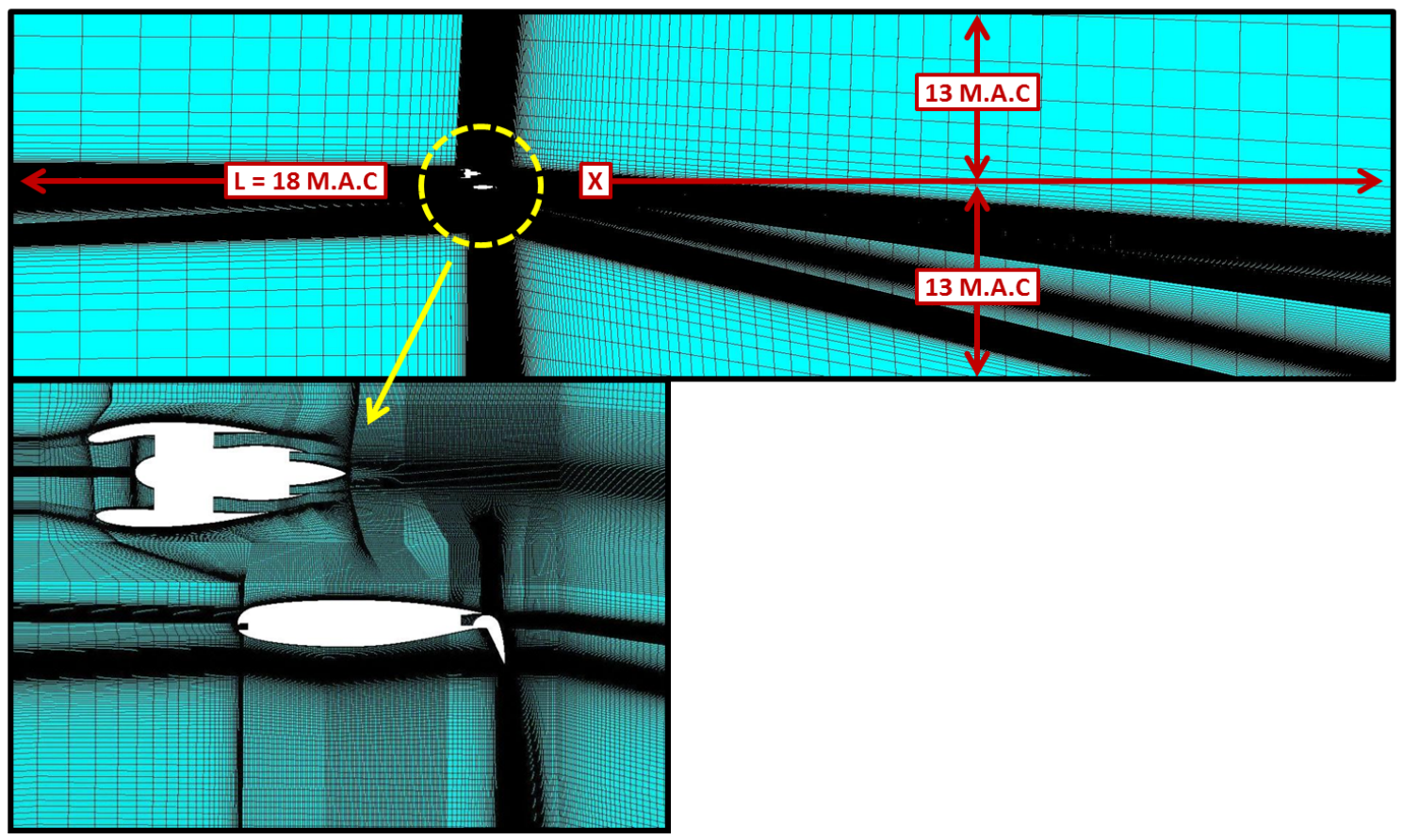

Figure 3.15: Far-body mesh extending many chords upstream, downstream, and side 


\section{Chapter 4}

\section{Simulation Setup}

\subsection{Solver Settings}

The numerical solver chosen for this thesis is FLUENT[5]. The numerical scheme chosen for the 3-D cases is an implicit compressible solver that couples and solves the governing equations of continuity, momentum, and energy simultaneously. The coupled solver is generally used for compressible flows. Although the majority of the flow field is low speed, incompressible flow, the CC slots will be exerting high speed, compressible flow. Thus, the compressible solver was chosen in hopes of achieving higher accuracy. Table 4.1 summarizes the solver settings used for the model.

Table 4.1: General FLUENT solver settings

\begin{tabular}{|l|l|}
\hline Solver & Density-Based \\
\hline Numerical Scheme & 2nd Order \\
\hline Wall Treatment & $\mathrm{y}+1$ \\
\hline Turbulence Model & $\kappa \epsilon$-Realizable \\
\hline Density calculator & Ideal Gas Law \\
\hline Viscosity calculator & Sutherland's Law \\
\hline
\end{tabular}




\subsubsection{Computational Resources}

As noted previously one of the more challenging parts to this work was the computational resources limiting the size and number of the solutions produced. The solutions were solved on a 92 core cluster with 184 gigabytes of RAM. The RAM limited the cluster to solving a maximum of approximately 40 million cell meshes. The meshes for this work were solved on this cluster in approximately 7-10 days. For pre- and post- processing an 8 core 64 gigabyte RAM desktop machine was used.

\subsection{Flow Conditions}

For the planned wind tunnel tests, there will be a test matrix varying different critical variables with AMELIA. To simplify this thesis, most of these variables were kept constant and was not of focus. However, the conditions chosen are expected to generate the worst case scenario test. Table 4.2 list the model conditions set prior to simulation.

Table 4.2: Model Conditions

\begin{tabular}{|l|l|}
\hline Freestream Reynolds Number & $8.85 \times 10^{5}$ \\
\hline Freestream Mach Number & 0.075 \\
\hline Freestream Velocity & $50 \mathrm{kts}$ \\
\hline Freestream Pressure & $14.7 \mathrm{psi}$ \\
\hline Freestream Temperature & $518.67 \mathrm{R}$ \\
\hline Freestream Density & $0.00238 \mathrm{slug} / \mathrm{ft}^{3}$ \\
\hline Freestream Angle of Attack & $0 \mathrm{deg}$. \\
\hline Flap Deflection Angle & $60 \mathrm{deg}$. \\
\hline Engine Location & Geometry $5[11]$ \\
\hline Reference Length & $4.3 \mathrm{ft}$. \\
\hline Reference Area & $5.8 \mathrm{ft} .{ }^{2}$ \\
\hline
\end{tabular}




\subsubsection{Boundary Conditions}

The boundary conditions employed on the model also have serious implications on the computational solution and are very difficult to define the correct boundary conditions to mimic the real physical representation of the flow field. Initial and boundary conditions are essential to solving the governing equations, thus, meaningful numerical solutions are highly dependent on the types of boundary conditions implemented and the values that initialize that boundary. For CCW simulations, jet slot boundary conditions must be specified to simulate the jet flow effects. Generally, the driving parameter for $\mathrm{CCW}$ simulations is the momentum coefficient, $\mathrm{C} \mu$, defined as the following,

$$
C_{\mu}=\frac{\dot{m} U_{j e t}}{\frac{1}{2} \rho_{\infty} U_{\infty}^{2} S_{r e f}}
$$

Or alternatively as the following,

$$
C_{\mu}=\frac{\rho_{j e t} U_{j e t}^{2} A_{j e t}}{\frac{1}{2} \rho_{\infty} U_{\infty}^{2} S_{r e f}}
$$

In part with this NRA project, Georgia Tech Research Institute (GTRI) conducted studies of a CCW wing and concluded that a $\mathrm{C} \mu$ between $0.4-0.6$ is most optimal. The results of this study is documented in Marshall[13]. However, there is no boundary condition in FLUENT that allows for the specification of $\mathrm{C} \mu$. The best available option is to specify the slots as a Pressure-Inlet boundary condition, where FLUENT requires the total pressure and temperature at the slot. The total temperature is assumed to be approximately equal to the total temperature of freestream. Obtaining the total pressure at the slot requires a few calculations. The slot faces are assumed to be the throat of the nozzle, which implies the local Mach number at the jet should 
be unity. The static temperature of the slot can be computed using the following equation.

$$
\frac{t_{0, j e t}}{t_{j e t}}=1+\frac{\gamma-1}{2} M_{j e t}^{2}
$$

Equation (4.3) can also be re-written to be the following,

$$
U_{j e t}^{2}=\frac{2 \gamma R}{\gamma-1}\left(t_{0, j e t}-t_{j e t}\right)
$$

From Ideal Gas Law, the following relation can be obtained,

$$
\rho_{\text {jet }}=\frac{p_{\text {jet }}}{R t_{j e t}}
$$

Substituting Eqns. (4.4) and (4.5) into Eq. (4.2), we get the following equation where the jet static pressure can be computed using a desired $\mathrm{C} \mu$ of 0.4 ,

$$
C_{\mu}=\frac{2 \gamma}{\gamma-1} \frac{A_{j e t}}{q_{\infty} S_{r e f}} \frac{p_{j e t}\left(t_{0, j e t}-t_{j e t}\right)}{t_{j e t}}
$$

With static pressure known, the following relation can be used to compute the total pressure at the slot.

$$
\frac{p_{j e t}}{p_{0, j e t}}=\left(1+\frac{\gamma-1}{2} M_{j e t}^{2}\right)^{-\frac{\gamma}{\gamma-1}}
$$

Table 4.3 shows boundary conditions used for the engine and slots along with the values used at that boundary. The engine boundary conditions come from Blessing[7]. From a simple 2-D study of a $\mathrm{CC}$ airfoil, the values computed from the solution compares very well with the values predicted using 1-D isentropic relations. Figure 4.1 illustrates the desired boundary conditions for the engine and circulation control 
slots.
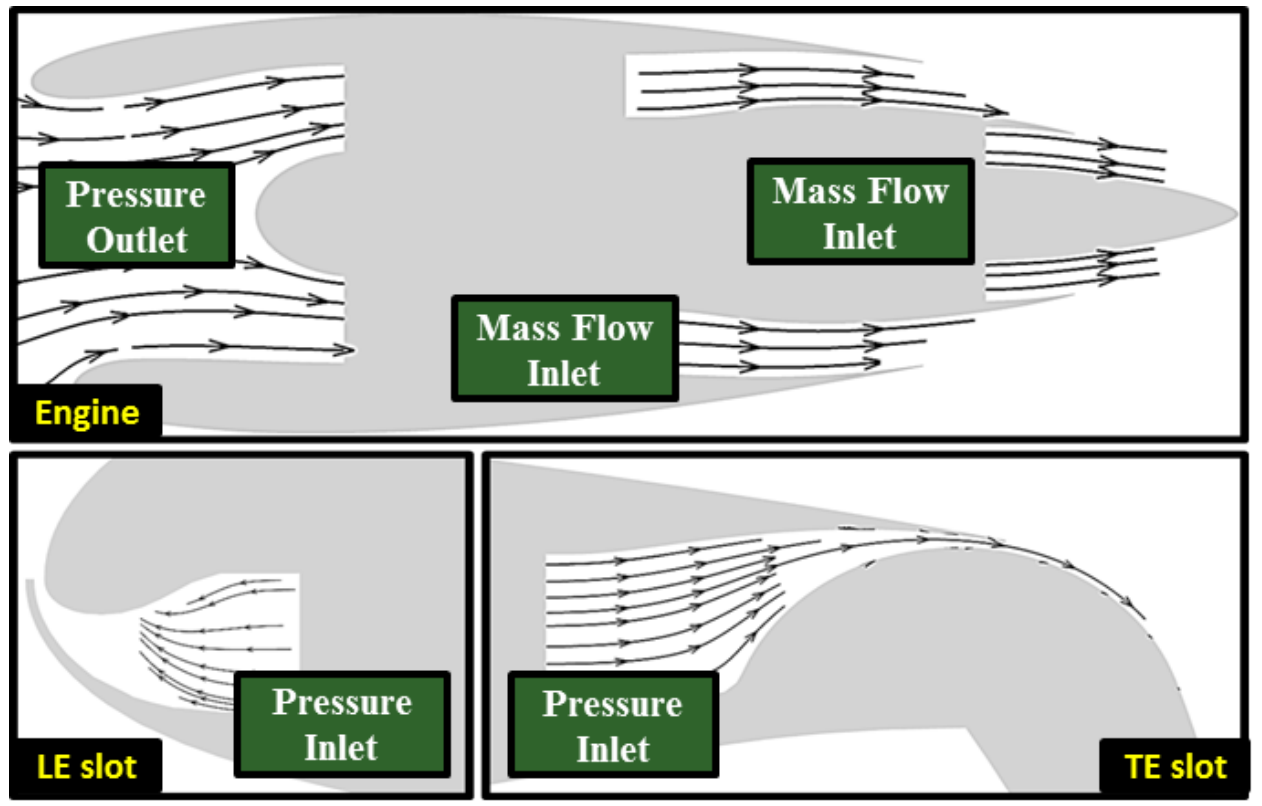

Figure 4.1: FLUENT Boundary conditions set for engine and circulation control slots 
Table 4.3: Quantities set for boundary conditions

\begin{tabular}{|l|l|}
\hline Freestream Conditions \\
\hline Boundary condition & Pressure-Far-Field \\
Pressure & $14.7 \mathrm{psi}$ \\
Density & $0.0765 \mathrm{lbm} / \mathrm{ft}^{3}$ \\
Mach Number & 0.07 \\
\hline (1) Engine Inlet \\
\hline Boundary condition & Pressure-Outlet \\
Static pressure & $11.5 \mathrm{psi}$ \\
Total temperature & $520.7 \mathrm{R}$ \\
\hline (2) Engine Fan Outlet \\
\hline Boundary condition & Mass-Flow-Inlet \\
Mass flow rate & $4.03 \mathrm{lbm} / \mathrm{s}$ \\
Total temperature & $421.92 \mathrm{R}$ \\
\hline (3) Engine Nozzle Outlet \\
\hline Boundary condition & Mass-Flow-Inlet \\
Mass flow rate & $1.32 \mathrm{lbm} / \mathrm{s}$ \\
Total temperature & $579.33 \mathrm{R}$ \\
\hline (4) Circulation Control Slots \\
\hline Boundary condition & Pressure-Inlet \\
Total pressure & $25.2 \mathrm{psi}$ \\
Total temperature & $519.7 \mathrm{R}$ \\
\hline
\end{tabular}

\subsection{Modeling Turbulence}

\subsubsection{Near Wall Treatment}

Since most flows in aerospace applications are turbulent in nature, the classical two-equation modeling approach of handling turbulence was employed for all numerical simulations. Turbulence models[6] are supposed to close the system of discretized governing equations. Nowadays, the two-equation modeling approach has formed the basis of turbulence calculations in numerous commercial and in-house CFD codes[41]. Turbulent flows are significantly affected by the presence of walls. Very close to the 
wall, viscous damping reduces the normal fluctuations. Toward the out part of the near-wall region, however, turbulence is rapidly growing because of the production of turbulence kinetic energy due to large gradients in mean vorticity. The near wall modeling significantly impacts the fidelity of the numerical solution. With hot air accelerated over the trailing edge flaps of the wing, it has been observed through CFD results that this region is highly viscous. Accurate representation of the flow in the near wall region is essential to successful predictions of wall bounded turbulent flows. Modeling the near wall region is generally associated with the velocity profile for turbulent flows. Through their studies of turbulent flows, Prandtl and Theodore von Karman concluded that the velocity profile consists of an inner layer, outer layer, and an intermediate overlap between the two[4]. The inner layer is dominated by viscous shear and is a function of the wall shear stress, fluid properties, and the distance, $y$, from the wall but not upon freestream parameters. The outer layer is dominated by turbulent shear and is a function of wall shear stress, layer thickness, and freestream pressure gradient, but not on viscosity. Meanwhile, the intermediate layer experiences both types of shear.

Confirmed through numerous experiments, the near wall region is subdivided into three layers and can be seen in Fig. 4.2. The inner layer, where turbulence is damped out and the boundary layer is dominated by viscous shear is also called the viscous sublayer. It is generally characterized as having a $\mathrm{y}^{+}<5$. The intermediate layer, sometimes called the buffer layer is characterized as $5<\mathrm{y}^{+}<30$. Anything between $30<\mathrm{y}^{+}<300$ is considered the outer layer or the log-law region of the velocity profile. The general consensus of the CFD community is to never model any cells within the buffer layer because it is neither linear nor logarithmic. If the first viscous mesh layer has a $\mathrm{y}^{+}$within either the viscous sublayer or the fully turbulent log-law 
region, then the boundary layer is considered sufficiently modeled. FLUENT has two techniques of modeling the boundary layer: 1). Wall Functions and 2). Near-Wall Treatment. This can be seen in Fig. 4.3.

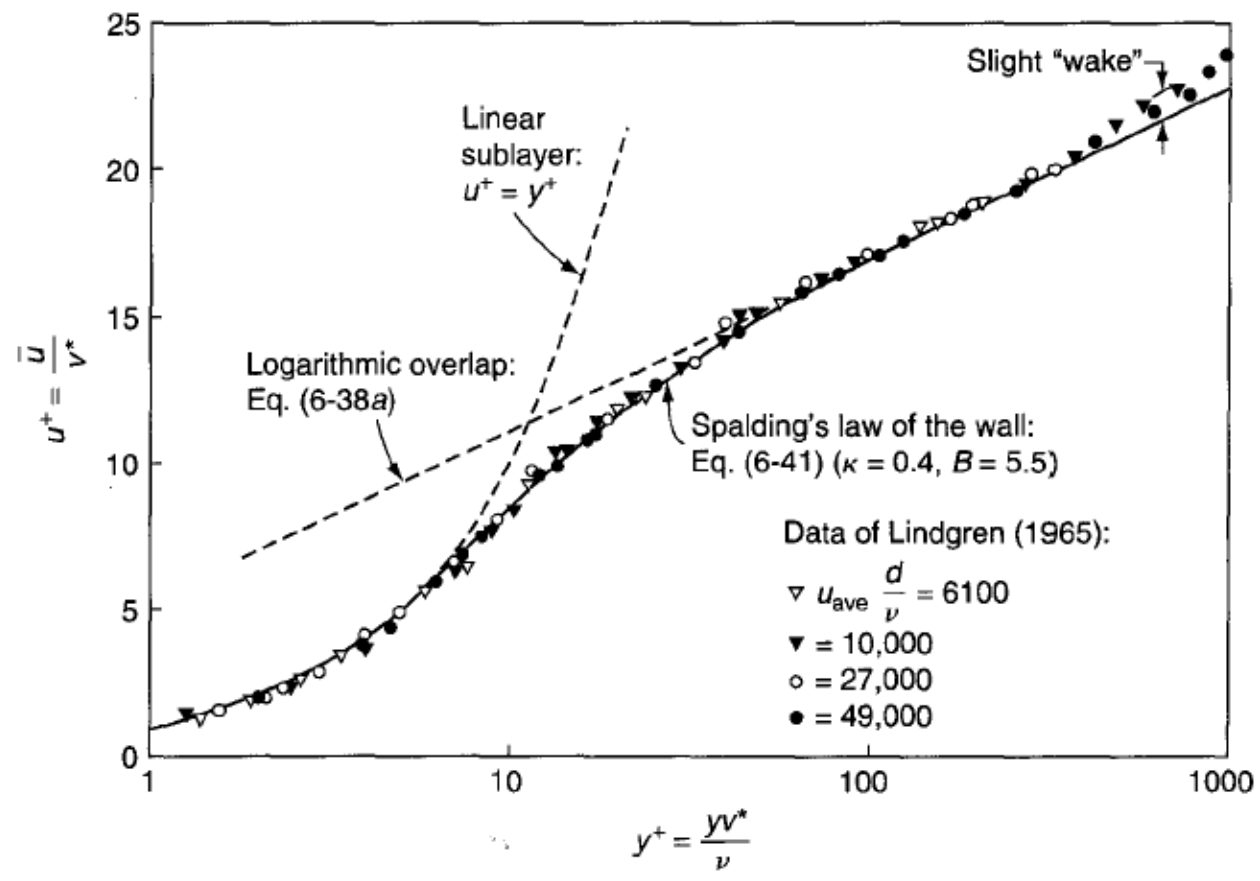

Figure 4.2: Velocity profile for turbulent flow

The first approach does not resolve the viscous dominated inner region, but instead uses semi-empirical formulas called "wall functions" to approximate and bridge the viscous sublayer and the fully turbulent log-law layer. For highly viscous dominated flow fields, this approach can cause inaccuracies in the solution. For most high Reynolds number flows, this approach experiences a much faster solution convergence because the viscous sublayer is not resolved. Using the wall function approach, all boundary layer cells must fall within the fully turbulent log-law region. The second approach requires a highly refined mesh near the wall in order to capture the viscous dominated region. The use of the Near-Wall Model requires a much more refined mesh near the wall which can easily spike the total cell count of the model. With a 
larger cell count, solution convergence will be much slower. However, with the highly viscous region behind the LE and TE slots, it is necessary to take this approach in order to obtain representable solutions.

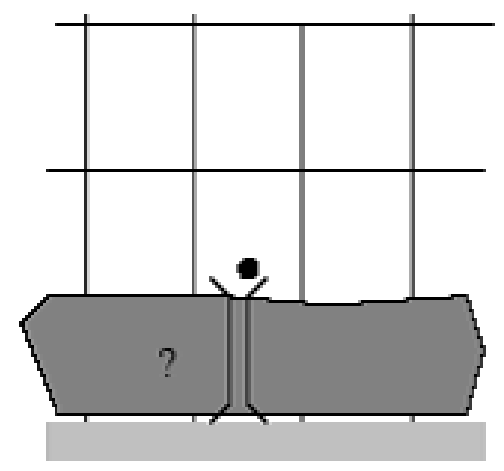

Wall Function Approach

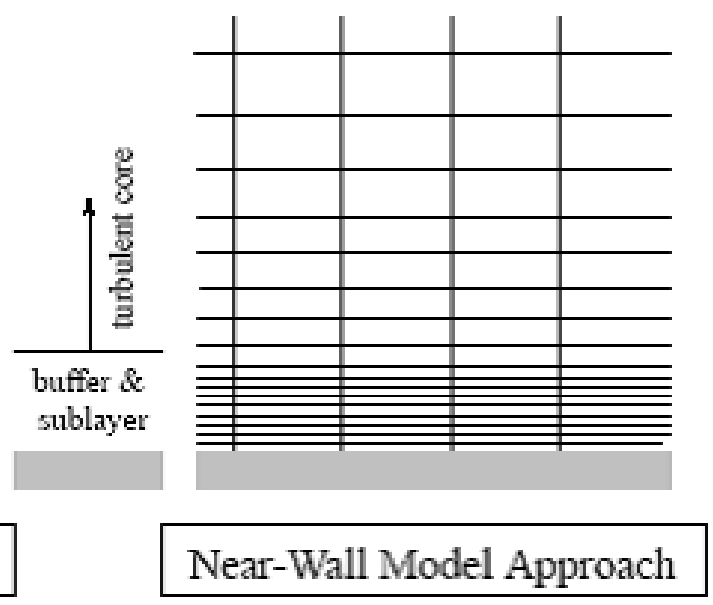

Near-Wall Model Approach

Figure 4.3: FLUENT boundary layer treatment methods

\subsubsection{Turbulence Model Selection}

At hand are several turbulence models that can be used to model turbulence in the problem. It is up to the user to carefully understand the flow characteristics expected in the flow field and to apply the appropriate turbulence model to capture those characteristics. The pressing choice of selecting a suitable turbulence model can be of great difficulty. FLUENT has several turbulence models available to the user. However, for this project, three turbulence models were chosen to be of primary focus in choosing the best turbulence model: a one equation model called Spalart-Allmaras[4], and two, two-equation models, $\mathrm{k}-\epsilon[6]$ and $\mathrm{k}-\omega[6]$. The $\mathrm{k}-\epsilon$ model is primarily valid for turbulent core flows which are found in the regions somewhat far from walls. The Spalart-Allmaras and k- $\omega$ models were designed to be applied throughout the boundary layer, provided that the near wall mesh resolution is sufficient. 
Performing 3-D analysis for various configurations for all three turbulence models would be too time consuming. The best approach was to conduct a 2-D case study. The study was conducted by Storm[1] and it involved simulating the GACC airfoil which is a widely used CC airfoil in the literature. All three turbulence models were used to show which would be the best to continue forward with for 3-D simulation and analysis. This 2-D case study is elaborated further in Section 5.1. In addition, the same turbulence models were evaluated in a later study conducted by Marcos[38] for a 3-D CC Wing with an over-the-wing engine configuration. This work was part of a collaborative effort with GTRI in hopes of improving computational methods for analyzing circulation control applications. This study is further elaborated in Section 5.1. Both studies concluded that the turbulence models evaluated do a very poor job of capturing circulation control physics. The trends seen in both studies was over-prediction of lift coefficient compared to experimental data. As part of the NRA, Storm[1] worked on developing a variation of the $v^{2}-f$ model that was not complete in time for use in this thesis. Moving forward, the k- $\omega$ SST model was used for all simulations because of its ability to better predict flow with high adverse pressure regions and wall bounded flows. The circulation control jets were of particular importance and k- $\omega$ is known to perform better with planer jets. 


\section{Chapter 5}

\section{Results}

\subsection{2-D GACC Airfoil Validation}

Storm utilized some experimental data on a General Aviation Circulation Control (GACC) airfoil to compare his CFD. The airfoil can be seen in Figure 5.1. The airfoil geometry has a slot over the upper flap surface. The geometry departs from a traditional rounded trailing edge and incorporates a dual radius flap similar to the geometry in this paper. The experimental work was performed by Lee-Rausch et al and Jones et al $[3,9]$

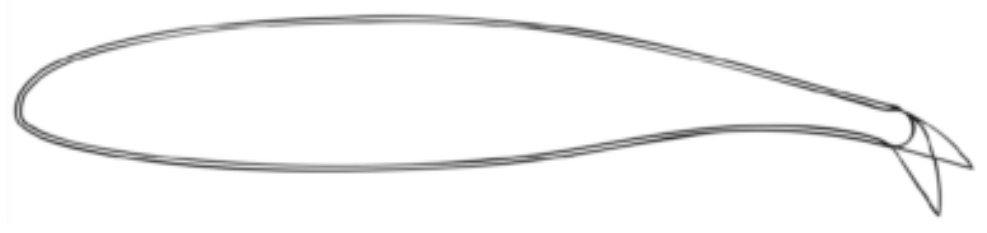

Figure 5.1: GACC validation airfoil

Comparison cases were run over a range of blowing coefficients, $\mathrm{C} \mu$, to compare against the experimental data. The original CFD data from Storm included the one equation Spalart-Allmaras data but it was removed because it performed poorly and 
was never discussed as a possible turbulence model for this work. Results shown in Figure 5.2 are all on structure meshes with $\mathrm{y}+$ of less than 1 . Lift coefficient was monitored to determine convergence.

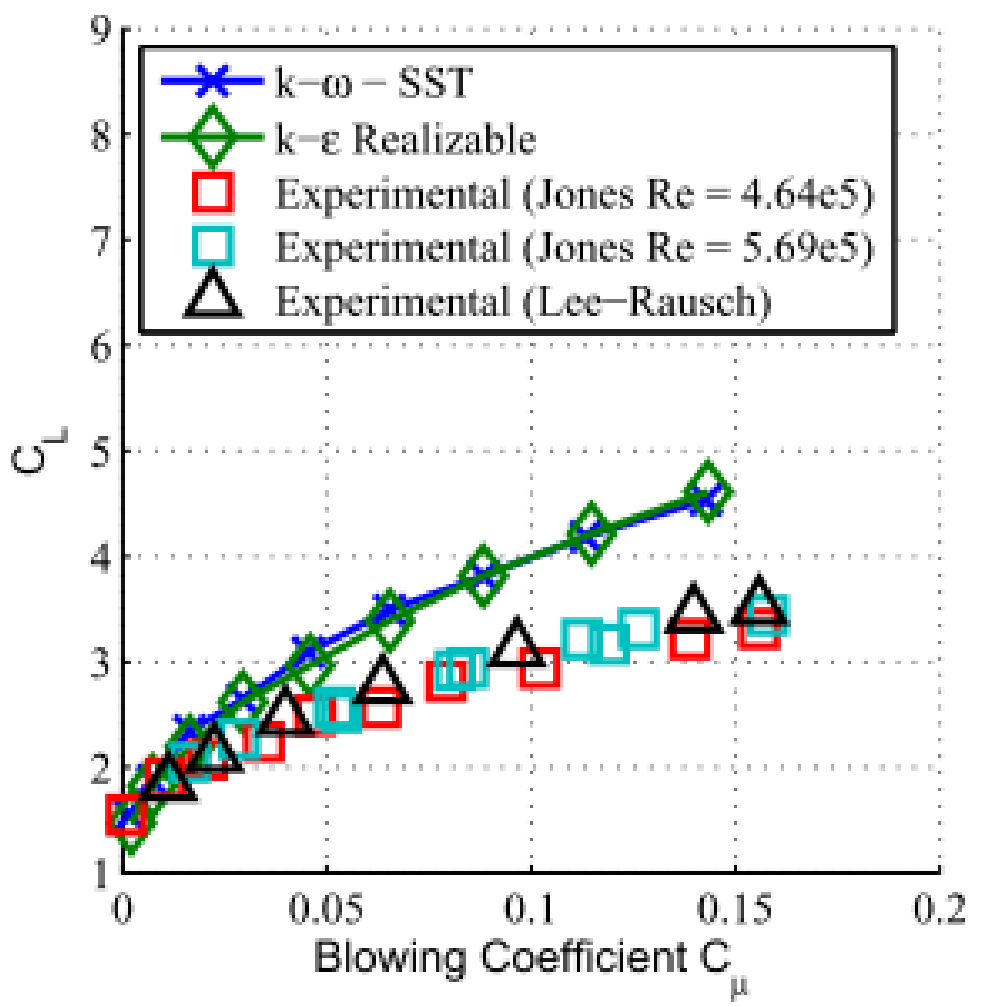

Figure 5.2: Blowing coefficient versus lift coefficient of a circulation control airfoil from Storm $[1,9]$

It is worth noting that the momentum coefficient shown in this study are much lower than the coefficients studied on the geometry for this paper. Even though the $\kappa-\omega$ and the $\kappa-\epsilon$ turbulence models showed very similar results in the validation shown above the $\kappa-\omega$ model was selected because it is generally considered more accurate. This model is particularly attractive because of its performance in high adverse pressure regions. It is also very good with planer jets. All CFD work observed shows clear over-prediction of lift forces and as the momentum coefficient increases as does over-prediction. The above work clearly shows that in order to predict actual $\mathrm{C}_{L}$ 
values (not just trends) a new turbulence model will be required. For the purposes of this work trends are considered accurate enough that a new solving technique is not required.

\subsection{3-D CCW and Engine Simulator Validation for GTRI}

To ensure that this 2D data translates to a full 3D model another validation effort was made into a wind tunnel experiment by Georgia Tech Research Institute(GTRI) [42]. This will serve as a closer resemblance of the $2 \mathrm{D}$ study because the meshing and solving practices will be the same as those for the geometry for this paper. The validation work was performed by Marcos and multiple cases were run by this author

to confirm select points to ensure quality and consistency between the work. Since all the test points were confirmed between the two authors the full work by Marcos will be presented here[38].

The GTRI geometry consists of a circulation control wing with a trailing edge slot over a dual radius flap geometry. There is an engine simulator mounted over the wing. The geometry is shown in Figure 5.3. The mesh for this geometry was 8 million cells and meshed in the same hybrid manner as previously discussed with a unstructured mesh close to the geometry with structured hexahedrals in the farfield domain. The $\mathrm{y}^{+}$was targeted to be one and $95 \%$ of the cells being below two. 


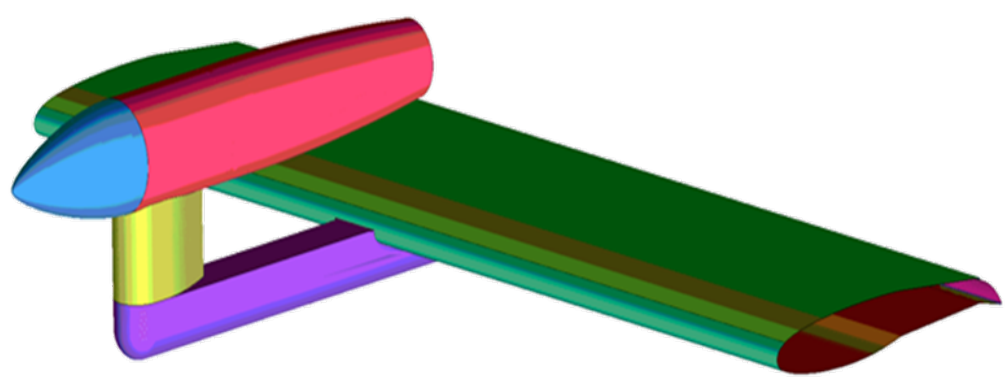

Figure 5.3: GTRI wind tunnel geometry for validation cases[10]

The GTRI model was run at a wide range of thrust and moment coefficients. Some of the results from Marcos and Englar are shown in Figure 5.4[10, 42]. As can be seen above both turbulence models consistently over predict lift. As was the case with the 2D GACC airfoil the higher the momentum coefficient the more the model over predicts. Considering that both the turbulence models are very closely aligned with each other for both studies it was necessary to make a decision based on knowledge of the inner workings of turbulence models. $\kappa-\omega$ SST was selected because of its ability to better predict flow with high adverse pressure regions and wall bounded flows. The circulation control jets were of particular importance and $\kappa-\omega$ is known to perform better with planer jets. 


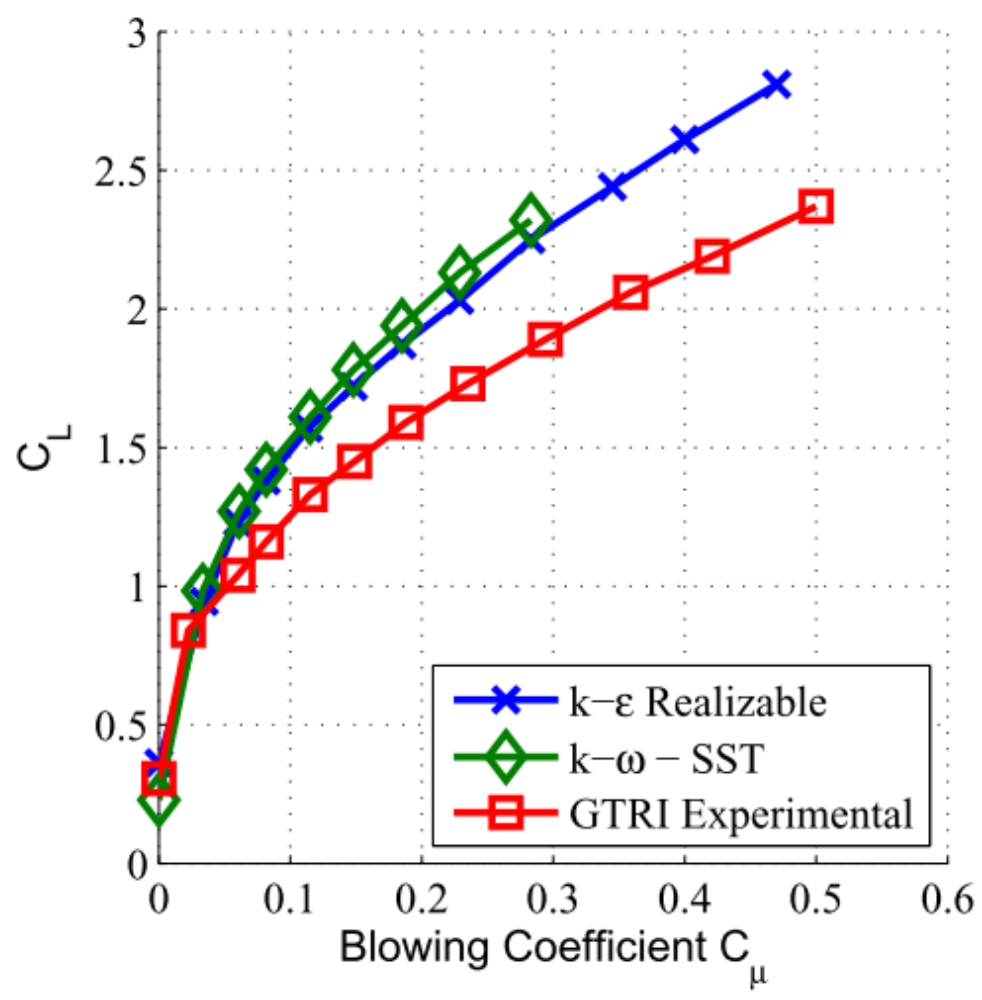

Figure 5.4: Blowing coefficient vs lift coefficient of GTRI model

\subsection{Aerodynamic Impacts from Fuselage Body}

To help reduce the amount of computational resources required, Blessing [7] investigated the impact of modeling the fuselage body. Simulations were conducted with and without the fuselage body at cruise conditions. Then, data slices of Coefficient of Pressure were taken at four different wing stations as seen in Figure 5.5. The overall lift coefficient only changed $2 \%$, so it was concluded that the fuselage body had negligible aerodynamic impact on the performance of the wing. Thus, removing the fuselage body gave confidence that it was not going to significantly influence the numerical simulation. 


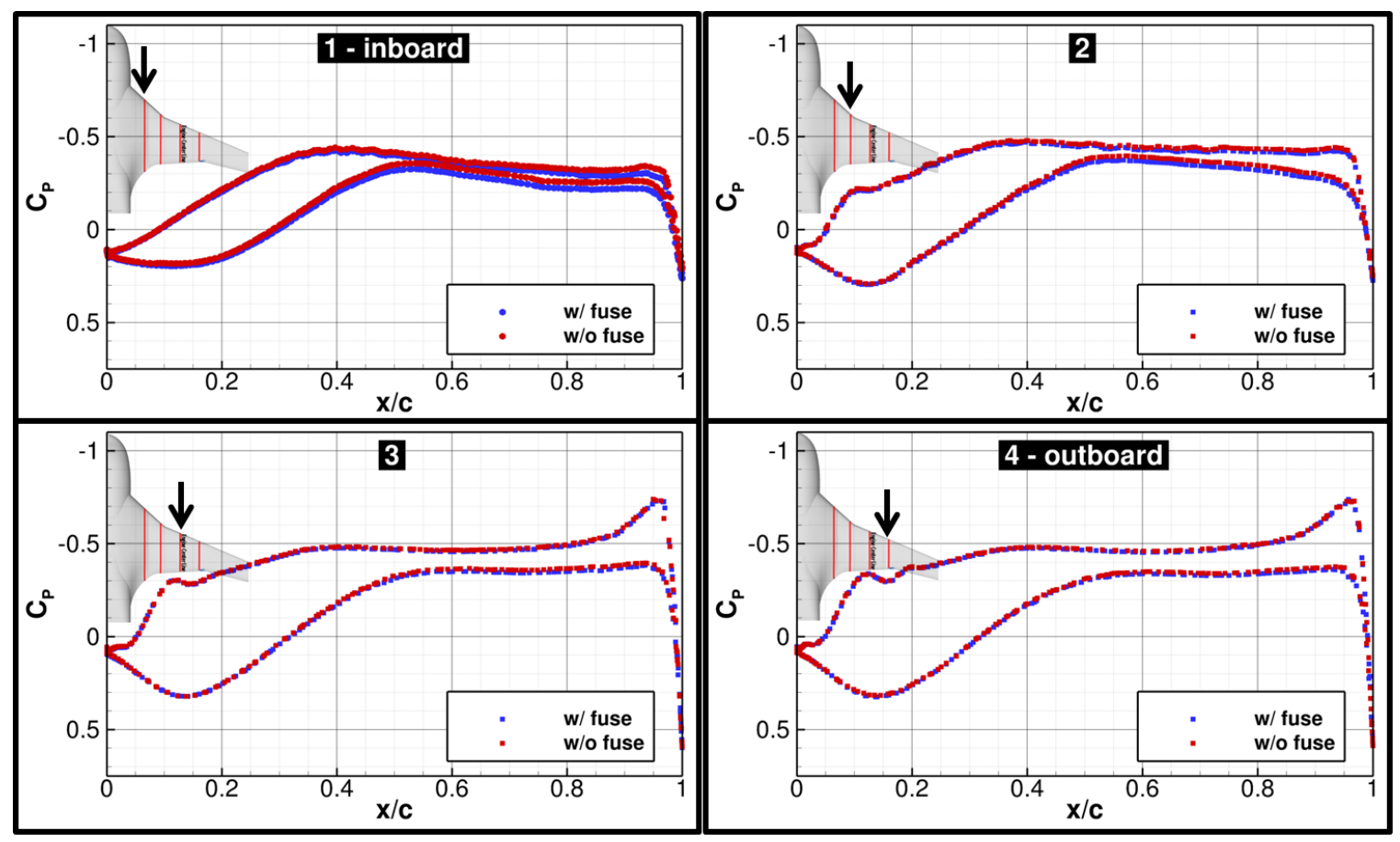

Figure 5.5: Fuselage influence on overall lift coefficient

\subsection{Slot Boundary Condition}

The slot boundary is an interesting and difficult boundary condition to set. There are two approaches to setting the boundary condition on a slot. Baker describes both in detail and the effect on solve time using each approach[43]. The first approach is to model the computational boundary at the slot exit. The second approach is to model the computational boundary upstream of the slot exit in the plenum.

The advantages of the first method are that it can dramatically lower cell count and thus reduce solve time. This approach can be tricky to implement because knowing the slot conditions in a complex 3D slot is not feasible. It also eliminates the ability to incorporate the velocity profile that would build up in the plenum and throat area. There are some ways to implement this velocity profile in $2 \mathrm{D}$ applications 
using FLUENTs User Defined Functions, but it becomes impossible with a 3D slot of this nature.

The advantages of modeling the plenum are that it fixes the boundary layer build up problem that exists in the previous method. The flow is allowed to develop freely as it would in the wind tunnel model. The down side to this approach is that the mesh complexity increases due to the small nature of the slot. See Section 2.3 for complete details. The increase in mesh size for the geometry in this paper is approximately 8 million cells. A schematic showing the two computational boundary locations is shown in Figure 5.6.

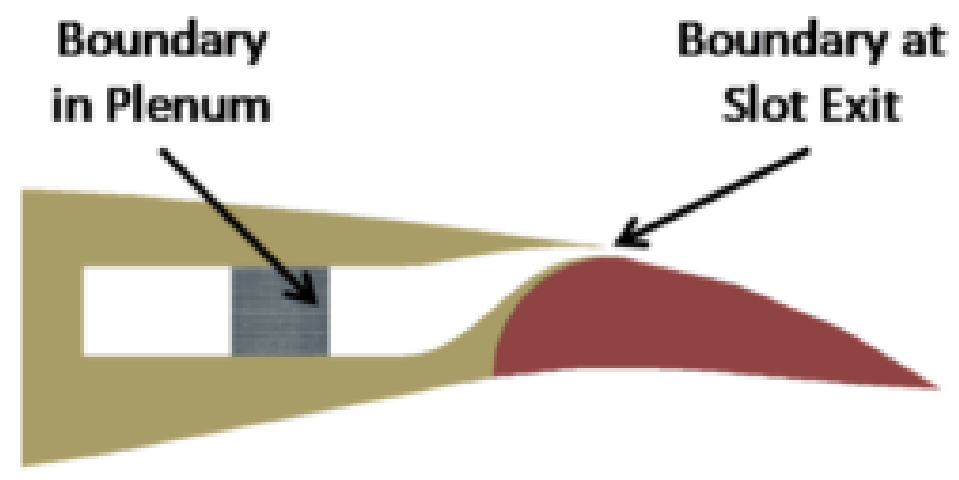

Figure 5.6: Computational boundary comparison for slot geometry. Computational plane modeled at slot exit (left) and computational plane modeled in plenum (right).

Both boundary conditions were modeled to compare the slot conditions. The slots were targeted to have a total blowing coefficient of 0.50 and the solution slices compared in Figure 5.7 are taken at the same wing section. Modeling the computational boundary at the slot is shown to be a poor choice considering the under expansion of the jet leaving the slot. It is also hard to set a specific $\mathrm{C} \mu$ due to the unsteady and divergent nature of the boundary condition. For this approach the mass flow has to be ramped up over many iterations to keep the solution from diverging. The plenum approach paid a cost in time per iteration by adding 8 million cells to the domain, 
but no ramp up was required and the solution was more stable. This second approach also allowed for the boundary layer to build up correctly.

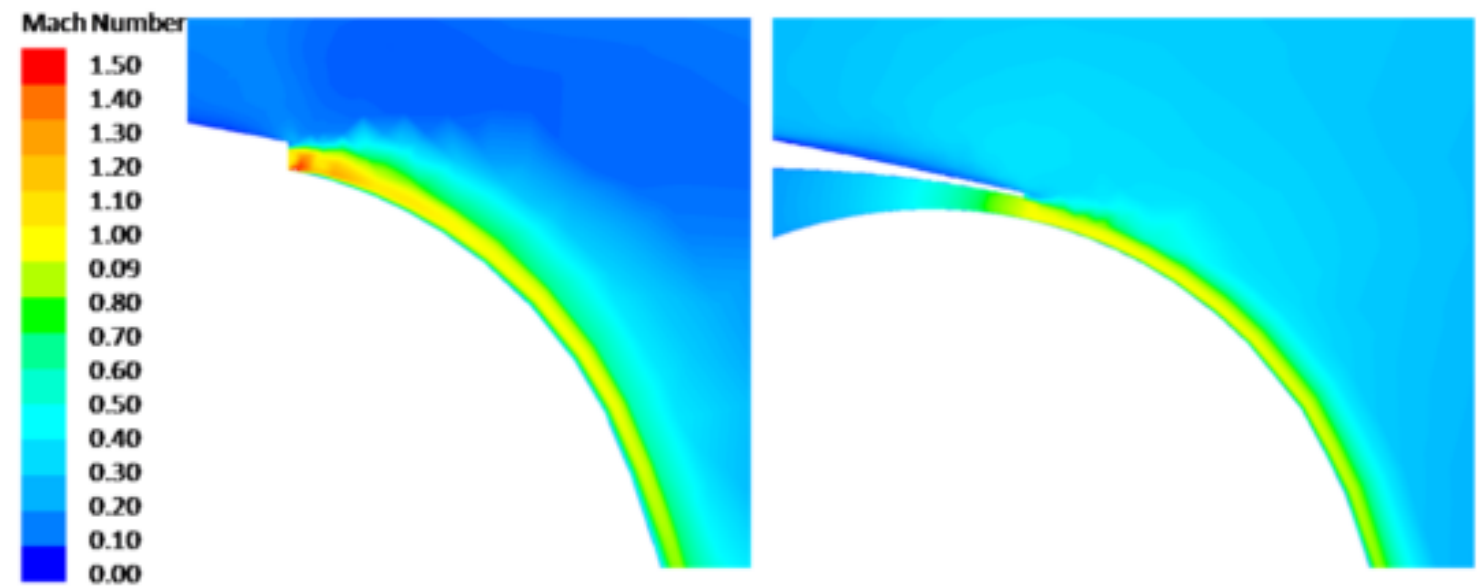

Figure 5.7: Mach contours comparing the two slot modeling approaches

In FLUENT a mass flow inlet is used when the boundary is set at the slot exit. The mass flow is determined based on isentropic hand calculations and it is believed that this boundary condition not only caused the over-expansion, but also the solution instability. For the plenum approach a pressure inlet is used. The boundary condition is determined by the pressure expectations in the tunnel. This is then adjusted slightly in order to get the approximate target $\mathrm{C} \mu$. In the end the plenum approach is chosen because it is more accurate and stable than the first approach. The increase in time per iteration is an acceptable drawback.

\subsection{Convergence}

Before a CFD solution can be evaluated, we must assure that the simulation has converged or settled. It was mentioned previously that the RANS solver simulates the Navier-Stokes equations but in its discretized form. This requires an iterative process before arriving at the final answer. For CFD simulations, the number of 
iterations vary depending on the complexity of the problem and the robustness of the software. Figure 5.8 shows an example of the iterative history of the governing equations. The residual history monitors the imbalance (i.e errors) of the discretized governing equations. Oscillations, peaks, and any other signs of unsteadiness point to the flow still aggressively changing with each new iteration step. Thus, the simulation is considered stable and approaching a numerical solution if residuals continue to drop as the simulation progresses. To obtain iterative convergence, first all the discretized equations (mass, mom, energy) are deemed converged when they reach a specified tolerance at every nodal location. Then second, the numerical solution no longer changes by a specified tolerance with additional iterations

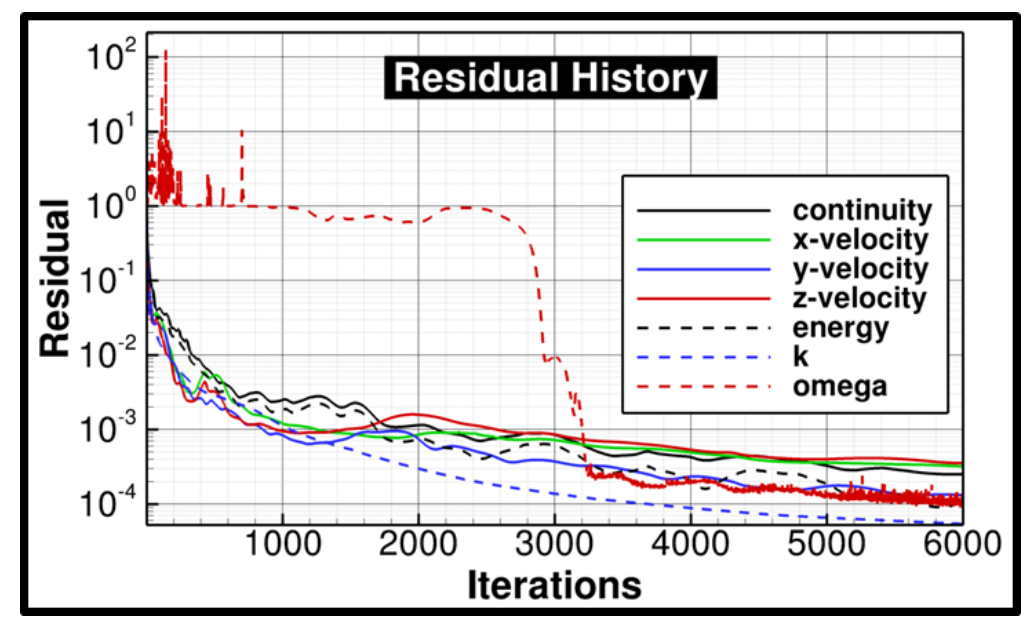

Figure 5.8: History of residual convergence by iteration steps

Monitoring residual history is not enough to decide convergence if there are specific variables of interest. For example, aircraft applications typically care about lift and drag of the aircraft, so these quantities should be monitored similarly to residuals. Figure 5.9 shows an example of on-going iterative history for lift and drag coefficient. Another thing to keep in mind is that simulation convergence does not imply accuracy. Accuracy is dependent upon numerous variables, and simulation convergence is only 
one of the many that need to be evaluated. Possible reasons for inaccurate results could be an ill-posed problem, poor quality mesh, inappropriate solver settings and boundary conditions.

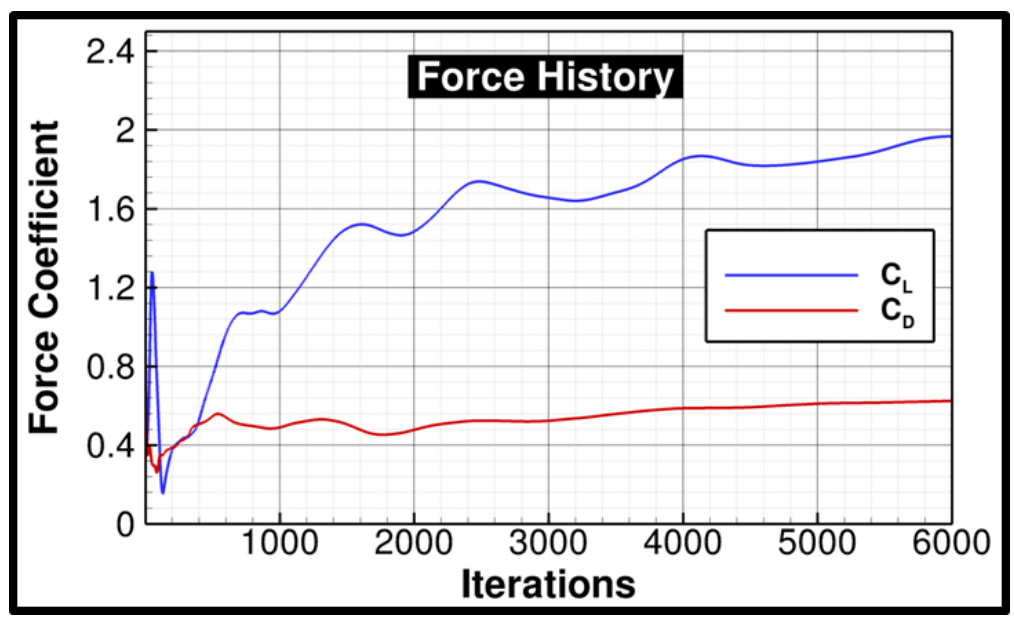

Figure 5.9: History of drag and lift convergence by iteration steps

Once you have quantitative convergence from the iterative history, the user has to be put on their detective hat and evaluate for qualitative convergence. As a rule of thumb for analyzing CFD solutions, a quick sanity check would be the eye test where the user investigates critical regions to identify any abnormalities in the solution that doesn't seem to make sense from an engineering standpoint. When conducting CFD, the user should at least have a general understanding of what to expect in the flow field so that physics which doesn't make sense could be easily spotted. For this dissertation, the focus is purely qualitative convergence comparing unstructured and structured meshing. The ultimate goal for validating against wind tunnel data is to have a mesh-independent solution, that shows no difference whether you use unstructured or structured meshing. 


\subsection{Comparison of Unstructured and Structured}

\section{Meshing}

Let's first take a look at a fluid slice of the engine nacelle as seen in Figure 5.10.

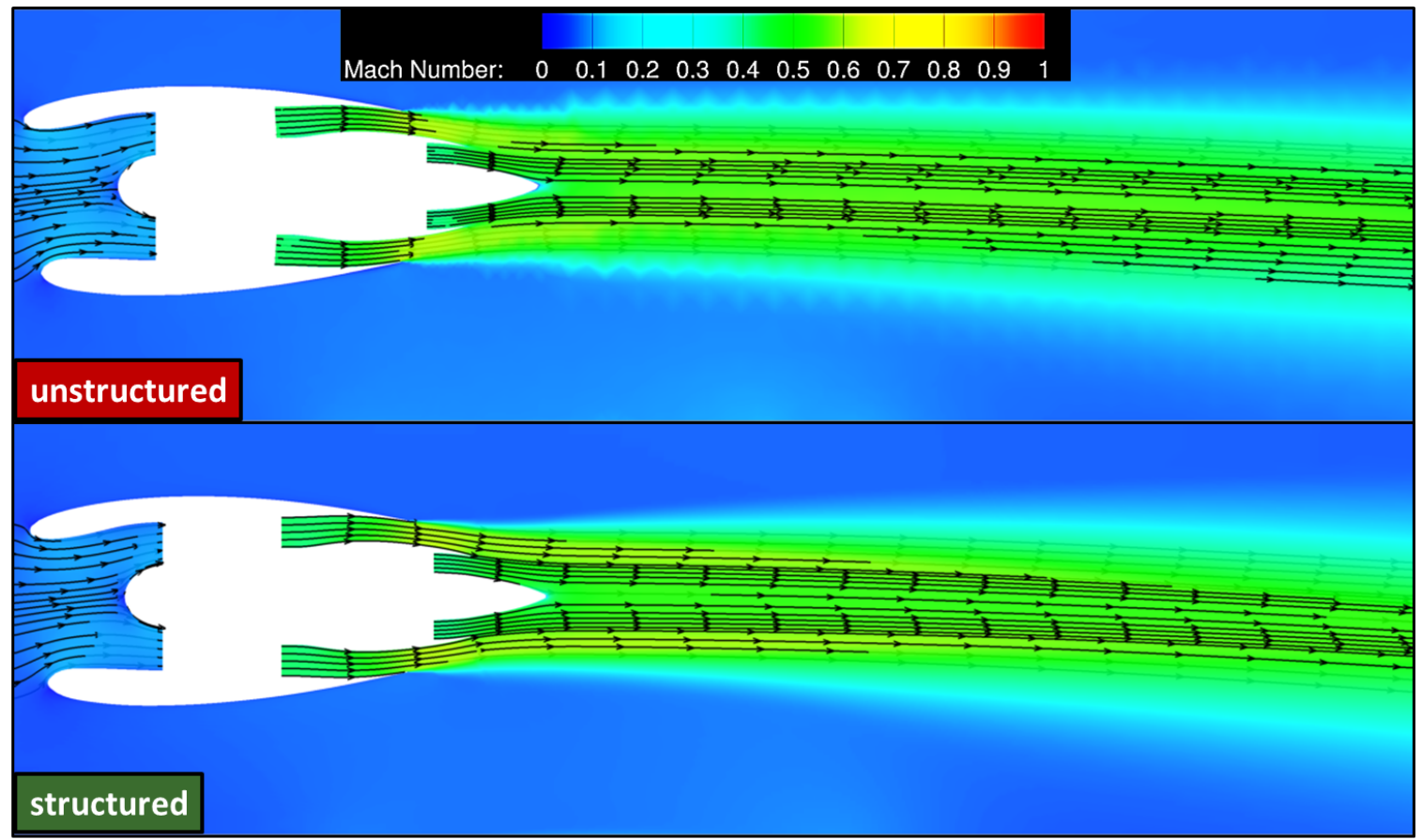

Figure 5.10: Fluid slice through engine centerline colored by Mach Number highlighting flow differences with engine jet exhaust for unstructured and structured meshing

Generally speaking, both meshing methods result in similar behavior from the engine jet exhaust. However, an in-depth look points to a critical difference at the shear layer coming off the engine trailing edges. Figure 5.11 shows a closer look at this region. 


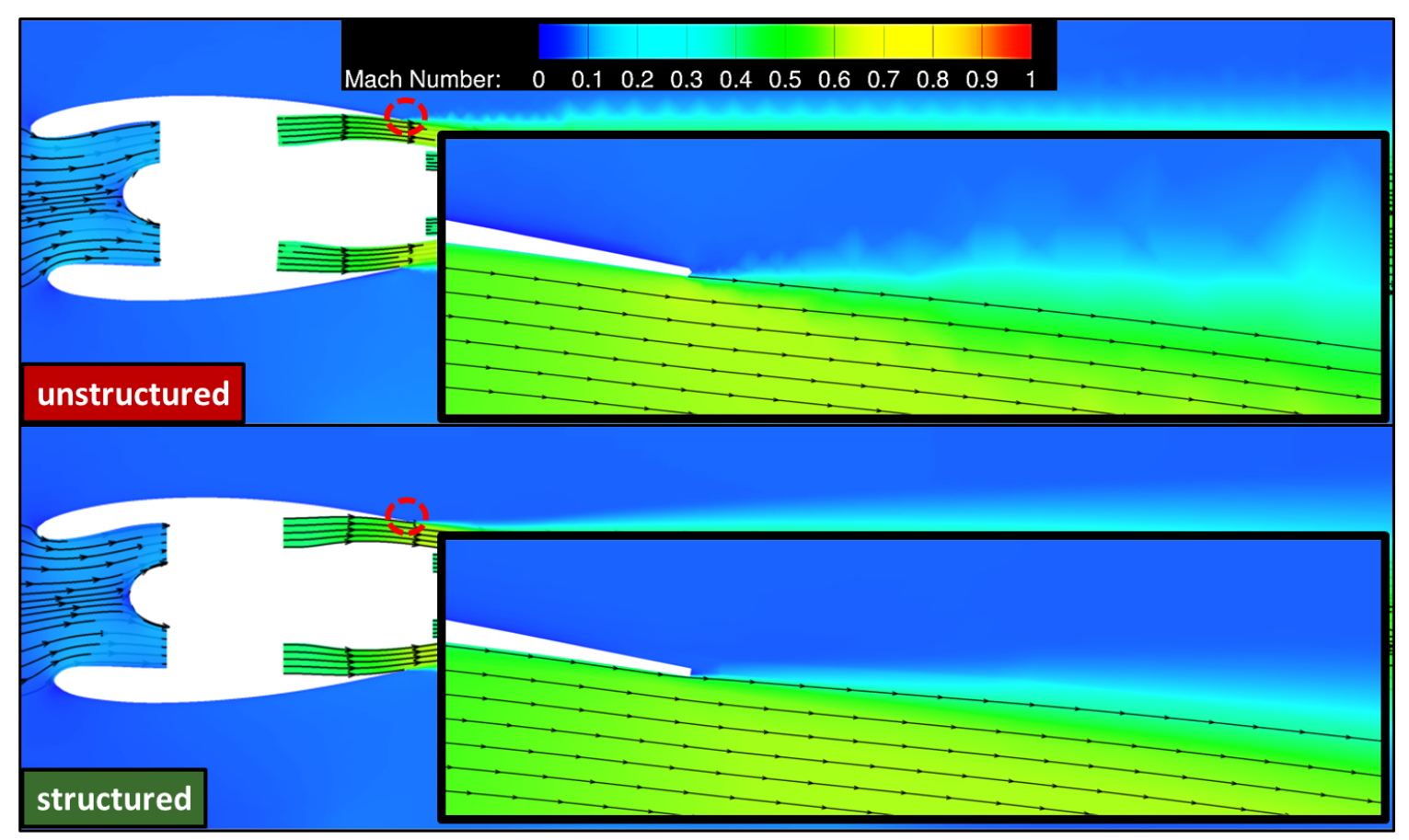

Figure 5.11: Fluid slice through engine centerline colored by Mach Number highlighting flow differences with shear layer coming off engine trailing edge

At first glance, the lack of resolution of the shear layer is apparent in the Unstructured image. This is critical because without proper modeling of the shear layer, additional instabilities are introduced into the flow field that result in more numerical error. The gradient pattern of the shear layer naturally follows the mesh edges of the tetrahedral elements. So, with elements too large to handle the strength of the engine jet, discrepancies in the CFD solution will be apparent as is in this case. If you recall, the total mesh size for both these approaches are near the maximum of what current computational resources can handle. Thus, to fix the visual misnomer one must either have the proper meshing tool that allows the user to stay within current computational resources by creating a mesh that is refined where needed and coarsened where not important such as the Structured strategy or, increasing the computational capacity such that it can handle more mesh elements. 
In Figure 5.12, we can see the instabilities introduced into the flow field. Comparing the side by side comparison, the flow just before and after the circulation control slot are quite different in both cases. The Unstructured streamlines takes a slight dip before rising up again to entrain over the wing flaps. However, the Structured streamlines appear to be stable, showing no signs of unusual physics in the flow field. In addition, the Structured image also clearly defines the jet height over the flap compared to the Unstructured image. This is important because it shows how advantageous the Structured elements are. Because the flow in this area is highly directional, it is ideal to build mesh elements such that the flow direction is perpendicular so that it ensures the least amount of numerical error

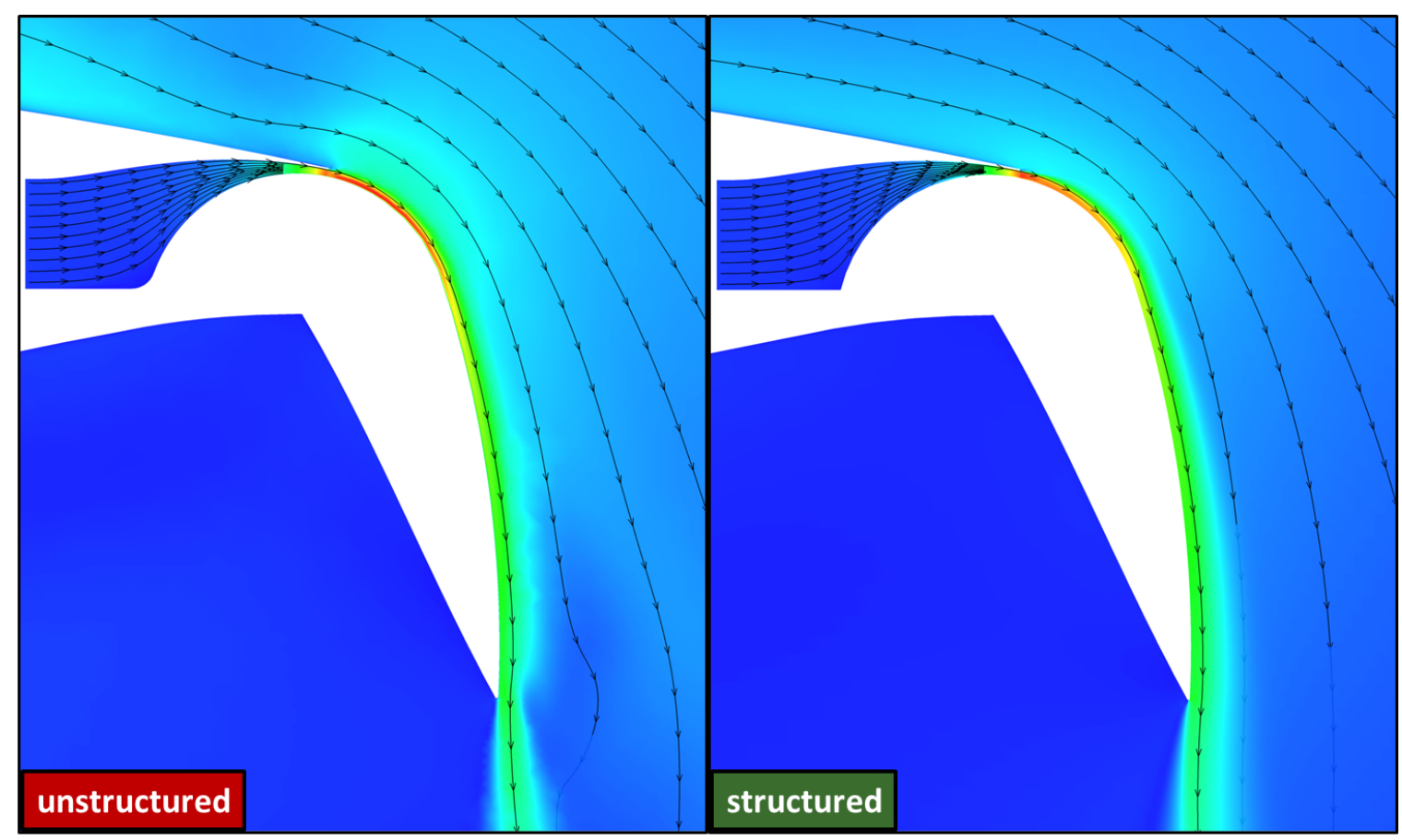

Figure 5.12: Fluid slice through engine centerline colored by Mach Number highlighting flow differences with CC jet flow over flaps

Looking closely at the slot exit in Figure 5.13, there is unusual physics occurring in the Unstructured image. With very large velocity magnitude coming out of the slot, 
it is going to create a very low pressure zone near the surface of the flap. This should theoretically pull more flow from the high pressure freestream toward the surface as seen in the Structured image. But this is not the case with the Unstructured image. Another interesting observation is that the upper surface flow of the wing appears to be separated in the Unstructured image evident by the low velocity region near the surface. This could explain the strange behavior of the streamlines in this area. More on this topic later. It should also be pointed out that near the slot edge of Structured image there is a flow field discrepancy due to meshing. With more time, this can be smoothen out with a better mesh.

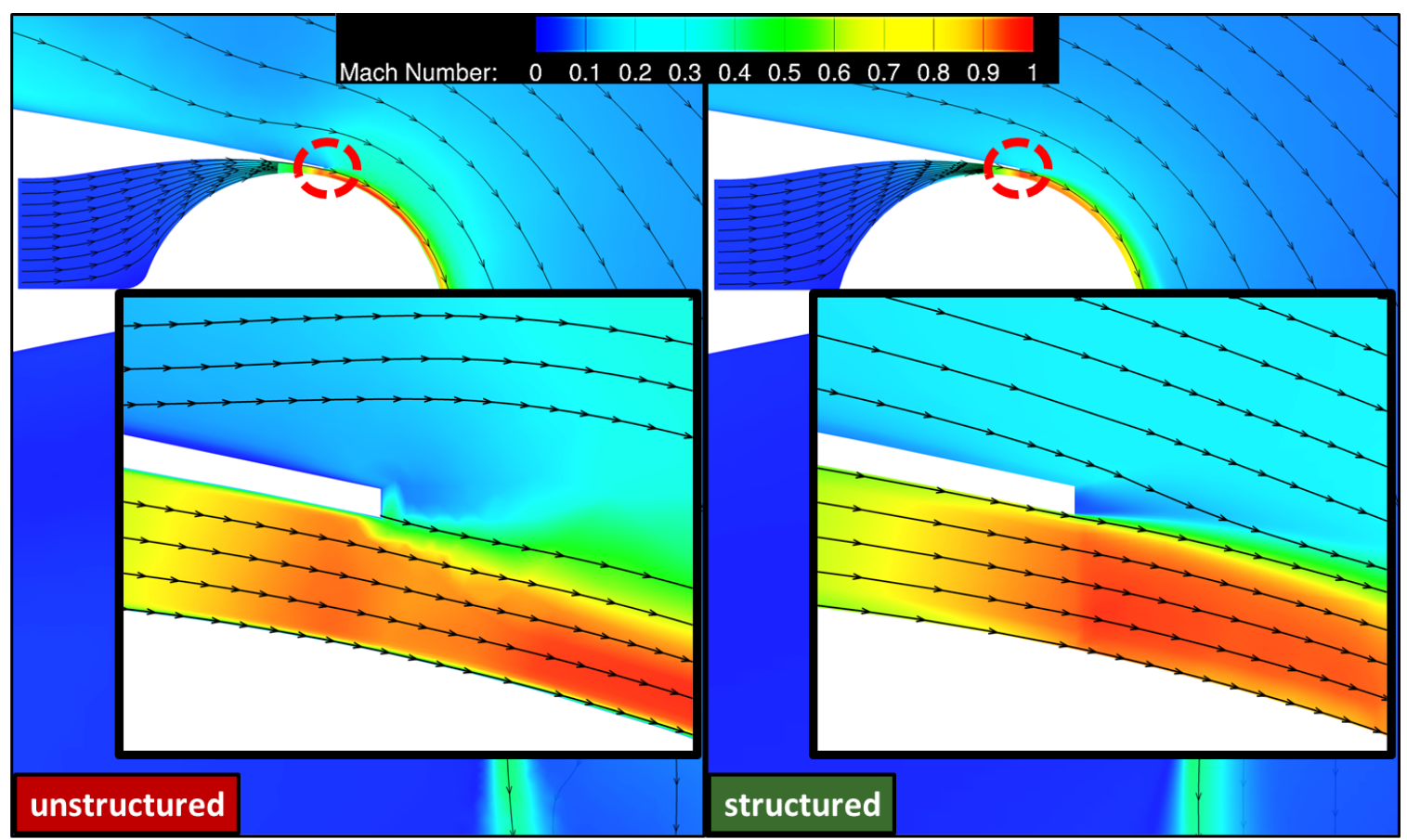

Figure 5.13: Fluid slice through engine centerline colored by Mach Number highlighting flow differences with shear layer and CC jet exit slot

Investigating further into the strange flow behavior of the Unstructured mesh, Blessing[11] acknowledges the same result in his Unstructured mesh. Figure 5.14 shows a top view of the wing surface pressure where you can see the separated region 
at the trailing edge of the untapered portion of the wing. This coincides with the same location referenced in Figure 5.13.

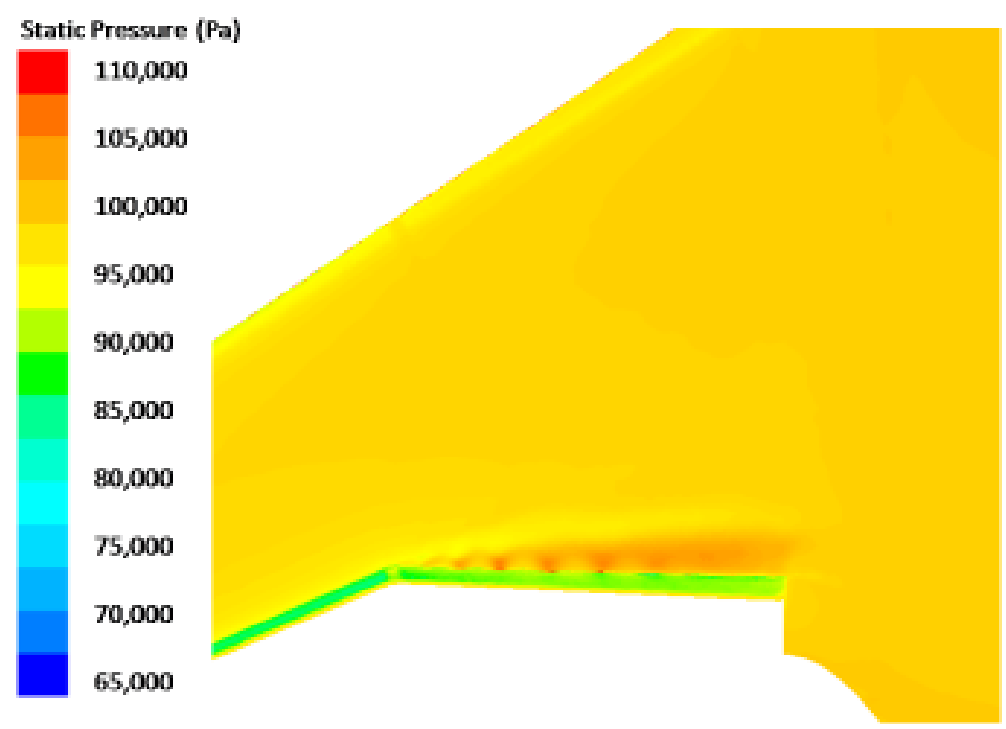

Figure 5.14: Static pressure contours showing separation upstream of slot exit as seen in Blessing [11]

Blessing[11] mentions that the separation could in fact be physical due to the flow dynamics of the leading edge and trailing edge circulation control slots. Figure 5.15 compares streamlines over the wing for the untapered and tapered portion of the wing. Notice that the leading edge stays nearly constant over the entire wing, while the trailing edge exhibits a straight and tapered section. The high speed air ejected by the leading edge slot travels perpendicular to the slot over the wing surface and meets up with the even faster air ejected from the trailing edge slots. For the tapered wing section, the flow at the trailing edge does not disrupt the flow path originating from the leading edge. However, the straight wing section forces the flow path to turn about 30 degrees. Blessing hypothesized that this turning of the flow is too severe and thus, the flow separates. 


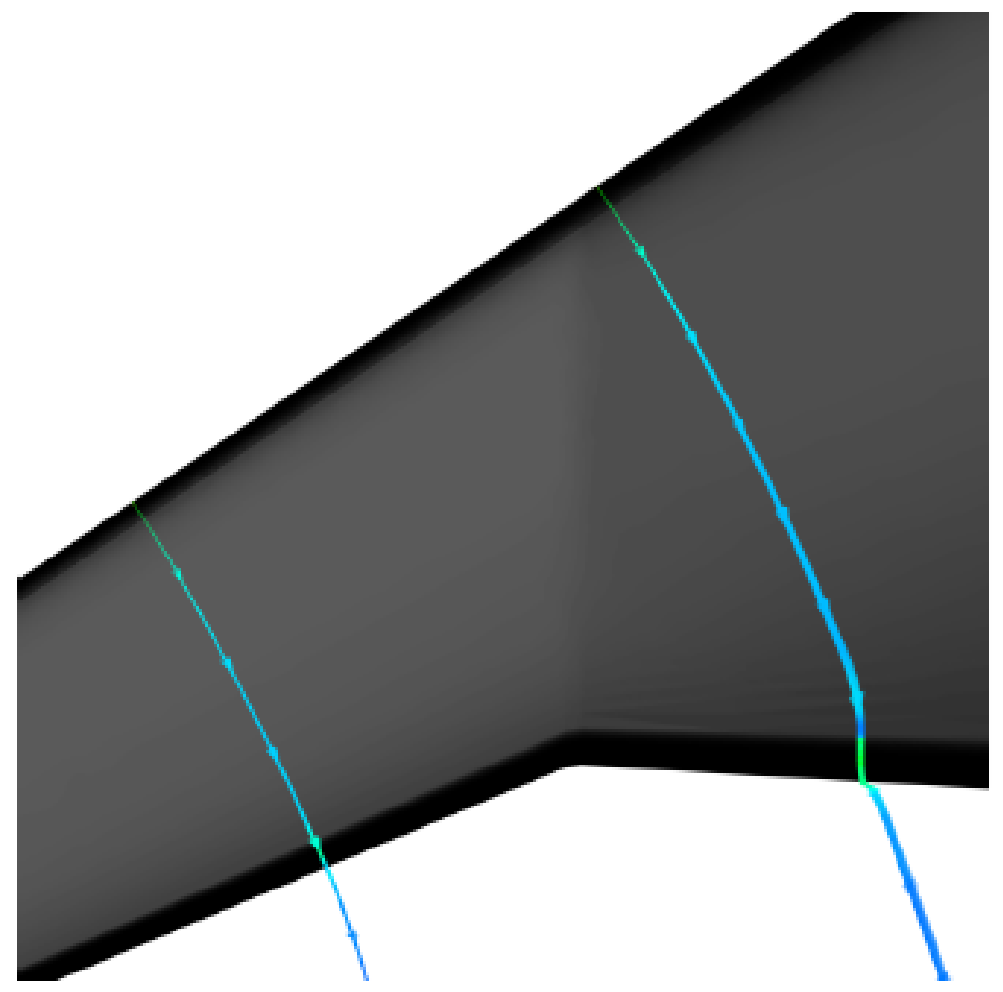

Figure 5.15: Streamlines showing flow path over the wing as seen in Blessing[11]

Blessing's hypothesis is certainly plausible and warrants further digging before arriving at a conclusion. Figure 5.16 compares $\mathrm{Cp}$ over different sections of the wing for the Unstructured and Structured meshes. The Unstructured data validates the points Blessing mentions in regards to the flow staying attached for the tapered sections but not for the straight section. However, the Structured data does not show the same trend for the straight section. Interestingly, the flow is just as attached as the other three sections where $\mathrm{Cp}$ was probed. The two meshes lead to contrasting results for the straight wing section and will require the results from the Wind Tunnel Test to determine which result is physical. 

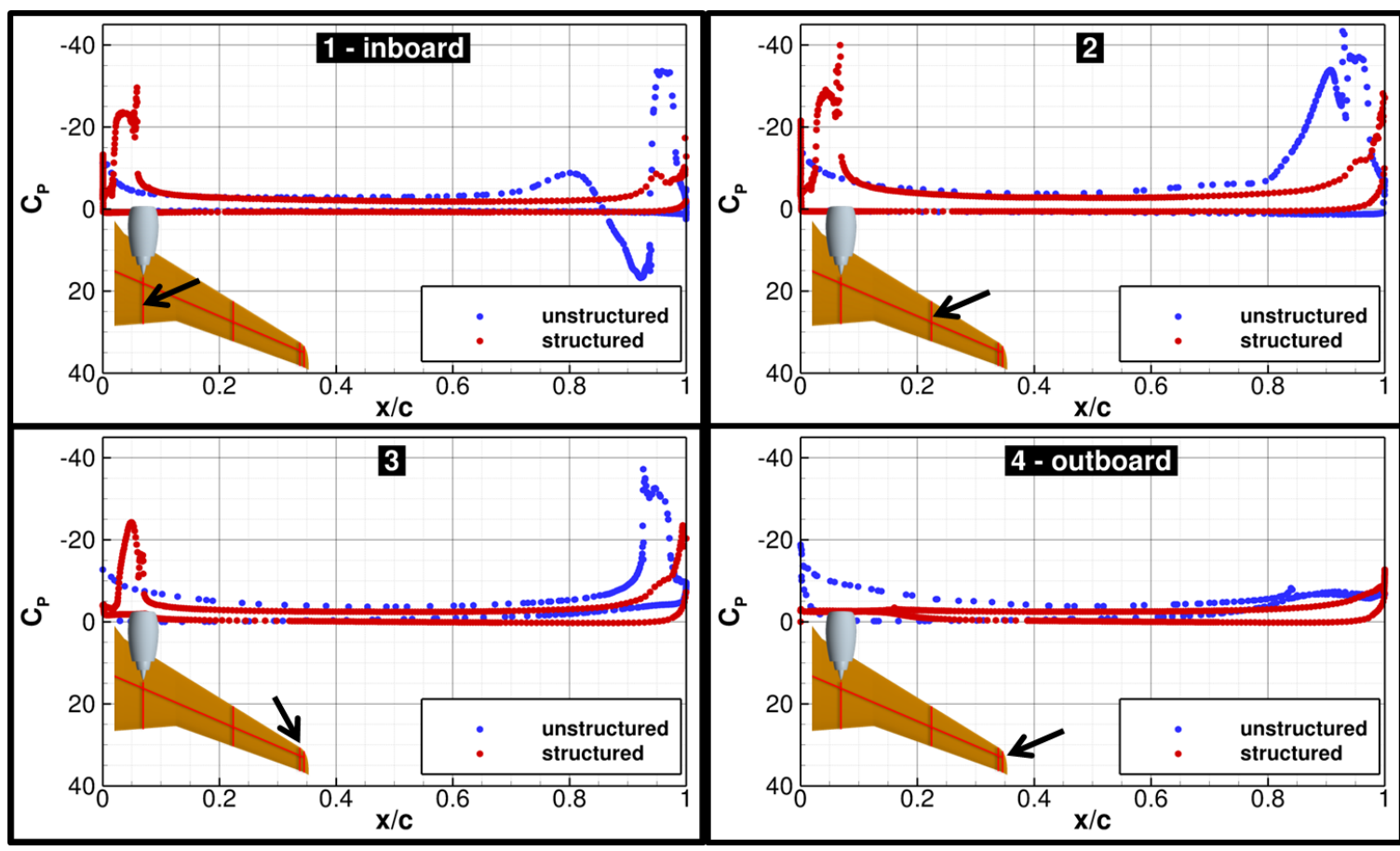

Figure 5.16: Comparison of Coefficient of Pressure distribution for various stations a long wing highlighting significant differences near CC slots

Unfortunately, at the time of this Thesis, the wind tunnel experimental data for the configuration modeled was not yet post-processed, so a true comparison cannot be made. However, preliminary uncorrected analysis of the same configuration, but with different testing conditions can be seen in Figure 5.17. The pressure coefficient data is measured a long the wing of the engine centerline. The flaps were deflected 60 degrees and the freestream Mach Number is 0.06. Although preliminary and uncorrected, the take away from the experimental data is that there's no indication of separated flow on the aft end of the wing as seen in the Unstructured Mesh. This confirms that the observed separated flow was in fact induced by the limitations of Unstructured Meshing. 


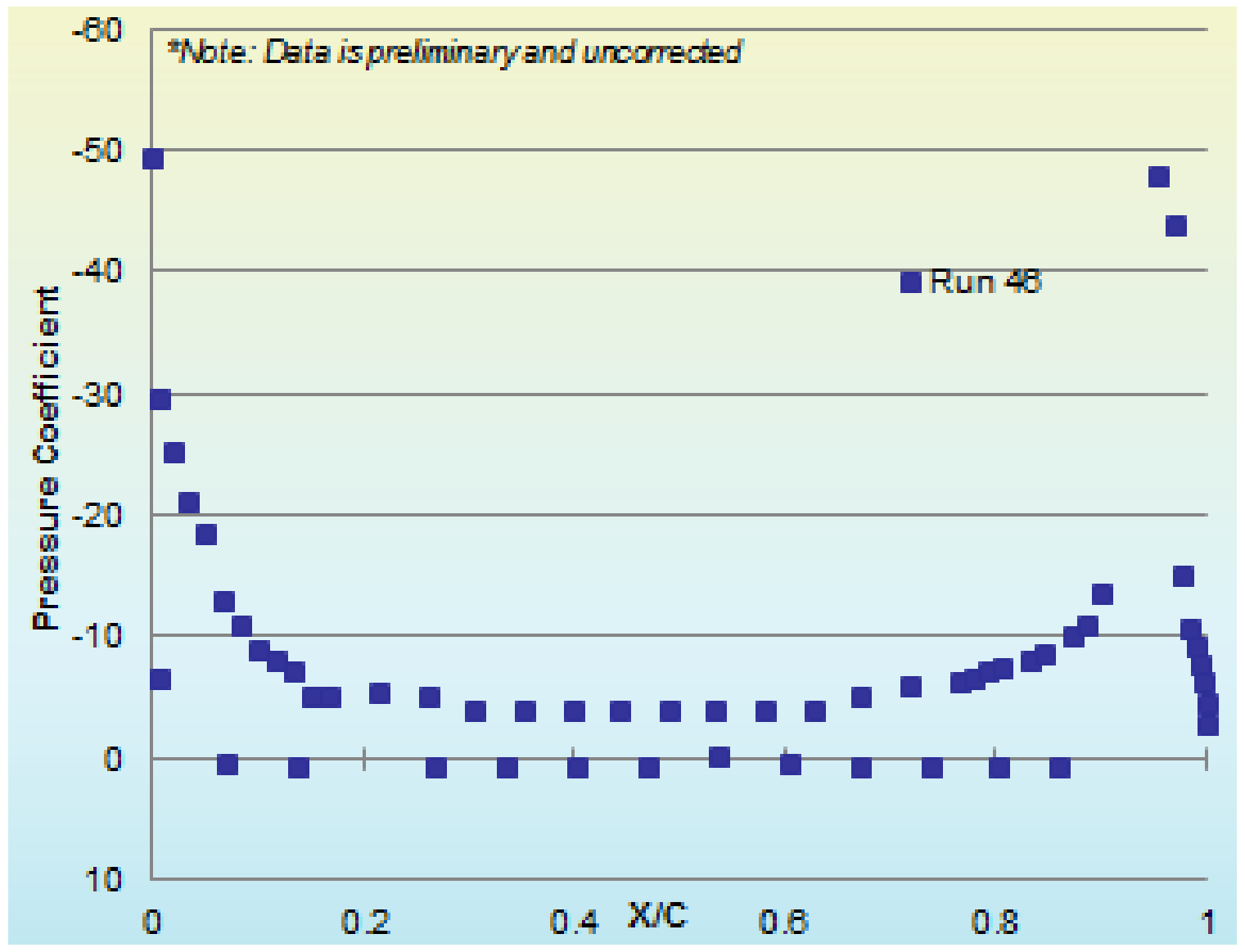

Figure 5.17: Preliminary experimental data of Pressure Coefficient at B/L 500 station

Let us now examine the far-field aerodynamics. Figure 5.18 compares the Unstructured and Structured methods roughly 20 engine nacelle lengths downstream of the wing. Once again, the instability of the Unstructured solution is evident by the unusual streamline behavior from the engine and wing. For the Unstructured image, the deflection of the engine jet entrainment is measured to be about 10 degrees versus only 6 degrees from that of the Structured image. In addition, the latter case does not display any of the downstream instabilities exhibited in the Unstructured image. Similar to the clarity of the circulation control jet over the flap, the Structured elements were created in anticipation of the engine jet have a deflection angle. Thus, the elements in the engine jet region were purposely positioned as orthogonal as possible 
to the engine jet. One might comment that the rotation of the elements is inducing the engine jet to deflect as seen in the image. This is a valid point, however, because we have an Unstructured image to compare against this cannot be true. The Unstructured approach is completely unbiased when it comes to element orthogonality, yet the downstream flow field exhibits similar behavior in both cases. Only difference is that the Structured image is able to distinctly capture the engine jet region while in the Unstructured image, this region is visually smeared.

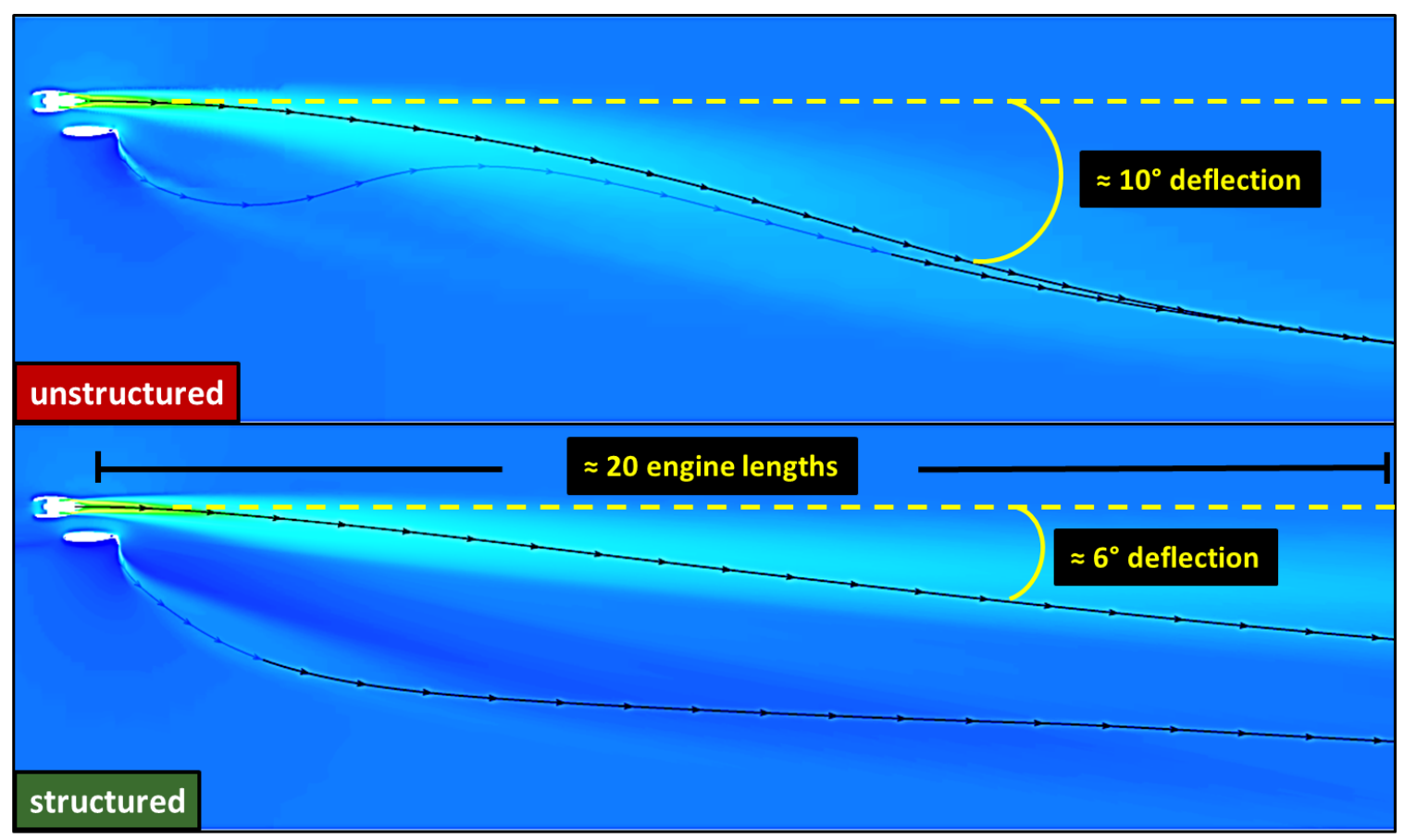

Figure 5.18: Fluid slice through engine centerline colored by Mach Number highlighting flow differences with farfield wake

\subsection{Mesh Independence}

As mentioned previously, error in CFD simulations can emanate from many sources. One that will be described in further detail is the resolution of the mesh. Because the Navier Stokes equations are discretized into differential equations, the size of the 
mesh becomes a critical component for minimizing error. When the size of the mesh is eliminated as a source of error, the CFD simulation is deemed mesh independent. True mesh independence occurs when the CFD solution no longer depends on the mesh as you change its size. Theoretically, the discretization error becomes more negligible when the finite quantities of the differential equations, $\Delta \mathrm{x}, \Delta \mathrm{y}, \Delta \mathrm{z}$ approaches zero. Setting up a new CFD simulation can be a daunting task when it comes to creating the mesh. Creating a mesh that is neither too coarse (error prone) or too refined (expensive) is usually guided by previous experience on what is acceptable for a given problem. However, there is a method called Richardson's Extrapolation that can quantitatively determine if the mesh is good enough to neglect discretization error. To summarize the method, the user must create three successively refined meshes of the same factor. Plotting mesh size against a quantity of interest such as Lift, the data should theoretically exhibit an asymptotic behavior as you increase mesh size. From these three meshes, using Richardson's Extrapolation will yield a theoretical extrapolated value if mesh size approached infinity. Unless the user had unlimited computational resources, it will not be possible to create a mesh to attain the exact extrapolated mesh. However, typically a $5 \%$ error bar is acceptable to achieve a reasonable answer. More details about Richardson's Extrapolation can be read in the Appendix. 


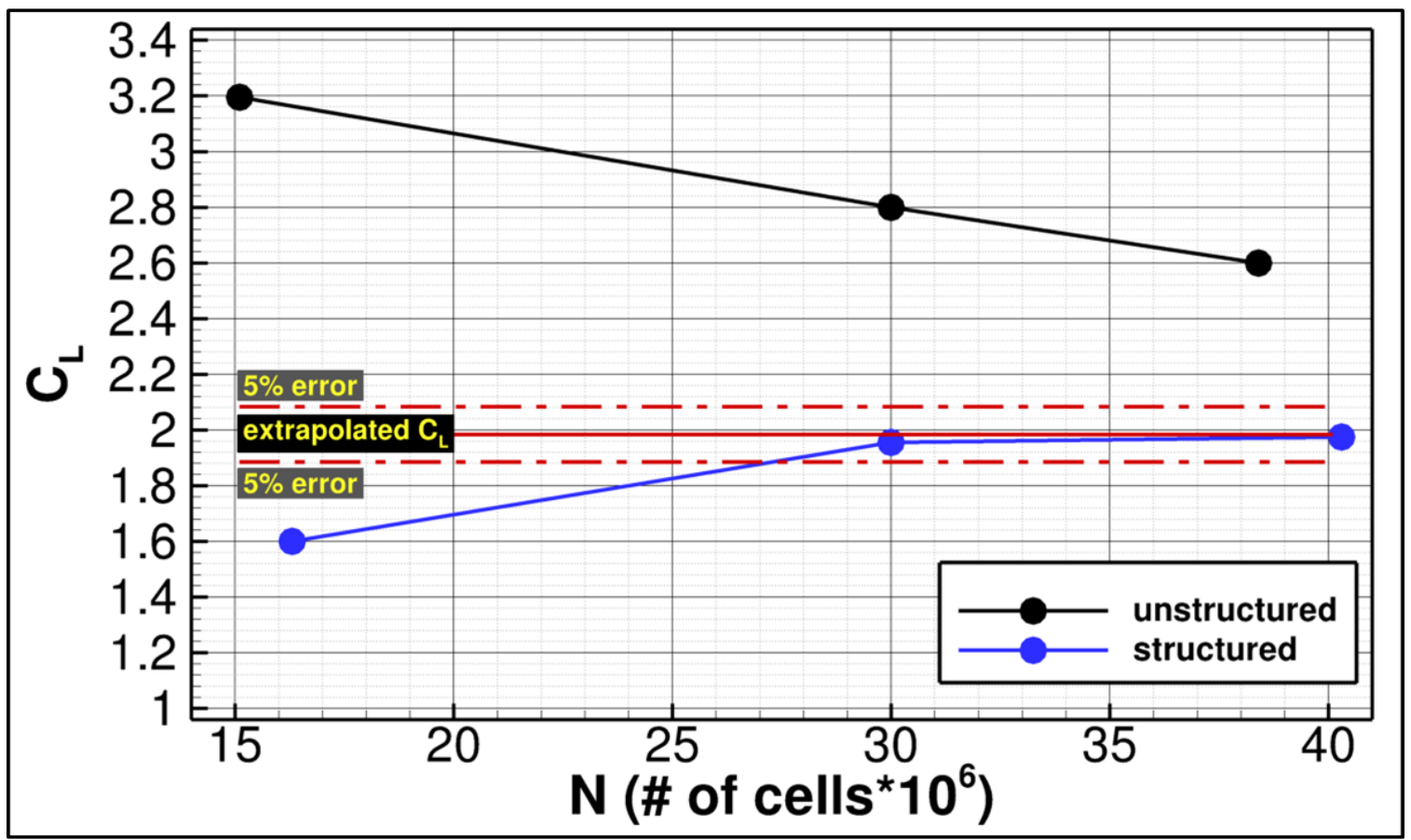

Figure 5.19: Grid independence study for 3 mesh sizes for unstructured and structured meshing to determine minimum amount of mesh elements required to reach within $5 \%$ accuracy 


\section{Chapter 6}

\section{Concluding Remarks and}

\section{Recommendations}

Numerical simulation of 3-D circulation control flow fields is a very difficult task as attributed to the extensive research seen in the past two decades. With more powerful computing, research into this application is very encouraging as we continue to gain more knowledge of what techniques are best for predicting accurate CFD solutions. In the early stages of this NRA, Cal Poly was tasked to down select the final AMELIA design from four different concepts. Because of the speed appeal of unstructured meshing, it was the preferred method in the initial phase. It yielded encouraging results but prompted further investigation into the accuracy of the method when considering validation against wind tunnel data. If wind tunnel data existed, it could be easily determined if the unstructured meshing approach employed for this dissertation is a feasible method, but with testing scheduled many months into the future, the most logical answer was to compare unstructured meshing against a well accepted method in the literature as a means of accuracy; structured meshing. This 
method gets a bad rep because of how much manual labor goes into preparing a mesh, let alone for a highly complex 3-D circulation control wing configuration that has yet to be accomplished in the literature. The trade off is that the user is able to eliminate the inefficiencies that are caused by automatic mesh generation algorithms for complicated 3-D flow fields with several dominating forces.

Although the results of unstructured meshing were poor compared to structured meshing, it cannot be concluded at this time if unstructured meshing is a feasible method for 3-D circulation control physics. However, it can be stated that the unstructured meshing method employed for this dissertation failed to capture the dominant forces seen in the flow field that is crucial for validating with wind tunnel data.

The tribulations faced with unstructured meshing for this dissertation could have potentially been due to two main reasons: 1) software limitations and 2) limited computational resources. Further investigations into better software tools that allow more user control with the mesh creation should be considered next. In addition, the max size mesh for this dissertation was on the order of 40 million elements. As seen in Figure 5.19, this is not nearly enough for unstructured meshing because at the core it is a less efficient method compared to structured meshing so it requires more resources to achieve the same result. However, the data in the figure for unstructured meshing is promising as it trends toward the Richardson Extrapolated solution as calculated from the structured mesh, but perhaps requires more elements (more resources) to reach the same desired result. Typically, engineers are asked to trade off between speed and time, and if given the necessary resources, unstructured meshing could potentially be a game changer for future research in 3-D circulation control applications. 


\subsection{Hybrid Meshing}

A suggestion for future researchers in this field is to investigate Hybrid Meshing as another meshing approach. Unstructured and structured meshing have their fair share of advantages that the other doesn't have. Combining the two together into a Hybrid Mesh would be the best of both worlds and optimizes computational resources. For the computational model used in this dissertation, the ideal meshing solution would be to create a structured mesh with an aspect ratio close to 1 to only encapsulate the areas where dominant forces are expected to occur (i.e boundary layer, shear layer, engine exhaust, jet flow). Meanwhile, everywhere else throughout the domain where flow is uniform and predictable, the use of large aspect ratio unstructured elements should be used. This was attempted for the engine exhaust area as seen in Figure 6.1 .

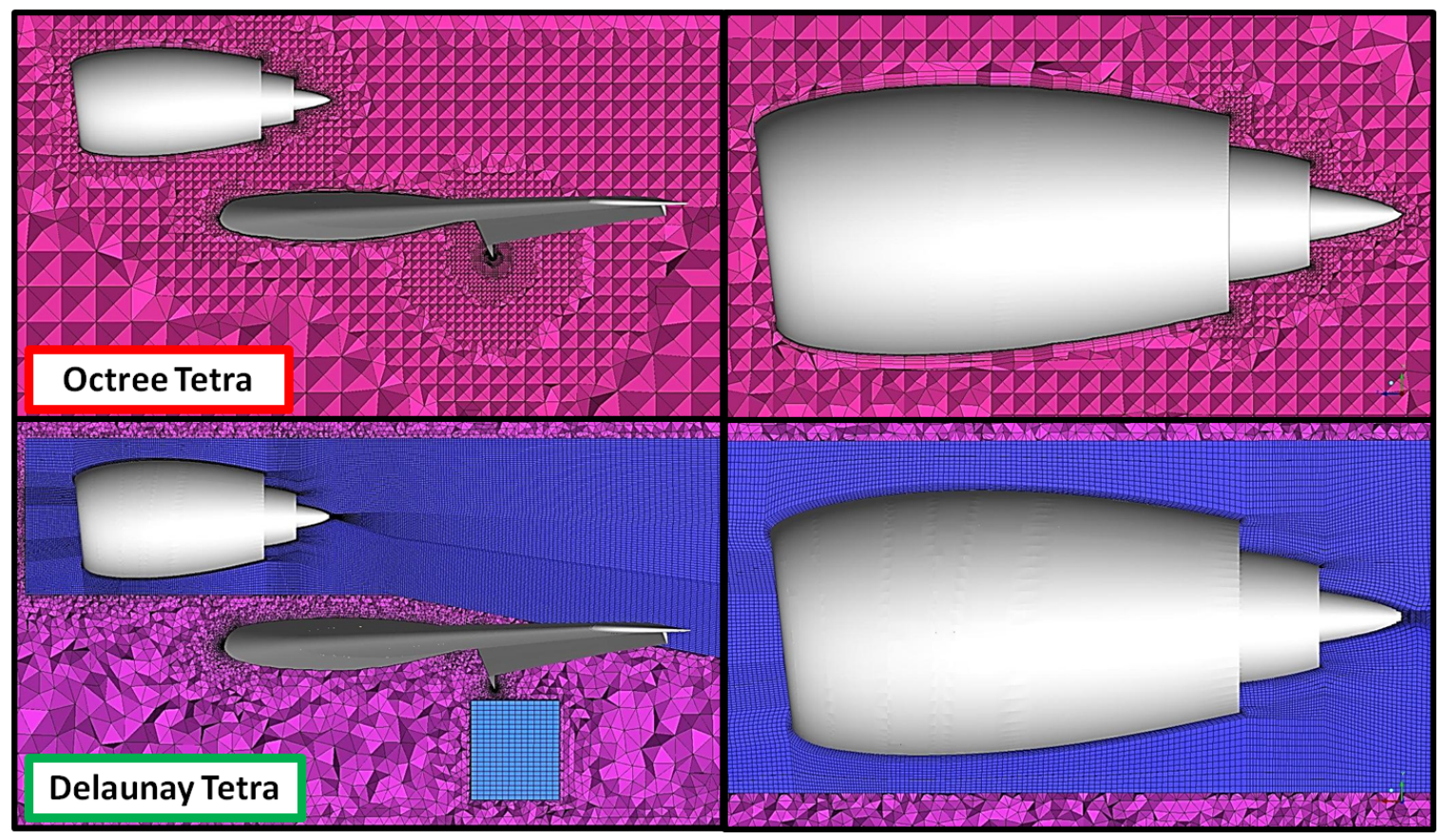

Figure 6.1: 1st attempt at creating a hybrid mesh for engine jet exhaust. More resources needed to create a high quality structured mesh for $\mathrm{CC}$ jet 
The difficulty of successfully creating a hybrid mesh is the interface of the unstructured and structured elements. With models that don't have small features to resolve, this won't be a concern, but with the model used for this dissertation as pointed out in Figure 2.5, the geometry was too complex given the tools and resources available to accomplish this task. Ideally, the interface should consist of near perfect elements with aspect ratio of 1 . However this criteria strains computational resources and forces the user to compromise by using larger aspect ratio elements. Figure 6.2 shows why this becomes troublesome when merging triangles and quadrilaterals together at the interface.
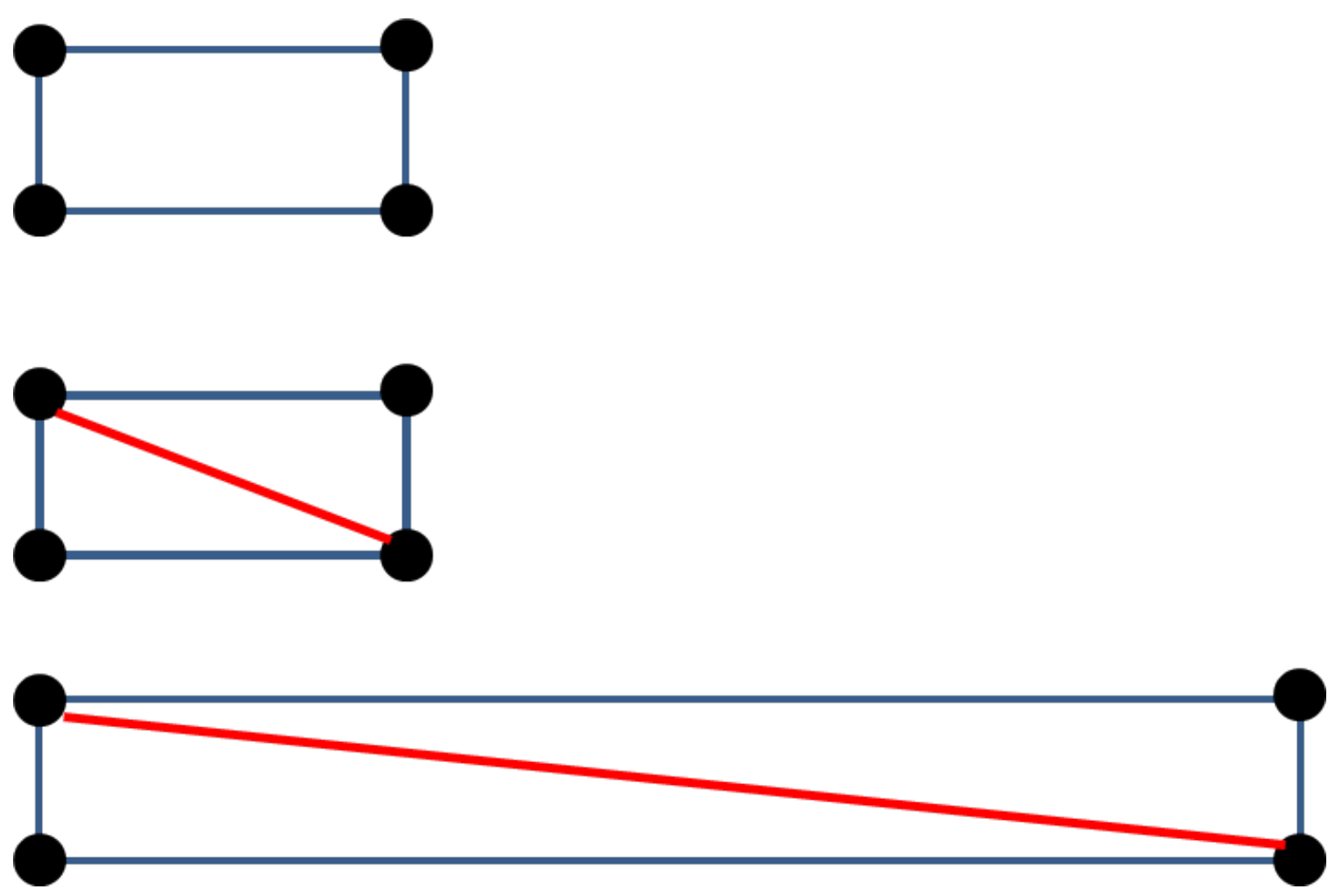

Figure 6.2: Interface is key component for successful hybrid mesh. With limited resources, very difficult to create perfect elements for merging at the interface. Aspect ratio and skewness can be compromised but could introduce too much numerical error

The problem stems from simulation solvers not equipped to handle very skewed mesh elements as it introduces a lot of numerical error into the simulation. This 
is why quadrilaterals are advantageous when it comes to large aspect ratio because it can get very large before skewness becomes a concern for the solver. However, triangle elements draw the short end of the stick when it comes to aspect ratio and skewness as illustrated by the the figure above. Thus, if the user has the luxury of having additional computational resources, more so than what was available for this dissertation, the Hybrid Meshing approach would be highly suggested moving forward with simulating 3-D circulation control applications.

\subsection{Lessons Learned}

In this section, I would like to outline some key lessons learned throughout the Meshing process to help assist prospective researchers. The tips are meant to be general suggestions and aimed to be independent of the meshing tool.

For Unstructured Meshing, most commercial codes will offer two main algorithms; Octree and Delaunay. Octree is the most robust of the two and can be applicable for the majority of applications. However, for complicated geometries with small detailed features to refine (i.e circulation control slots), the Octree method produces poor mesh results due to its top-down approach of subdividing cells by a power of 2 . This results in very poor transition from one size to the next when refining small features. The Octree method was used for this Thesis and it can be seen in the CFD results why this method should be avoided. It is recommended to the user if Unstructured Meshing is chosen that the Delaunay method be used. This algorithm generates the mesh from the bottom-up and produces a gradual transition from various sized elements. Although not ideal, this would have done a better job at capturing the shear layer than the Octree method employed for this Thesis. For the boundary layer mesh, it is 
recommended to create the surface mesh first, then offset these elements to generate prism elements. There is also an option to generate the boundary layer mesh after the fact when the surface and volume mesh has been created, however this is not as stable of an approach when it comes to building the boundary layer mesh for features such as the scissor junction made by the wing flaps and wing tip.

When it comes to Structured Meshing, there are various techniques available to arrive at the final mesh. As mentioned previously, the method employed with ICEMCFD was called HEXA blocking, however, a similar method should be available with any commercial meshing software. With challenging geometries such as AMELIA that embodies many geometry complexities, it will be easiest to take a bottom up approach where you start "'blocking", around the complicated geometries and then merge it with the remaining volume. In the case of AMELIA, the blocking strategy originates from the circulation control plenum and then continues to the engine nacelle. As the user prepares the blocking strategy, it is recommended to carve out as few of blocks as possible. With complicated geometries, grid lines will be abundant and can become very challenging to manage in the end if problems arise. It is also recommended to apply a scripting language early on if multiple configurations are to be meshed.

In summary these are the key points for meshing a geometry similar to AMELIA

1. Delaunay algorithm is the preferred method for its bottom-up approach and gradual mesh size transitioning ((applies to unstructured))

2. Boundary layer mesh should be created prior to the volume mesh ((applies to unstructured))

3. User should anticipate what kind of post processing will be conducted. This will affect how the geometry is separated a priori to the mesh. Otherwise it will be 
cumbersome after the fact (i.e pressure coefficient slice a long the upper surface of flaps) ((applies to unstructured and structured))

4. If using a HEXA strategy, create as few of blocks as possible to easily manage the final blocking file ((applies to structured))

5. If using a HEXA strategy, blocking algorithm should allow for specified growth rate. This will help minimize cell count far away from the geometry ((applies to structured)) 


\section{Bibliography}

[1] Storm, T. and Marshall, D. D., "Assessing the v2-f Turbulence Models for Circulation Control Applications," AIAA-2010-1054, 48th AIAA Aerospace Sciences Meeting, 2010.

[2] Golden, R. and Marshall, D. D., "Design and Performance of Circulation Control Flap Systems," AIAA-2010-1053, 48th AIAA Aerospace Sciences Meeting, 2010.

[3] Lee-Rausch, E., Vatsa, V., and Rumsey, C., "Computational Analysis of Dual Radius Circulation Control Airfoils," AIAA Paper 2006-3012, 2006.

[4] White, F., Viscous fluid flow, McGraw-Hill Higher Education, 2006.

[5] software. Vers. 6.3.26. www.ansys.com, A. F. C.

[6] Wilcox, D., Turbulence Modeling for CFD, 3rd Edition, 2006.

[7] Blessing, B., "Analyzing The Engine Entrainment of An Over the Wing Engine Coupled With A Circulation Control Wing," International Powered Lift, Philadelphia PA, 2010.

[8] software. Vers. 12.1. www.ansys.com, A. I. C. C. 
[9] Jones, G., Lin, J., Allan, B., Milholen, W., Rumsey, C., and Swanson, R., "Overview of CFD Validation Experiments for Circulation Control Applications at NASA," International Powered Lift Conference, 2008.

[10] Marcos, J. and Marshall, D., "Computational and Experimental Comparison of Powered Lift, Upper Surface Blowing Configuration," AIAA-2010-0502, 48th AIAA Aerospace Sciences Meeting, 2010.

[11] Blessing, B., A COMPUTATIONAL STUDY OF ENGINE DEFLECTION USING A CIRCULATION CONTROL WING, Ph.D. thesis, Cal Poly SLO, 2011.

[12] Englar, R., "Development of Circulation Control Technology for Powered-Lift STOL Aircraft," NASA Ames Research Center Proceedings of the CirculationControl Workshop, 1987.

[13] Marshall, D., "The Integrated Modeling and Verification of Hybrid Wing-Body Low Noise ESTOL Aircraft," NRA Contract No. NNL07AA55C, 2010.

[14] Englar, R. and Huson, G., "Development of Advanced Circulation Control Wing High-Lift Airfoils," Journal of Aircraft, Vol. 21, No. 7, 1983.

[15] Panitz, T. and Wasan, D. T., "Flow Attachment to Solid Surfaces: the Coanda Effect," AIChE Journal, Vol. 18, 1972.

[16] Rumsey, C., Gatski, T., Sellers, W., Vatsa, V., and Viken, S., "Summary of the 2004 CFD Validation Workshop on Synthetic Jets and Turbulent Separation Control," AIAA Paper 2004-2217, 2004.

[17] Jones, G., "Pneumatic Flap Performance for a 2D Circulation Control Airfoil, Steady \& Pulsed," Proceedings of the 2004 NASA/ONR Circulation Control Workshop Part 2, 2004, pp. 845-888. 
[18] Slomski, J., Gorski, J., Miller, R., and Marino, T., "Numerical Simulation of Circulation Control Airfoils as Affected by Different Turbulence Models," AIAA Paper 2002-0851, 2002.

[19] Paterson, E. and Baker, W., "Simulation of Steady Circulation Control for Marine-Vehicle Control Surfaces," AIAA Paper 2004-0748, 2004.

[20] Chang, P., Slomski, J., Marino, T., and Ebert, M., "Numerical Simulation of Two- and Three-Dimensional Circulation Control Problems," AIAA Paper 2005$0080,2005$.

[21] Swanson, R., Rumsey, C., and Anders, S., "Progress Towards Computational Method for Circulation Control Airfoils," AIAA Paper 2005-0089, 2005.

[22] Englar, R. J., Smith, J. J., K. S. M., and Rover III, R. C., "Application of Circulation Control to Advanced Subsonic Transport Aircraft, Part I: Airfoil Development," Journal of Aircraft, Vol. 31, No. 5, Sept. 1994, pp. $11601168 .$.

[23] Jones, G., Yao, C., and Allan, B., "Experimental Investigation of a 2D Supercritical Circulation-Control Airfoil Using Particle Image Velocimetry," AIAA Paper 2006-3009, 2006.

[24] Slomski, J., Chang, P., and Arunajatesan, S., "Large Eddy Simulation of a Circulation Control Airfoil," AIAA Paper 2006-3011, 2006.

[25] Baker, W. and Paterson, E., "RANS CFD Simulation of a Circulation-Control Foil: Validation of Performance, Flow Field, and Wall Jet," AIAA Paper 20063010, 2006.

[26] Friedman, C., Jamchi, Z., Yasovitch, S., and Arieli, R., "Mach Effects On Circulation Control and Jet Flap Airfoils," AIAA Paper 2008-6716, 2008. 
[27] Jones, G., Viken, S., Washburn, A., Jenkins, L., and Cagle, M., "An Active Flow Circulation Controlled Flap Concept for General Aviation Aircraft Application," AIAA Paper 2002-3157, 2002.

[28] McGowan, G. and Gopalarathnam, A., "CFD Analysis of Circulation Control Airfoil Using FLUENT," Proceedings of the 2004 NASA/ONR Circulation Control Workshop Part 2, 2004, pp. 813-843.

[29] Pfingsten, K. and Radespiel, R., "Experimental and numerical investigation of a circulation control airfoil," AIAA Paper 2009-0533, 2009.

[30] Englar, R., Jones, G., Allan, B., and Lin, J., "2-D Circulation Control Airfoil Benchmark Experiments Intended for CFD Code Validation," AIAA Paper 20090902, 2009.

[31] Friedman, C., Arieli, R., and Levy, Y., "Numerical Investigation of Unsteady Circulation Control," AIAA Paper 200\%-3918, 2007.

[32] Salem-Said, A. and Ragab, S., "RANS Simulation of Circulation Control on a Circular Planform Wing," AIAA Paper 2008-4326, 2008.

[33] Swanson, R. and Rumsey, C., "Numerical Issues for Circulation Control Calculations," AIAA Paper 2006-3008, 2006.

[34] Swanson, R., Rumsey, C., and Anders, S., "Aspects of Numerical Simulation of Circulation Control Airfoils," Proceedings of the 2004 NASA/ONR Circulation Control Workshop Part 1, 2004, pp. 227-273.

[35] Liu, Y., Sankar, L., Englar, R., Ahuja, K., and Gaeta, R., "Computational Evaluation of the Steady and Pulsed Jet Effects on the Performance of a Circulation 
Control Wing Section," Proceedings of the 2004 NASA/ONR Circulation Control Workshop Part 1, 2004.

[36] Marshall, D. and Jameson, K., "Overview of Recent Circulation Control Modeling Activities at Cal Poly," AIAA-2010-0348, 48th AIAA Aerospace Sciences Meeting, 2010.

[37] Blessing, B. and Pham, J., "Using CFD as a Design Tool on New Innovative Airliner Configurations," AIAA-2009-0045, 47th AIAA Aerospace Sciences Meeting, 2009.

[38] Marcos, J. and Marshall, D., "Improved Computational and Experimental Validation Using Different Turbulence Models," AIAA-2010-4937, 28th AIAA Applied Aerodynamics Conference, 2010.

[39] Lichtwardt, J. and Marshall, D., "Investigation of Unsteady Behavior of a Circulation Control Wing Using Computational Fluid Dynamics," Submitted to 49th AIAA Aerospace Sciences Meeting, 2011.

[40] Lane, K. A. and Marshall, D. D., "Inverse Airfoil Design Utilizing CST Parameterization," AIAA-2010-1228, 48th AIAA Aerospace Sciences Meeting, 2010.

[41] Tu, J., G. H. Y. and L.., C., Computational Fluid Dynamics A Practical Approach, Butterworth-Heinemann, 2007.

[42] Englar, R., Blaylock, G., and Gaeta, R., "Recent Experimental Development of Circulation Control Airfoils and Pneumatic Powered Lift," AIAA Paper 2010, 2010. 
[43] Baker, W. and Paterson, E., "Simulation of Steady Circulation Control for the General Aviation Circulation Control (GACC) Wing," Proceedings of the 2004 NASA/ONR Circulation Control Workshop Part 2, 2004, pp. 791-811.

[44] Abramson, J., Rogers, E., and Taylor, D., "High-Speed Characterstics of Circulation Control Airfoils," AIAA Paper 1983-0265, 1983.

[45] Ahuja, K., Sankar, L., Englar, R., Munro, S., Yi, L., and Gaeta, R., "Application of Circulation Control Technology to Airframe Noise Reduction," GTRl Report A5928/2003-1, 2003.

[46] Alexander, M., Anders, S., and Johnson, S., "Trailing Edge Blowing on a TwoDimensional Six-Percent Thick Elliptical Circulation Control Airfoil Up to Transonic Conditions," NASA TM-2005-213545, 2005.

[47] Alexander, M., Anders, S., and Johnson, S., "A Wind Tunnel Experiment for Trailing Edge Circulation Control on a 6Mach Numbers," Proceedings of the 2004 NASA/ONR Circulation Control Workshop Part 1, 2004, pp. 407-434.

[48] Allan, B., Jones, G., and Lin, J., "Reynolds-Averaged Navier-Stokes Simulation of a 2D Circulation Control Wind Tunnel Experiment," AIAA-2011-0025, 2011.

[49] Baker, W., Simulations Of Coanda Effect Circulation Control Using Reynoldsaveraged Navier-stokes Computational Fluid Dynamics, Master's thesis, Pennsylvania State University, 2004.

[50] Bardina, J., Huang, P., and Coakley, T., "Turbulence Modeling Validation, Testing, and Development," NASA-TM-1997-110446, 1997. 
[51] Burdges, K., "Design And Fabriction Of Circulation Control Test Articles," Proceedings of the 2004 NASA/ONR Circulation Control Workshop Part 2, 2004, pp. $723-741$.

[52] Cagle, C. and Jones, G., "A Wind Tunnel Model to Explore Unsteady Circulation Control for General Aviation Applications," AIAA Paper 2002-3240, 2002.

[53] Celik, I., Ghia, U., Roache, P., and Freitas, C., "Procedure for Estimation and Reporting of Uncertainty Due to Discretization in CFD Applications," Journal of Fluids Engineering, Vol. 130, No. 7, 2008.

[54] Cerchie, D., Cullen, L., Goldstein, J., Halfon, E., Han, G., Taubert, L., Trouve, L., and Wygnanski, I., "Some Circulation Control Experiments," Proceedings of the 2004 NASA/ONR Circulation Control Workshop Part 1, 2004, pp. 369-405.

[55] Chan, W., Gomez, R., Rogers, S., and Buning, P., "Best practices in overset grid generation," AIAA Paper 2002-3191, 2002.

[56] Chang, P., Slomski, J., Marino, T., Ebert, M., and Abramson, J., "FullReynolds Stress Modeling of Circulation Control Airfoils," Proceedings of the 2004 NASA/ONR Circulation Control Workshop, Part 1, 2004, pp. 141-166.

[57] Dash, S., York, B., Sinha, N., and Dvorak, F., "Wall jet analysis for circulation control aerodynamics. Part 1: Fundamental CFD and turbulence modeling concepts," NASA. Ames Research Center Proceedings of the Circulation-Control Workshop, 1986, p 23-69, Number of Pages = 47, 1986.

[58] Driver, D., "Application of oil-film interferometry skin-friction measurement to large wind tunnels," Experiments in Fluids, Vol. 34, 2003, pp. 717725. 
[59] Driver, D. and Drake, A., "Skin-Friction Measurements Using Oil-Film Interferometry in NASAs 11-Foot Transonic Wind Tunnel," AIAA Journal, Vol. 46 No. 10, 2008.

[60] Driver, D. and Zilliac, G., "Oil Film Interferometry Shear Stress Measurements in Large Wind Tunnels Technique and Applications," AIAA Paper 2004-2113, 2004 .

[61] Englar, R., Nichols, J., Harris, M., Eppel, J., and Shovlin, M., "Circulation Control Technology Applied to Propulsive High Lift Systems," SAE, , No. 841497, 1984.

[62] Fasel, H., Gross, A., and Wernz, S., "Investigation of Turbulent Coanda Wall Jets Using DNS and RANS," Proceedings of the 2004 NASA/ONR Circulation Control Workshop Part 1, 2004, pp. 337-367.

[63] Frith, S. and Wood, N., "The Use Of Circulation Control For Flight Control," Proceedings of the 2004 NASA/ONR Circulation Control Workshop Part 2, 2004, pp. $657-688$.

[64] Giunta, A., "Sensitivity Analysis Method For Aeroelastic Aircraft Models," Pergamon, Vol. Aircraft Design 2, 1999, pp. 207-230.

[65] Hinze, J. O., Turbulence 2nd Ed, 1975.

[66] Jones, G. and Englar, R., "Advances In Pneumatic-Controlled High-Lift Systems Through Pulsed Blowing," AIAA Paper 2003-3411, 2003.

[67] Joslin, R., "Circulation Control: Issues for Naval Applications," Proceedings of the 2004 NASA/ONR Circulation Control Workshop Part 2, 2004, pp. 553-575. 
[68] Katz, A. and Sankaran, V., "Mesh Quality Effects on the Accuracy of CFD Solutions on Unstructured Meshes," AIAA-2011-0652, 2011.

[69] Lee-Rausch, E., Buning, P., Morrison, J., Park, M., Rivers, S., and Rumsey, C., "CFD Sensitivity Analysis of a Drag Prediction Workshop Wing/Body Transport Configuration," AIAA Paper 2003-3400, 2003.

[70] Liu, Y., Numerical Simulations Of The Aerodynamic Characteristics Of Circulation Control Wing Sections, Ph.D. thesis, Georgia Institute of Technology, 2003.

[71] Liu, Y., Sankar, L., Englar, R., and Ahuja, K., "Numerical Simulations of the Steady and Unsteady Aerodynamic Characteristics of a Circulation Control Wing Airfoil," AIAA Paper 2001-0704, 2001.

[72] Loth, J., "Why Have Only Two Circulation-Controlled STOL Aircraft Been Built And Flown In Years 1974 - 2004." Proceedings of the 2004 NASA/ONR Circulation Control Workshop Part 2, 2004, pp. 603-640.

[73] McGowan, G., Computational Study of Adaptive Circulation Control Airfoils, Master's thesis, North Carolina State University, 2004.

[74] McGowan, G., Gopalarathnam, A., Xiao, X., and Hassan, H., "Role of Turbulence Modeling in Flow Prediction of Circulation Control Airfoils," Proceedings of the 2004 NASA/ONR Circulation Control Workshop Part 1, 2004, pp. 275-293.

[75] Menter, F. R., "Two Equation Eddy-Viscosity Turbulence Models for Engineering Applications," AIAA Journal, Vol. 32, 1994, pp. 15981605.

[76] Munro, S., Ahuja, K., and Englar, R., "Noise Reduction Through Circulation Control," Proceedings of the 2004 NASA/ONR Circulation Control Workshop Part 1, 2004, pp. 497-551. 
[77] Nishino, T., Hahn, S., and Shariff, K., "Calculation of the Turbulence Characteristics of Flow Around a Circulation Control Airfoil Using LES," AIAA-2010$0347,2010$.

[78] Pannell, D., "Sensitivity analysis of normative economic models: theoretical framework and practical strategies," Agricultural Economics, Vol. 16, 1997, pp. $139-152$.

[79] Paterson, E. and Baker, W., "RANS and Detached -Eddy Simulation of the NCCR Airfoil," Proceedings of the 2004 NASA/ONR Circulation Control Workshop Part 1, 2004, pp. 167-197.

[80] Pham, J. and Marshall, D., "Investigation of Improved Meshing Techniques for RANS CFD Simulation of a Circulation Control WIng," AIAA-2011-1042, 2011.

[81] Rogers, E. and Abramson, J., "Selected Topics Related to Operational Applications of Circulation Control," Proceedings of the 2004 NASA/ONR Circulation Control Workshop Part 2, 2004, pp. 743-770.

[82] Rumsey, C., "Consistency, Verification, And Validation Of Turbulence Models For Reynolds-averaged Navier-stokes Applications," 3rd European Conference for Aerospace Sciences, 2009.

[83] Rumsey, C. and Nishino, T., "Numerical Study Comparing RANS and LES Approaches on a Circulation Control Airfoil," AIAA-2011-1179, 2011.

[84] Schlecht, R. and Anders, S., "Parametric Evaluation of Thin, Transonic Circulation-Control Airfoils," AIAA Paper 2007-0272, 2007. 
[85] Stern, F., Wilson, R., Coleman, H., and Paterson, E., "Comprehensive Approach to Verification and Validation of CFD SimulationsPart 1: Methodology and Procedure," Journal of Fluids Engineering, Vol. 123, 2001, pp. 793-802.

[86] Stern, F., Wilson, R., Coleman, H., and Paterson, E., "Comprehensive Approach to Verification and Validation of CFD SimulationsPart 2: Application for Rans Simulation of a Cargo/Container Ship," Journal of Fluids Engineering, Vol. 123, 2001, pp. 803-810.

[87] Swanson, R. and Rumsey, C., "Computation of circulation control airfoil flows," Computers $\&$ Fluids, Vol. 38, 2009, pp. 1925-1942.

[88] Tannehill, J. C., A. D. A. and Pletcher, R. H., Computational Fluid Mechanics and Heat Transfer Second Edition, 1997.

[89] Viswanathan, A. and Tafti, D., "Numerical Analysis of Circulation Control on a NCCR 1510-7607N Airfoil using RANS Models," Proceedings of the 2004 NASA/ONR Circulation Control Workshop Part 1, 2004, pp. 197-226. 


\section{Appendix A}

\section{Governing Equations}

For reader sanity the full derivation of the governing equations will not be provided, but rather a summary of the basics will be presented. For full derivations feel free to explore Tannehill et. al[88]. Since FLUENT was used as the solver, the equations presented below come from the FLUENT User Manuel[5].

\section{A.1 Continuity Equation}

Conservation of mass is satisfied by solving the continuity equation. For an inertial reference frame its most general form is written as

$$
\frac{\partial \rho}{\partial t}+\rho \nabla \vec{U}=0
$$

where $\vec{U}$ is the velocity vector. In order to add a source term to compensate for mass added to the system $S_{m}$ is added to the right hand side of the equation.

$$
\frac{\partial \rho}{\partial t}+\rho \nabla \vec{U}=S_{m}
$$


$\mathrm{S}_{m}$ accounts for any vaporization or user defined values that are added to the system.

\section{A.2 Momentum Equation}

The momentum equation for a non-accelerating inertial reference frame can be written as

$$
\frac{\partial(\rho \vec{v})}{\partial t}+\nabla \cdot(\rho \vec{v} \vec{v})=-\nabla p+\nabla \cdot(\bar{\tau})+\rho \vec{g}+\vec{F}
$$

where $p$ the static pressure, $\rho \vec{g}$ is the gravitational body force, $\vec{F}$ is the external body forces, and $\bar{\tau}$ is the stress tensor and can be written as

$$
\bar{\tau}=\mu\left[\left(\nabla \vec{v}+\nabla \vec{v}^{T}\right)-\frac{2}{3} \nabla \cdot \vec{v} I\right]
$$

where $\mu$ is the molecular viscosity and $I$ is the unit tensor.

\section{A.3 Energy Equation}

The energy equation can be written as

$$
\frac{\rho E}{\partial t}+\nabla \cdot[\vec{v}(\rho E+p)]=\nabla \cdot\left[k_{e f f} \nabla T-\sum h_{j} \vec{J}_{j}+\left(\bar{\tau}_{e f f} \cdot \vec{v}\right)\right]+S_{h}
$$

where $k_{e} f f$ is the effective conductivity. $k_{e} f f$ equals $k+k_{t}+$ kt where the latter is the turbulent conductivity added by the turbulence model. $\vec{J}_{j}$ is the diffusion flux of species $j . \mathrm{S}_{h}$ is the heat of chemical reaction and includes other volumetric heat 
sources. The other three terms on the right hand side of the above equation (from left to right) are energy transfer due to conduction, species diffusion, and viscous dissipation.

$E$ from the above equation can be written as

$$
E=h-\frac{p}{\rho}+\frac{v^{2}}{2}
$$

where $h$ is sensible enthalpy and can be defined as

$$
h=\sum Y_{j} h_{j}
$$

where $Y_{j}$ is the mass fraction of species $j$ and

$$
h_{j}=\int_{T_{r e f}}^{T} c_{p, j} d T
$$

where $T_{\text {ref }}$ is $298.15 \mathrm{~K}$. 


\section{Appendix B}

\section{Turbulence Modeling}

A quote from Hinze says Turbulent fluid motion is an irregular condition of flow in which the various quantities show a random variation with time and space coordinates so that statistically distinct average values can be discerned.[65] As of today turbulence is accounted for in CFD in one of two ways; first turbulence can be solved via Direct Numerical Simulation (DNS) and secondly a model can be used to approximate the turbulence in the solution. DNS is very computationally expensive due to having to be able to resolve the solution to the length scales of the smallest eddy to the largest feature in the solution. Today DNS can be used on relatively simple geometries at great computational expense. Due to limitations in todays computational resources DNS is not reasonable for solutions of this complex nature. Thus, turbulence models become an important discussion in this work.

\section{B.1 Boussinesq Approximation}

The Boussinesq approximation lays the ground work for many turbulence models by hypothesizing that shearing stress is related to the rate of mean strain through 
an apparent scalar turbulent viscosity. This is how most common turbulence models approximate Reynolds stress. The Boussinesq assumption give the following

$$
-\overline{\left(\rho u_{i}^{\prime}\right)}=2 \mu_{T} S_{i j}-\frac{2}{3} \delta_{i j}\left[\mu_{T} \frac{\partial u_{k}}{\partial x_{k}}+\rho \bar{k}\right]
$$

where $\mu$ is the turbulent viscosity, $\bar{k}$ is the kinetic energy of turbulence defined by

$$
\bar{k}=\frac{u_{i}^{\prime} u_{j}^{\prime}}{2}
$$

where $u^{\prime}$ are the turbulent fluctuations in the flowfield. The mean strain tensor from above can be described as

$$
S_{i j}=\frac{1}{2}\left[\frac{\partial u_{i}}{\partial x_{j}}+\frac{\partial u_{j}}{\partial x_{i}}\right]
$$

For some flow regimes these calculations have been validated and proven to be a good approximation. It will be assumed that the solutions in this paper will fall into one of these regimes. The models explored and discussed for this work are the standard $\mathrm{k}-\epsilon$. model, the $\mathrm{k}-\epsilon$ realizable model, the standard $\mathrm{k}-\omega$ model and the shear stress transport k- $\omega$ models. Some effort has been made as part of Cal Polys NASA grant to develop the $v^{2}-f$ model in FLUENT, but it will not be discussed in detail in this paper. All of these models rely on the Boussinesq approximation.

\section{B.2 Standard k- $\epsilon$ Model}

The standard $\mathrm{k}-\epsilon$ is one of the most common and robust turbulence models available today. The model is accurate and stable for a large range of flow fields. This turbulence model was attractive because of its wide use and very stable nature of 
the solution calculations. Two other variants of the two-equation $\mathrm{k}-\epsilon$ are available in FLUENT. The renormalization group theory (RNG) k- $\epsilon$ model and the realizable $\mathrm{k}-\epsilon$ model make improvements to the performance to the standard k- $\epsilon$ version. The RNG $\mathrm{k}-\epsilon$ model will not be discussed in this paper but the realizable $\mathrm{k}-\epsilon$ will be explored later.

The k- $\epsilon$ model assumes that the flow is fully turbulent. Recent developments in FLUENT allow for transition models to be used but it is believed that due to the high velocity slot flow it is a good assumption to assume fully turbulent flow. The turbulent kinetic energy $k$ and is dissipation rate $\epsilon$ are given from the following transport equations[5].

$$
\frac{\partial(\rho k)}{\partial t}+\frac{\partial\left(\rho\left(\rho k u_{i}\right)\right.}{\partial x_{i}}=\frac{\partial}{\partial x_{j}}\left[\left(\mu+\frac{\mu_{t}}{\sigma_{k}}\right) \frac{\partial k}{\partial x_{j}}\right]+G_{k}+G_{b}+\rho \epsilon-Y_{M}+S_{k}
$$

and

$$
\frac{\partial(\rho \epsilon)}{\partial t}+\frac{\partial\left(\rho \epsilon u_{i}\right)}{\partial x_{i}}=\frac{\partial}{\partial x_{j}}\left[\left(\mu+\frac{\mu_{t}}{\sigma_{\epsilon}}\right) \frac{\partial \epsilon}{\partial x_{j}}\right]+C_{1 \epsilon} \frac{\epsilon}{k}\left(G_{k}+C_{3 \epsilon} G_{b}\right)-C_{2 \epsilon} \rho \frac{\epsilon^{2}}{k}+S_{e}
$$

where $G_{k}$ is the generation of turbulent kinetic energy. This is calculated in a manner described by the Boussinesq approximation. $G_{b}$ is the turbulent kinetic energy added due to buoyancy. $\mathrm{C}_{1 \epsilon}, \mathrm{C}_{2 \epsilon}$, and $\mathrm{C}_{3 \epsilon}$ are constants that are tuned by experimental data[4]. $\sigma_{k}$ and $\sigma_{\epsilon}$ are the turbulent Prandle numbers for $k$ and $\epsilon$ respectively. If extra source terms are added by the user they are accounted for using $S_{k}$ and $S_{\epsilon}$.

The turbulent viscosity $\mathrm{t}$ is calculated using 


$$
\mu_{t}=\rho C_{\mu} \frac{k^{2}}{\epsilon}
$$

where $C_{\mu}$ is a constant. The constants as described by White are presented in Table B.1

Table B.1: Constants for the standard k- $\epsilon$ model as described by White[4]

\begin{tabular}{|l|l|}
\hline Solver & Value \\
\hline$C_{1 \epsilon}$ & 1.44 \\
$C_{2 \epsilon}$ & 1.92 \\
$C_{\mu}$ & 0.09 \\
$\sigma_{k}$ & 1.0 \\
$\sigma_{\epsilon}$ & 1.3 \\
\hline
\end{tabular}

These constants are not universal for all problems or variations of the $\mathrm{k}-\epsilon$ turbulence model and the constants can be tuned for a specific problems.

\section{B.3 Realizable k- $\epsilon$ Model}

The realizable $\mathrm{k}-\epsilon$ model is modified in two ways. First, turbulent viscosity is calculated differently from the standard version. Secondly, there is a new transport equation for dissipation rate $\epsilon$. The most applicable benefit for the realizable $\mathrm{k}-\epsilon$ model is that it predicts spreading rate better for jets. Considering the wing has both leading and training edge planer jets realizable $\mathrm{k}-\epsilon$ is considered the better $\mathrm{k}-\epsilon$ model for the application in this paper.

While the transport equation for kinetic energy is identical to the standard version the new turbulent dissipation transport equations is described by 


$$
\frac{\partial(\rho \epsilon)}{\partial t}+\frac{\partial\left(\rho \epsilon u_{i}\right)}{\partial x_{i}}=\frac{\partial}{\partial x_{j}}\left[\left(\mu+\frac{\mu_{t}}{\sigma_{\epsilon}}\right) \frac{\partial \epsilon}{\partial x_{j}}\right]+\rho C_{1} S_{\epsilon}-\rho C_{2} \frac{\epsilon^{2}}{k+\sqrt{\nu \epsilon}}+C_{1 \epsilon} \frac{\epsilon}{k} C_{3 \epsilon} G_{b}+S_{\epsilon}
$$

where

$$
\begin{gathered}
C_{1}=\max \left[0.43, \frac{\eta}{\eta+5}\right] \\
\eta=S \frac{k}{\epsilon} \\
S=\operatorname{sqrt} 2 S_{i j} S i j
\end{gathered}
$$

In the above equations $G_{k}$ is the generation of turbulent kinetic energy due to the mean velocity gradients. As in the standard version the eddy viscosity is calculated using

$$
\mu_{t}=\rho C_{\mu} \frac{k^{2}}{\epsilon}
$$

the difference in the realizable model is the method with which $\mathrm{C} \mu$ is calculated. Before $\mathrm{C} \mu$ is a constant and now is calculated using

$$
C_{\mu}=\frac{1}{A_{0}+A_{s} \frac{k U^{*}}{\epsilon}}
$$

while I will spare you the details of the rest of the calculation it can be found in full in the FLUENT User Manual[5]. The constants for this model are listed in Table B.2 
Table B.2: Constants for the realizable k- $\epsilon$ model as described by FLUENT[5]

\begin{tabular}{|l|l|}
\hline Solver & Value \\
\hline$C_{1 \epsilon}$ & 1.44 \\
$C_{2}$ & 1.9 \\
$\sigma_{k}$ & 1.0 \\
$\sigma_{\epsilon}$ & 1.2 \\
\hline
\end{tabular}

This version of $k-\epsilon$ shows good results for free shear flows, jet flows and flows with strong mixing layers among many other types. The model tends to fall apart in wall bounded flows with high pressure gradients and flows with high adverse pressure gradients[50]. It is worthy to note that the realizable $\mathrm{k}-\epsilon$ is considered to be superior in accuracy and stability over the standard version of $\mathrm{k}-\epsilon$. This is why realizable $\mathrm{k}-\epsilon$ is strongly considered as the turbulence model for this project.

\section{B.4 Standard k- $\omega$ Model}

The k- $\omega$ model was developed by Wilcox[6]. His model improved on some of the shortfalls of other turbulence models such as: low-Reynolds number effects, compressibility, and shear flow spreading. The model greatly improved prediction of free shear flow spreading for wakes, free shear flows and jets. This makes this turbulence mode attractive because the circulation control jet is a wall bounded planer jet with high free shear flow. The transport equations describing the k- $\omega$ model are as follows:

$$
\begin{gathered}
\frac{\partial(\rho k)}{\partial t}+\frac{\partial\left(\rho k u_{i}\right)}{\partial x_{j}}=\frac{\partial}{\partial x_{j}}\left(\Gamma_{k} \frac{\partial k}{\partial c_{j}}\right)+G_{k}-Y_{k}+S_{k} \\
\frac{\partial(\rho \omega)}{\partial t}+\frac{\partial\left(\rho \omega u_{i}\right)}{\partial x_{j}}=\frac{\partial}{\partial x_{j}}\left(\Gamma_{k} \frac{\partial \omega}{\partial c_{j}}\right)+G_{\omega}-Y_{\omega}+S_{\omega}
\end{gathered}
$$


where $G_{k}$ is the turbulent kinetic energy due to mean velocity gradients and $G_{\omega}$ represents the generation of the dissipation rate. $Y_{k}$ and $Y_{\omega}$ are the dissipation of $k$ and $\omega$ due to turbulence. $\Gamma_{k}$ and $\Gamma_{\omega}$ are the effective diffusivity of $k$ and $\omega$ respectively. The effective diffusivity are calculated using

$$
\begin{gathered}
\Gamma_{k}=\mu+\frac{\mu_{t}}{\sigma_{k}} \\
\Gamma_{\omega}=\mu+\frac{\mu_{t}}{\sigma_{\omega}}
\end{gathered}
$$

where $\sigma_{k}$ and $\sigma_{\omega}$ are the turbulent Prandtl numbers for $k$ and $\omega$ respectively. The turbulent viscosity $\mu_{t}$ is calculated by

$$
\mu_{t}=\alpha^{*} \frac{\rho k}{\omega}
$$

where $\alpha^{*}$ is a damping term for the turbulent viscosity correcting for low Reynolds number flows. The term $G_{k}$ (production of turbulence kinetic energy) from above is calculated in the same manner as $\mathrm{k}-\epsilon$ using the Boussinesq approximation. The production of $\omega$ given by $G_{\omega}$ is calculated using

$$
G_{\omega}=\alpha \frac{\omega}{k} G_{k}
$$

Some of the model constants given by Wilcox are shown in Table B.3. While the standard k- $\omega$ model made good progress at improving some of the shortfalls of earlier turbulence models it doesnt come without faults. The standard k- $\omega$ model can have issues with solution instability and divergence in freestream flow outside of boundary layer. For this reason a new formulation of the $\mathrm{k}-\omega$ model was developed called the 
shear stress transport k- $\omega$ model.

Table B.3: Constants for the standard k- $\omega$ model as described by Wilcox[6]

\begin{tabular}{|l|l|}
\hline Solver & Value \\
\hline$\sigma_{k}$ & 2.0 \\
$\sigma_{\epsilon}$ & 2.0 \\
\hline
\end{tabular}

\section{B.5 Shear Stress Transport k- $\omega$ Model}

The Shear Stress Transport k- $\omega$ model was developed by Menter in the early 1990s[75]. Menter combined the near wall accuracy of the $\mathrm{k}-\omega$ model and utilizes the $\mathrm{k}-\epsilon$ model in freestream flow away from walls. This coupling provides a balance between accuracy and stability that creates a powerful turbulence model. The blended model performs exceptionally well in adverse pressure gradient flows. This makes it very attractive for circulation control airfoil flow. The transport equations for $k-\omega$ SST are a slight variant on the standard k- $\omega$ model. They are written as follows

$$
\frac{\partial(\rho k)}{\partial t}+\frac{\partial\left(\rho k u_{i}\right)}{\partial x_{j}}=\frac{\partial}{\partial x_{j}}\left(\Gamma_{k} \frac{\partial k}{\partial c_{j}}\right)+\tilde{G}_{k}-Y_{k}+S_{k}
$$

and

$$
\frac{\partial(\rho \omega)}{\partial t}+\frac{\partial\left(\rho \omega u_{i}\right)}{\partial x_{j}}=\frac{\partial}{\partial x_{j}}\left(\Gamma_{k} \frac{\partial \omega}{\partial c_{j}}\right)+G_{\omega}-Y_{\omega}+D_{\omega}+S_{\omega}
$$

where notable differences are $\tilde{G}_{k}$ represents the generation of turbulent kinetic energy due to mean velocity gradients. $\tilde{G}_{k}$ is calculated as follows:

$$
\tilde{G}_{k}=\min \left(G_{k}, 10 \beta^{*} k \omega\right)
$$


$\tilde{G}_{k}$ is calculated the exact same way as in the standard k- $\omega$ model shown in Equation B.18. $D_{\omega}$ is the cross-diffusion term and is calculated as described below. All other terms are consistent with the standard k- $\omega$ model. In order to blend the k- $\omega$ and the $\mathrm{k}-\epsilon$ models together the cross-diffusive term $D_{\omega}$ is added to Equation B.20. $D_{\omega}$ is calculated as follows

$$
D_{\omega}=2\left(1-F_{1}\right) \rho \sigma_{\omega, 2} \frac{1}{\omega} \frac{\partial k}{\partial x_{j}} \frac{\partial \omega}{\partial x_{j}}
$$

to see the rest of the derivation please see Menter[75] or FLUENT User Manual[5]. Some of the constants are given in Table B.4

Table B.4: Constants for the shear stress transport k- $\omega$ model as described by FLUENT[5]

\begin{tabular}{|l|l|}
\hline Solver & Value \\
\hline$\sigma_{k, 1}$ & 1.176 \\
$\sigma_{k, 2}$ & 1.0 \\
$\sigma_{\omega, 1}$ & 2.0 \\
$\sigma_{\omega, 2}$ & 1.168 \\
$\beta^{*}$ & 0.09 \\
\hline
\end{tabular}

